U.S. Department

of Transportation

Nátional Highway

Traffic Safety

Administration

DOT HS 808203

January 1995

Final Report

\title{
Assessment of Year-Round and Holiday Ride Service Programs
}


This publication is distributed by the U.S. Department of Transportation, National Highway Traffic Safety Administration, in the interest of information exchange. The opinions, findings and conclusions expressed in this publication are those of the author(s) and not necessarily those of the Department of Transportation or the National Highway Traffic Safety Administration. The United States Government assumes no liability for its contents or use thereof. If trade or manufacturers' name or products are mentioned, it is because they are considered essential to the object of the publication and should not be construed as an endorsement. The United States Government does not endorse products or manufacturers. 
Technical Report Documentation Page

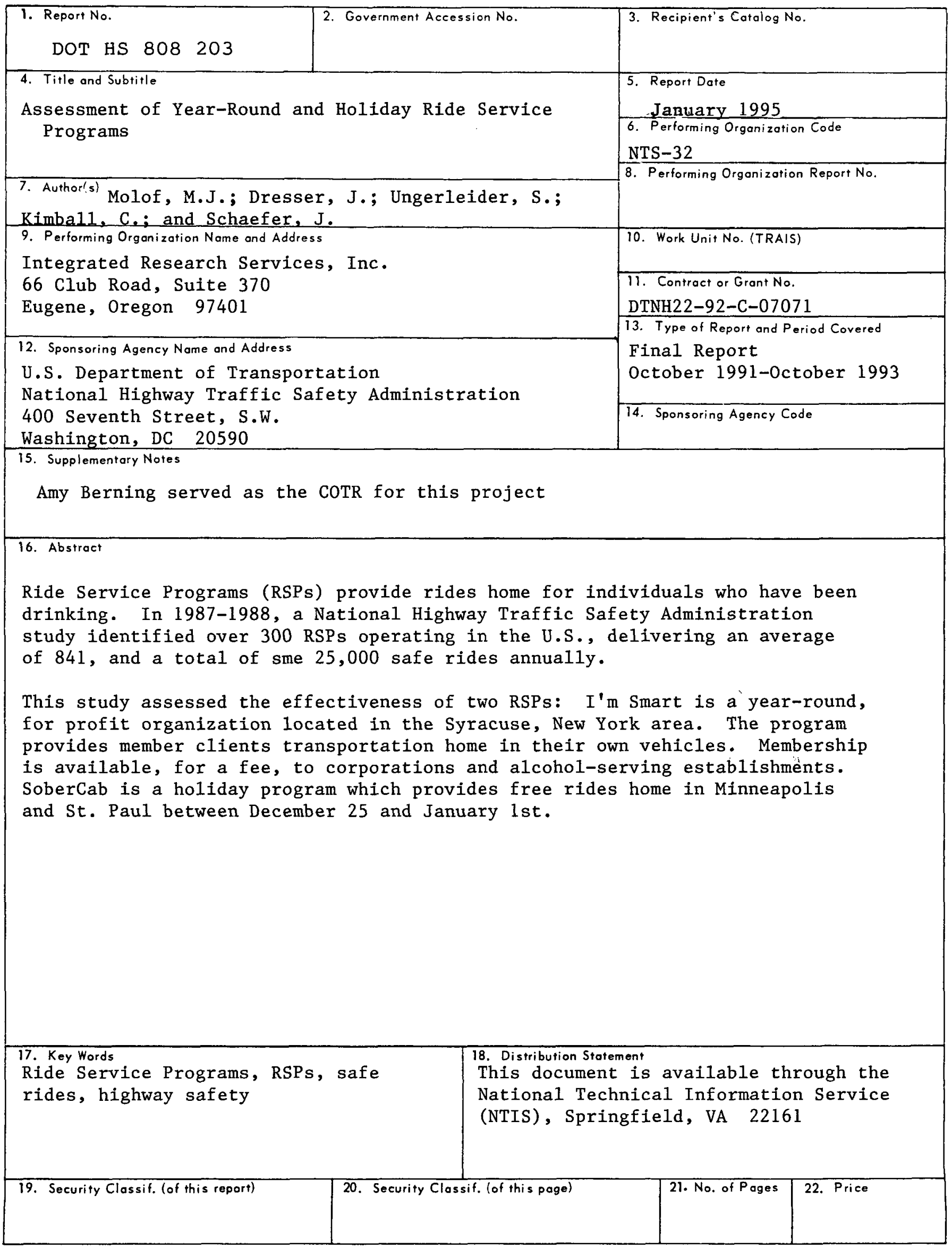




\title{
ACKNOWLEDGEMENTS
}

The contractors wish to express their appreciation to the people and organizations, without whose assistance this project would not have been possible.

\author{
Ms. Mary Ellen Gonzalez \\ Ms. Debbie Frailey \\ Ms. Kristyn Winters \\ Mr. Martin Yenawine \\ Mr. Phil Forgione \\ Ms. Tiffany Yenawine and the I'm Smart staff; \\ Mr. Tom Seery and staff at the New York State DMV offices; \\ Mr. Don Wyland \\ Ms. Debbie Ernowine \\ Mr. Tim Swiler and staff at Airport Taxi; \\ Mr. Robin High \\ Ms. Pam Shomaker \\ Dr. Mikal Aasved
}




\section{National Highway Traffic Safety Administration Addendum}

Comparing the slopes of least square lines as was done in this study to compare crash tends for the New York counties with Ride Service Programs (RSPs) requires that the assumption of normatility is met. This is usually not the case when the independent variable is time, as it is here.

Two alternatives could have been considered. One alternative would be to construct a regression model both with the baseline trend and a change in level. A significant (negative) coefficient for the change in level coincident with the implementation of the RSPs could then be considered as indicative of RSP effectiveness. Another alternative would be to link the data on alcohol-related crashes to data on non-alcohol-related crashes and model the proportion alcohol-related or their ratio. Both approaches could include modelling comparison series from other counties without RSPS. Using these approaches, however, may not have changed the study's conclusions. 
I. NEED FOR EVALUATION OF MODEL RSP PROGRAMS $\ldots \ldots \ldots \ldots \ldots \ldots \ldots$

II. SELECTION OF TWO MODEL RSPS FOR EVALUATION $\ldots \ldots \ldots \ldots \ldots \ldots \ldots$

III. DESCRIPTIONS OF I'M SMART AND SOBERCAB $\ldots \ldots \ldots \ldots \ldots \ldots \ldots$

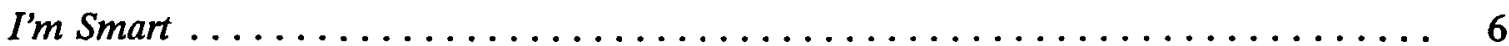

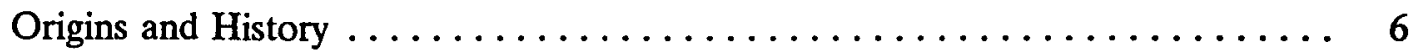

Operational Features $\ldots \ldots \ldots \ldots \ldots \ldots \ldots \ldots \ldots \ldots \ldots \ldots \ldots \ldots \ldots \ldots \ldots \ldots \ldots \ldots \ldots \ldots \ldots \ldots \ldots \ldots \ldots \ldots \ldots \ldots \ldots \ldots$
SoberCab $\ldots \ldots \ldots \ldots \ldots \ldots \ldots \ldots \ldots \ldots$

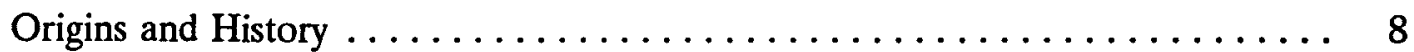

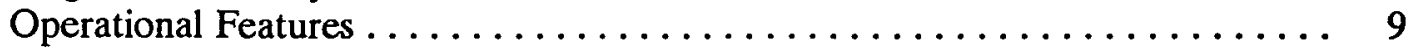

IV. EVALUATION QUESTIONS TO BE ADDRESSED $\ldots \ldots \ldots \ldots \ldots \ldots \ldots \ldots \ldots$

V. METHODS AND RESULTS $\ldots \ldots \ldots \ldots \ldots \ldots \ldots \ldots \ldots \ldots \ldots \ldots \ldots \ldots \ldots$

To what extent is the driving community aware of the RSP? $\ldots \ldots \ldots \ldots \ldots \ldots \ldots 12$

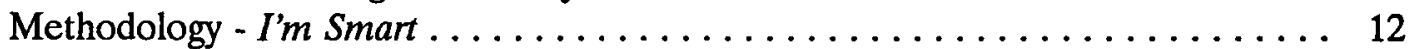

Results - I'm Smart ............................... 13

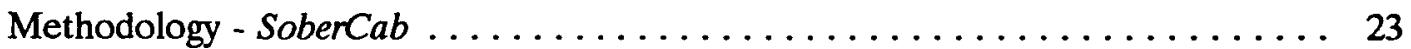

Results - SoberCab ............................... 23

To what extent are those who are more likely to have need of an RSP (i.e., those who drink alcohol and those who drink and drive) aware of and have knowledge of the

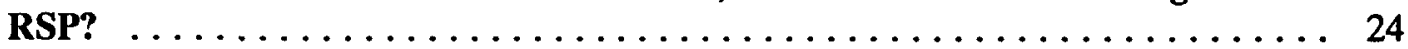

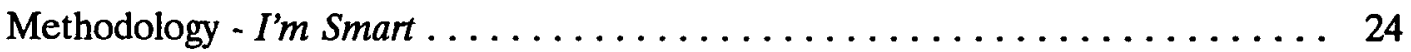

Results - I'm Smart .............................. 24

Methodology - SoberCab ............................ 28

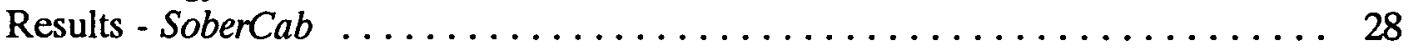

How many individuals use the RSP and what are their characteristics? $\ldots \ldots \ldots \quad 30$

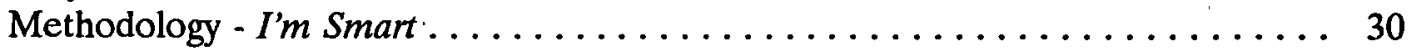

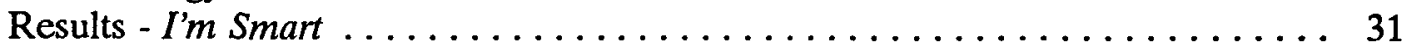

Methodology - SoberCab ......................... 36

Results - SoberCab ........................... 37

Are users those who are targeted by the program (i.e., individuals who are impaired and have driven to the location where they drink) $\ldots \ldots \ldots \ldots \ldots \ldots \ldots$. . . . 41

Methodology $-I^{\prime} m$ Smart . . . . . . . . . . . . . . . . . . . 41

Results - I'm Smart ................................ 41

Methodology - SoberCab ....................... 42

Results - SoberCab ............................. 42

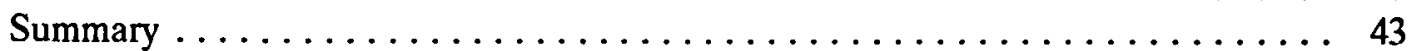

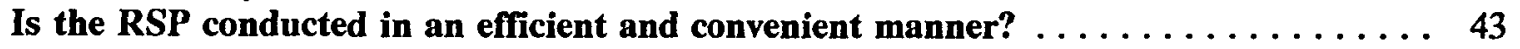

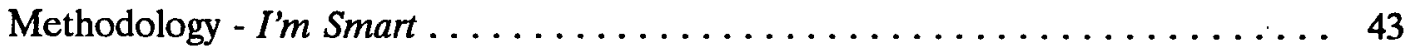

Results - I'm Smart ............................. 43

Methodology - SoberCab ...................... 45

Results - SoberCab ............................ 45

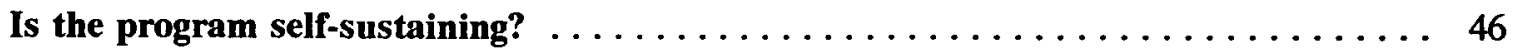

Methodology $-I^{\prime} m$ Smart . . . . . . . . . . . . . . . . . . . 46

Results - I'm Smart ............................. 46

SoberCab...................................... 48

Would the users of the RSP employ means of transportation, other than driving their

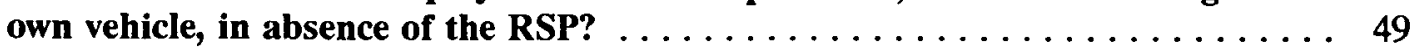

I'm Smart ................................ 49 
Methodology - SoberCab ......................... 49

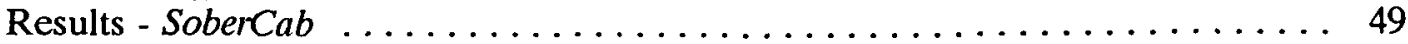

What alternatives to driving after drinking do drinkers report using? . . . . . . . 50

Methodology $-I$ I'm Smart . . . . . . . . . . . . . . . . . . . . . 50

Results - I'm Smart ............................. 50

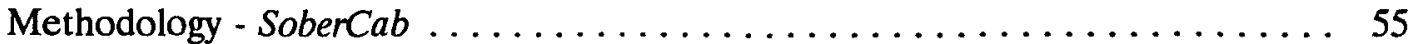

Results - SoberCab ............................. 55

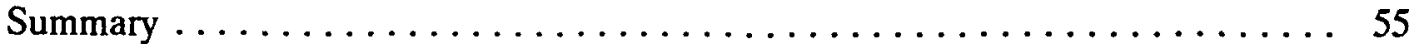

How many alcohol-related trips are reduced due to the use of the RSP? . . . . . 56

Methodology - I'm Smart ........................... 57

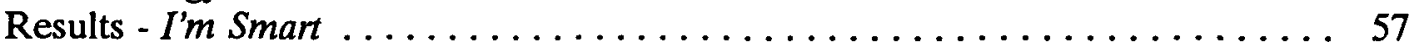

Methodology - SoberCab ........................ 58

Results - SoberCab ............................. 58

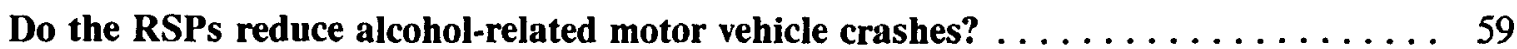

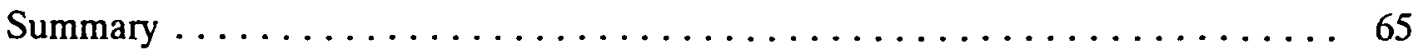

Did a targeted publicity campaign change awareness and knowledge of I'm Smart

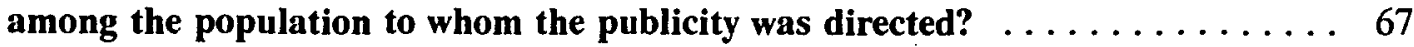

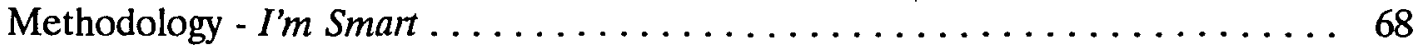

Results- I'm Smart . . . . . . . . . . . . . . . . . . . . . 68

VI. RESEARCH SUMMARY AND CONCLUSIONS $\ldots \ldots \ldots \ldots \ldots \ldots \ldots \ldots \ldots$

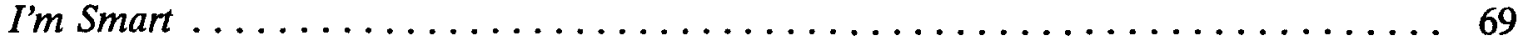

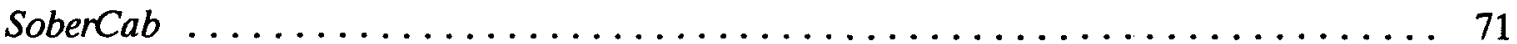

General Conclusions and Recommendations ................... 72

VII. RESEARCH ISSUES AND RECOMMENDATIONS $\ldots \ldots \ldots \ldots \ldots \ldots \ldots$

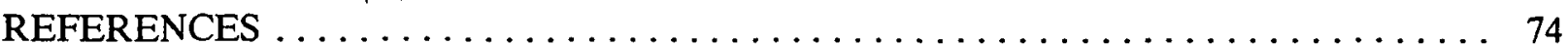




\section{LIST OF TABLES}

Table 1

Characteristics of RSPs Interviewed by Telephone $\ldots \ldots \ldots \ldots \ldots \ldots \ldots \ldots \ldots$

Table 2

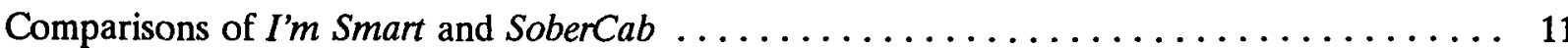

Table 3

Syracuse and Comparison Area DMV Surveys, 1992 and 1993

Awareness of an RSP and Name Recognition of I'm Smart

Table 4

Syracuse DMV Survey, 1993

Sources of Information About RSP

(Only Respondents Who Checked Hearing of I'm Smart)

\section{Table 5}

Syracuse DMV Surveys, 1992 and 1993 combined

Coded Categories of Response to Knowledge Question About the RSP

(Only Those Respondents Who Indicated They had Heard of $I$ 'm Smart) $\ldots \ldots \ldots \ldots \ldots$

\section{Table 6}

Discussions with Alcohol-Serving Establishment Customers in Syracuse and Albany, 1992 and 1993 Name Recognition, Sources of Information About I'm Smart,

Knowledge of How to Use I'm Smart and Prior Use of I'm Smart . . . . . . . . . . . . 19

\section{Table 7}

RID State Fair Survey, 1992

Awareness of an RSP and Mention of I'm Smart by Respondent Residence . . . . . . . .

Table 8

Discussions with Alcohol-Serving Establishment Customers, Twin Cities, 1992 and 1993

Name Recognition, Knowledge of How to Use and Prior Use of SoberCab

\section{Table 9}

Syracuse DMV Surveys, 1992 and 1993 Combined

Differences in Drinking Behavior and Drinking and Driving Behavior

Between Respondents who Had and Had Not Heard of I'm Smart . . . . . . . . . . . . . 2

Table 10

Syracuse DMV Surveys - 1992 and 1993 Combined

Relationships Between Name Recognition of I'm Smart and Demographic Variables

\section{Table 11}

Discussions with Alcohol-Serving Establishment Customers in Syracuse, 1992 and 1993 Combined

Relationships of Name Recognition of I'm Smart to other Variables

\section{Table 12}

University of Minnesota Telephone Survey, Fall, 1992

Relationships of Demographic Variables to Name Recognition of SoberCab from

All Listed Relationships Statistically Significant at the .05 Level or Greater . . . . . . . . . 
Table 13

I'm Smart Drivers' Observations

Characteristics of I'm Smart Users as Judged by Drivers

Table 14

Discussions with Alcohol-Serving Establishment Customers in Syracuse, 1992 and 1993 Combined

Characteristics of Those Who Reported to Have Used I'm Smart in the Past . . . . . . . . 35

Table 15

Number of Sober Cab Rides for $1991-92$ and $1992-93 \ldots \ldots \ldots \ldots \ldots \ldots \ldots \ldots$

Table 16

Ride-Along Interview of SoberCab Users

Characteristics of Riders

\section{Table 17}

Discussions with Alcohol-Serving Establishment Customers, Twin Cities, Combined Experimental and Control

Characteristics of Previous Users of Sober $C a b \ldots \ldots \ldots \ldots \ldots \ldots \ldots \ldots \ldots$

Table 18

Survey of I'm Smart Corporate Members

Percent of Respondents Rating Each Dimension of I'm Smart on Each Scale Point ........

Table 19

Syracuse and Albany Area DMV Surveys - 1992 and 1993 Combined

Reported Alternatives to Driving After Drinking

Only those people that have drank in the last 12 months

Table 20

RID State Fair Survey

Alternatives When Feeling Unable to Drive Safely

(Only respondents who indicated that at times they felt unable to drive home safely) .......

\section{Table 21}

Discussions with Alcohol-Serving Establishment Customers in Syracuse, 1992 and 1993 Combined Planned Means of Getting Home, Previous Use of I'm Smart and

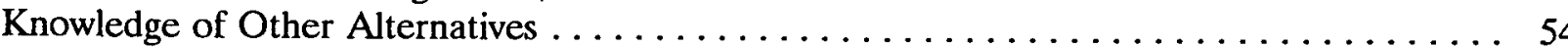

Table 21A

Discussions with Alcohol-Serving Establishment Customers in Syracuse, 1992 and 1993 Combined

Planned Means of Getting Home by Self-Reported Indicators of Impairment . . . . . . . . . 54

Table 22

Discussions with Alcohol-Serving Establishment Customers in Syracuse and Albany, 1992 and 1993

Planned Means of Getting Home for by Various Indicators of Impairment . . . . . . . . . 58

Table 23

Percent of all accidents that are alcohol-related for Hennepin/Ramsey Counties and Statewide All year, Christmas-New Year's, and Other Drinking Holidays.

Appendix A

Summary of the Evaluation Questions, Data Collection Instruments/Sources of Data Analytic Approaches and Limitations on Answers ............... Appendix A - 1 


\section{LIST OF FIGURES}

Figure 1

I'm Smart Total Rides for 1984-1992

Figure 2

Alcohol Involved Accidents, New York State

\section{Figure 3}

Minnesota Alcohol-Related Crashes

Christmas-New Year's Period 1987-1992

Hennepin and Ramsey Counties Combined versus Remainder of State . . . . . . . . . . 64

Figure 4

Minnesota Alcohol-Related Crashes

Total Year 1987-1992

Hennepin and Ramsey Counties Combined versus Remainder of State $\ldots \ldots \ldots \ldots$

\section{Figure 5}

Minnesota Alcohol-Related Crashes

Comparisons of Christmas-New Year Period with Other Holiday Periods Combined

Hennepin and Ramsey Counties Combined versus Remainder of State $\ldots \ldots \ldots \ldots 6$ 


\section{LIST OF APPENDICES}

A $\ldots \ldots \ldots \ldots$ Summary of Evaluation Questions, Data Collection and Limitations on Answers.

B ................. Syracuse/Albany Area DMV survey - 1992

Syracuse/Albany Area DMV survey - 1993

C ..... Discussion Topoics with Alcohol-Serving Establishment Customers and SoberCab Users

D $\ldots \ldots \ldots \ldots \ldots \ldots \ldots$ New York State Fair/RID survey

E . . . . . U University of Minnesota Survey questions on SoberCab

F $\ldots \ldots \ldots \ldots \ldots \ldots$ Formulas Used to calculate B.A.C.

G .............. I'm Smart Driver Observation Form

H $\ldots \ldots \ldots \ldots \ldots \ldots \ldots$ SoberCab Driver Interview Form

I ................. I'm Smart Corporate Questionnaire 


\section{NEED FOR EVALUATION OF MODEL RSP PROGRAMS}

Ride Service Programs (RSPs) provide safe rides home for individuals who are judged (by themselves or others) incapable of driving themselves due to alcohol impairment. RSPs emerged in the 1980s as an "environmental" approach to reducing drinking and driving problems. The need for safe alternative transportation for drinkers is substantial. A study by Integrated Research Services in two northern California communities in 1987-88 (Caudill, Kantor \& Ungerleider, 1990) found that $70 \%$ of bar drinkers admitted driving while feeling intoxicated, and did so an average of 14 times each in the previous year. This study also investigated the awareness, prior use, and perceived utility of RSPs among these respondents, finding that $62 \%$ knew of RSPs but less than $7 \%$ of the total sample had ever used one, and less than $8 \%$ of "heavy drinkers" had ever used any alternative source of transportation.

In 1987-88, Harding, Apsler, and Goldfein (1988a; 1988b) identified over 300 RSPs operating throughout the United States, delivering an average of 841 and a total of some 25,000 safe rides annually. Of these RSPs, only 52 were studied in any detail. Very little is known about the people who use them, public awareness of them, public attitudes about them, attitudes of the drinking public about them, or their effectiveness (Harding et al., 1988a; 1988b). The present study attempts to increase our knowledge base on these and other questions. Harding et al. (1988a) found considerable variation among the programs in structure, sponsorship, operational methods, periods of operation, geographic areas covered, riders targeted, number of rides given, funding and other characteristics. However, there is a lack of evidence in the literature about the effectiveness of RSPs with respect to their influence on traffic safety or reduced number of alcohol-related trips. In addition, there has been little information on the best methods to structure and operate an RSP to maximize effectiveness.

The prevalence of these programs, as well as the many organizations, public and private, who operate and contribute to RSPs, provide an impetus to study these programs as one approach to reduce driving while under the influence (DWI) of alcohol or other impairment. Several questions need to be answered about RSPs in order to assess their role in reducing DWI. Among them are:

(1) Can ride service programs measurably reduce the number of drivers who are impaired by alcohol and does this influence traffic safety data?

(2) Under what conditions can RSPs be effective in reducing the traffic safety hazards of impaired drivers?

(3) Who should be targeted as potential users of RSPs and what is the best approach to publicize the service and motivate these individuals to use it?

(4) Who uses RSPs, and are these the individuals who would drive impaired in the absence of an RSP?

(5) Who should operate RSPs and how should they be financed? and

(6) What are the organizational structures within which an RSP can operate most effectively?

These questions provided a general framework for conducting an evaluation study. Empirical data on these and other related questions will aid organizations and communities who currently have or support RSPs or who are considering RSP development as one approach to increasing traffic safety. In addition, 
answers will provide an assessment of the contribution of RSPs to an overall traffic safety strategy. It is important to note that RSPs are only one, perhaps small, part of the efforts by federal, state and local governments as well as commercial and non-profit agencies and groups to prevent DWI.

A major difference among RSPs is whether they operate year-round (including those operating mainly on week-ends) or only during certain holiday periods such as the Christmas-New Year's Eve period. Consequently, the National Highway Traffic Safety Administration designated that evaluation should be conducted on one year-round and one Christmas-New Year's Eve program.

\section{SELECTION OF TWO MODEL RSPS FOR EVALUATION}

Several decisions were required prior to the selection of RSPs to study. Initially a decision was made to use existing programs rather than developing new programs. It was determined that the time, effort and expense involved in developing a new program in one or two communities was beyond the fiscal and time resources allocated to the evaluation. Using existing programs has the following positive factors for evaluation:

- a time span long enough to assess the outcomes of interest;

- availability of records from the RSP as well as traffic safety and DWI data for a relatively long period;

- stable and established programs;

- use of programs that are among the best of what exists; and

- allowing time and other resources to be spent on evaluation as opposed to program development.

Perhaps the most important rationale for choosing existing programs for evaluation is the latter. In other words, there was not enough time in the contract period to start a new program and follow it to the level at which a meaningful evaluation of its effects and effectiveness could be accomplished.

Thus, the decision was made to evaluate two existing programs. This decision was bolstered by comprehensive telephone interviews with nine RSPs. Based on their data and the information we obtained from the telephone interviews, several year-round and holiday programs were identified as good candidates for evaluation.

In order to facilitate the decision process a set of dimensions was defined that were considered to be components of a model program. Ideas were suggested on how each of several structural and operational components would function in a comprehensive model program. These program components were based on the reports by Harding et al., (1988a, 1988b), extensive telephone interviews with nine programs, and general principles of DWI prevention. Six of the nine programs interviewed were among the 12 selected by Harding et al., (1988b) for a site visit. Their selection started with a total of 52 programs based on: (1) new or combination of features; (2) considered successful by various sources; (3) programs that had been in operation for at least one year or one holiday season; and (4) number of rides provided in terms of the size of the target population. Similar criteria were used to select 12 from the 52 . For this evaluation, telephone interviews did not include programs selected by Harding et al. that focused on limited populations (e.g., students), provided very few rides, and one that operated only on New Year's Eve. Our sample included programs operated for profit and non-profit, year-round and holiday programs, and programs in small, medium and large population areas. RSPs interviewed included stand alone organizations, programs using existing taxi systems but not administered by these systems, and those 
operated and administered by taxi companies. The small sample represented a variety of the common organizational structures found among RSPs. One program visited in the Harding, et. al. study was not operating but a program covering the same area was identified and participated in the telephone survey. Two programs not visited in the previous study were also interviewed. Table 1 presents a list of the programs interviewed.

Model RSPs were defined in the following manner:

(1) Program Targets and Eligibility - Targets would be the general population of drinkers who drive, organizations and establishments where they drink, social hosts, and specific socio-demographic groups at high risk for drinking and driving (e.g., young males, patrons of alcohol-serving establishments). The criteria for eligibility to use the RSP should be rather loose, erring on the side of leniency, at the same time focusing on the person who is impaired, especially by alcohol, who probably would have driven after drinking. Rides should also be given to impaired non-drivers for their own personal safety as well as passengers of an intoxicated driver who refuses to use an RSP.

(2) Publicity - The program is publicized through a variety of media (newspapers, radio, TV, billboards, signs on public transportation and direct mail to organizations such as alcohol-serving establishments, corporations, government agencies) and at point of drinking (alcohol-serving establishments) to reach the broadest possible target population. Information about the program is posted in various organizations especially in offices and at alcohol-serving establishments (posters on the walls, table tents, cardholders and information on walls of restrooms). The name and number of the program is available through public media including at point-of-drinking. For holiday programs a media "blitz" starts at least one week before the service commences and continues throughout the period. For year-round programs the publicity activities occur periodically at less intensity than the holiday "blitz" with greater intensity during the high-risk DWI holiday periods.

(3) Adjunctive Prevention Services - The RSP, in addition to safe rides, provides other relevant prevention and intervention services such as training alcohol-serving establishments in responsible service, corporate event risk-management and providing non-intrusive written information to customers on BAC levels, signs of substance abuse, and phone numbers where they may receive information or help. RSPs operated by organizations such as cab companies, are generally not involved nor able to provide such services. These RSPs might make cooperative arrangements with prevention organizations (public or private) to add these services.

(4) Funding - A model RSP, especially a year-round program, receives a relatively small percent of funding from each of many sources in order to insure stable funding and reduce the risk that withdrawal or reduction of funding from one or two sources would limit the ability of the program to function. Maintaining a diversity of sources might increase the administrative workload of the program, but would reduce dependence on larger donors. Funding resources would include cash, in-kind services (publicity) and equipment. For holiday programs, a more limited funding base may be appropriate. For both types of programs, resources are sought from such groups as hospitality industry groups, alcohol-serving establishments, alcoholic beverage manufacturers and distributors, local government agencies, health care organizations, service clubs, citizens groups, community groups, insurance companies, transportation companies, media organizations and business groups. Organizational membership in the program with provision of rides and other services to employees and customers is another approach to funding. 


\section{DESCRIPTIONS OF I'M SMART AND SOBERCAB}

\section{I'm Smart}

\section{Origins and History}

I'm Smart originated in 1982 in Syracuse, New York under the guidance of business entrepreneur Martin Yenawine. Mr. Yenawine has many years experience in the transportation business as owner of Eastern Ambulance Service since 1978, and in community service prior to that as coordinator of United Way activities in upstate New York. He received national recognition for innovative program development on drinking and driving from President Reagan for his development of I'm Smart, and has received similar recognition from New York's Governor Cuomo. The RSP in Syracuse has expanded its ride service volume tenfold in ten years of operation, as well as expanding its range of services. During the past few years it has provided approximately 2,500 rides annually with no reliance on public funds.

In its ten years of experience, I'm Smart has developed and refined its operations to include several innovative features which are capable of export to new communities: (1) as a for-profit operation relying on no public funds, it is a promising approach in the current government fiscal environments; (2) as a demonstrated for-profit model, it can appeal to community-oriented businesspeople in any city, especially as an adjunct to other transportation businesses; and (3) it is designed to be relevant to the financial selfinterest of participating companies and establishments, and does not depend on altruistic motives.

\section{Operational Features}

I'm Smart is a year-round, for-profit corporation that provides safe rides to intoxicated customers from bars and from corporate and social host parties including those of college students and fraternal organizations. It also provides rides to medically impaired persons (e.g., after outpatient surgery). I'm Smart provides clients transportation to their homes in their own vehicles. An I'm Smart staff member drives the customer while another staff member follows. This avoids the common RSP problem of leaving the customer's car, one important source of underutilization identified by Harding et al. (1988), and also avoids a source of program abuse: the patron without a car who is therefore not a DWI risk, however intoxicated.

Very importantly, the RSP is included within a broader DWI countermeasure approach which includes server intervention training for participating establishments and a corporate risk management program for participating companies. It is these larger programs providing reduced liability exposure which motivate the businesspeople who provide a stable funding base for the program.

I'm Smart provides dispatchers with training to efficiently record information from potential users. Currently, the principal dispatcher served previously as a driver for seven years. Locations of driving teams are continuously monitored on computer screen so the closest available team can be dispatched to respond to each call. The dispatcher ascertains the customer's name and location, name of establishment, destination, and method of payment. This includes the corporate account number if the user is an I'm Smart cardholder. Non-cardholders receive a discounted rate if coming from a participating I'm Smart establishment, which may be paid by the customer or the establishment. Some establishments maintain an open account with I'm Smart for this purpose, although most encourage the customer to pay. All calls are automatically recorded for future legal contingencies. Establishments appreciate this feature 
since it documents their efforts to get intoxicated customers home safely even if the customer refuses or fails to use the service at time of pick-up.

I'm Smart drivers transport the customers home in their own vehicles. An I'm Smart vehicle with a second driver follows the customer's vehicle home to provide a return ride for the customer's driver. This also assures that a back-up exists if there is trouble with the customer's vehicle, the customer(s), or inclement weather. The driving team consists of a male and female, and each customer is driven by a same-sex driver. Drivers are required to have the appropriate chauffeurs category license, and take a special driver training course on defensive driving and communication skills including assertiveness training. Drivers have a specific protocol for transporting intoxicated customers. This system assures customer and driver safety and minimizes ride abuse (non-intoxicated or convenience rides).

Driving teams are scattered around the city during evening hours, remaining on call by cellular phone. There are typically two teams available on weeknights, five on weekends, and as many as 20 on New Year's Eve. Drivers use their own cars and are reimbursed for mileage. They are paid a nominal hourly salary to remain on call and an additional $\$ 5-7$ for each ride provided. Staffing formulas for managing slow and busy times of the week and evening(s) are maintained to assure having adequate numbers of drivers to respond to calls in a timely fashion.

Corporate members pay a fee depending on the number of employees: less than 25 employees, $\$ 365 ; 26$ 50 employees, $\$ 500$; more than 50 employees, $\$ 500$ plus $\$ 3.00$ per each additional employee. I'm Smart provides alcohol awareness sessions for employees, a monthly newsletter, and cards for each employee entitling them to free and confidential use of the RSP. The companies are billed monthly for use of the RSP by their employees, at the discounted rate, while the anonymity of the employee users is strictly safeguarded. In Syracuse during ten years of activity, over 300 business partners and some 30,000 employees have become involved in reducing excessive drinking and protected from driving home when intoxicated through the I'm Smart's corporate program. The annual fee covers the costs of I'm Smart ride services, alcohol education, risk control sessions, and corporate party planning. Company managers receive responsible social host training, and a stand-by ride service is provided on request for company parties. The large majority of RSP users over the past four years are corporate cardholders. Some 18,000 rides have been provided over the program's 10-year history. Currently, approximately 200 companies are I'm Smart members. Syracuse University has an I'm Smart program for training campus social hosts in "respectable partying," and one SU fraternity uses the RSP.

Drinking establishments may become members by paying an annual fee of $\$ 400$. This service consists of (1) server intervention training for all alcohol service staff, (2) five complimentary ride service passes each year, (3) documentation of all efforts - successful or not - to induce intoxicated patrons to use the RSP, and (4) reduced RSP rates for their patrons whether the establishment or patron pays for the service ( $\$ 33$ compared to $\$ 60$ for non-members).

At the beginning of 1992 a total of 342 organizations paid to belong to I'm Smart. This included 198 private, public and non-profit organizations and 144 commercial alcohol-serving establishments and private clubs. The members included a very diversified group of organizations, including manufacturing, distribution, professional, social and service organizations. Among the types of organizations belonging to I'm Smart were: accounting firms, brokerage companies, fire departments, medical service organizations, automobile dealers, banks, communication companies, local government agencies, utility companies, radio and TV stations, manufacturing companies, a major beer company, insurance companies, and service clubs. Among alcohol-serving establishments, members included large hotels, taverns, 
restaurants, golf clubs, private clubs and bowling centers. The number of member alcohol-serving establishments ranged from 108 to 145 between 1986 and 1993, with an average annual membership of 122. During the 1990 to 1993 period, the range of members was 123 to 145 . There is a sales person who markets the program to various organizations. Contributing to the longevity of the program is its diversity of organizational clients. The number of member organizations and establishments has been relatively stable for several years.

The server training covers dram shop liability laws, age identification, intoxication intervention and techniques for encouraging intoxicated driving customers to use the I'm Smart RSP or other alternative transportation. These trainings are provided weekly for new employees and licensees in this high turnover business. All trainings are documented, which provides establishment owners important dram shop liability protection as well as $15-30 \%$ reductions in dram shop liability insurance premiums. One owner reported that his participation was very useful in defending a liability suit last year.

I'm Smart has used a wide variety of publicity techniques. These included television news features, public service announcements, newspaper feature articles, small circulation newspapers, national news media, newsletters and bulletins of organizations for awareness messages, radio feature stories, interviews and panel programs, flyers and brochures, and such feature events as charity dances, marathons, extra distance endurance races, county and feature event fairs, and bazaars.

\section{SoberCab}

\section{Origins and History}

This program has an 8-year history. In 1984 a Minneapolis chemical dependency treatment facility, CompCare, Inc., sponsored a safe transportation program for intoxicated bar patrons in the Twin Cities area of Minneapolis and St. Paul during the Christmas/New Year's Eve holiday period. This was one of many holiday ride service programs developed at that time nationwide by CompCare. The program was actively promoted through public service announcements in the print, talk and electronic media.

Called SoberCab, CompCare contracted with a local taxicab company to assign cabs through their dispatcher to respond to calls from customers in local bars. The company kept a record of the name of the rider, the location from which the customer was picked up, and the address where the customer was delivered. The ride was free to the customer, but the fare was billed to the sponsoring corporation, CompCare, Inc. SoberCab has averaged approximately 700 rides during the last two Christmas - New Year's Eve periods.

CompCare discontinued sole sponsorship in 1988, and was replaced by a consortium of 24 hospital corporations which currently sponsors SoberCab. Records are maintained on calls, places of pick-up, "no loads" (instances where a cab went to pick up a rider but no rider was transported), rides canceled, and rides provided. These are records sufficient for billing of the Hospital Council by Airport Taxi which provides the ride service. This data has been computerized for only two years. Data is not recorded on rider characteristics or destinations, but the destination must be a private residence. Since it is only an eight to ten day program once a year, cost effectiveness dictates that personnel and other operating costs be kept to a minimum. The leanness of the operation has no doubt contributed to its longevity. 


\section{Operational Features}

Sober Cab uses several volunteer dispatchers from the sponsoring hospitals during the Christmas through New Year's Eve holiday season, using space and phone facilities provided by one of the hospitals. The dispatchers take calls from customers and contact the taxicabs that contract to provide the ride service on a cost reimbursement basis at an average cost of approximately $\$ 10$ a ride. Training of the dispatchers takes place prior to the start-up date regarding procedures for recording calls and making sure that use is limited to rides to residences for intoxicated bar patrons only. Records are kept on the origin of the ride.

SoberCab has used various publicity strategies, including TV spots, newspaper feature articles, radio and posters/flyers as the principal means for getting the word out to potential users. One principal vehicle is a press conference in mid-December to which all local print and broadcast media are invited. A second important vehicle is provision of flyers to alcohol-serving establishments to make the SoberCab number conveniently available to patrons, waitstaff, and bartenders. One local college - Augsburg College provides the SoberCab number on their student body cards.

Rides are provided only from public drinking establishments to private residences. The Hospital Council considers transportation home from private parties to be the responsibility of the social hosts, and this concept is promoted during the holiday season by AAA and MADD in the Twin Cities area. The SoberCab dispatcher broadcasts potential pick-ups to cabs by radio, announcing location of the customer, and cabs in the pick-up vicinity "bid" on the call with the nearest bidder getting the assignment. Since as many as 100 Airport Taxi cabs may be on the street at any given time, there is usually a timely response. On busy nights there might be some wait in the later hours between $11 \mathrm{pm}$ and 2am, since most Sober $\mathrm{Ca} b$ calls are concentrated in this time period and many drivers have already gone home. This taxi company services many corporate accounts, specializing in on-time transportation to and from the airport, and the drivers - who are independent contractors - therefore do a lively daytime business. As one driver explained it, "cabbies like freedom and like cash," and many drivers have a subjective daily income "quota" which after meeting they go home. Delays are more likely in the suburbs where fewer cabs operate. However, during four nights of research ride-alongs which included listening to the dispatchers' broadcast bids, driver responses were usually timely and significant delays were not observed. Delays can also occur when the weather is particularly inclement, although Twin Cities taxi drivers are not easily deterred by weather.

In this RSP the patron's vehicle is not transported and patrons who plan to use SoberCab often take another ride to the bar, leaving their cars safely garaged, especially during cold weather. Patrons understandably avoid leaving their car overnight in a bar parking lot exposed to the sub-zero temperatures common during Minnesota winters. Otherwise, the inconvenience of a stalled car the next day might be a disincentive to using Sober $C a b$. Thus, some riders who did not drive their own cars to the bar might have done so were Sober $C a b$ not available, and might therefore represent alcohol-impaired rides saved rather than "abusers" of the service.

Airport Taxi is well suited to conduct the SoberCab program. It is the largest cab company in the Twin Cities with 25 - 30 cabs serving downtown Minneapolis and St. Paul and over 100 serving the suburbs. This is appropriate to the SoberCab program needs. The principal Twin City drinking areas are in downtown Minneapolis, including an entire floor of the world's largest mall (The Mall of America) occupied exclusively by bars, clubs, and restaurants, and another large indoor bar, club, and entertainment 
complex on the riverfront called "Mississippi Live." Many suburbanites therefore drink in town and would have a long drive home without SoberCab.

The company manager of Aiport Taxi carefully observes and supervises his drivers. Driver morale was reported to be good by the two drivers interviewed. A third of the cars are leased from the company by the drivers, which they find convenient since a full-time shop is maintained by the company and operating vehicles are continuously available to these drivers. Dispatchers were described as "not overworked," and drivers are able to earn extra money through making deliveries for a courier service associated with the taxi company, assuring near-continuous work while on duty. The company was described by the drivers as unusually well organized and "disciplined," with less "internal friction" than most cab companies. Their many corporate contracts make it possible to work largely during daytime hours, and many drivers work evenings only on weekends and during SoberCab week. Even at night, most of these drivers work the airport and transport few bar patrons home. Thus, the SoberCab program supplements rather than competes with their normal business.

Table 2 presents summary information on characteristics of the two RSPs.

\section{EVALUATION QUESTIONS TO BE ADDRESSED}

The questions to be answered by the evaluation were designed to provide answers to both effectiveness (e.g. alcohol trips reduced) and operational aspects of the RSPs including:

- level of use;

- extent of community awareness;

- efficiency;

- characteristics of users and those who are aware of the programs;

- funding and other support related to the continuation of the programs;

- appropriateness of users to the goals of the programs; and

- effects of a publicity campaign of the year-round program targeted at minorities in the I'm Smart service area.

The specific evaluation questions to be addressed are:

- To what extent is the driving community aware of the program;

- Are those who are more likely to have need of an RSP (i.e., those who drink alcohol and those who drink and drive) aware of the RSP?;

- How many individuals use the RSP and what are their characteristics?;

- Are the users the most appropriate targets of the program (i.e., impaired individuals who have driven to the location where they drink or would have driven in the absence of the RSP)?;

- Is the RSP conducted in an efficient and convenient manner?;

- Is the program self-sustaining?;

- Would the users of the RSP employ means of transportation, other than driving their own vehicle, in absence of the RSP?;

- What alternatives to driving after drinking do drinkers report using?; 
- How many alcohol-related trips are reduced due to the use of the RSP?;

- Do the RSPs reduce alcohol-related crashes; and

- Did a targeted publicity campaign change awareness and use of I'm Smart among the communities to whom the publicity was directed?

Several of the questions are highly interrelated.

Table 2

Comparisons of I'm Smart and SoberCab

\begin{tabular}{|c|c|c|}
\hline Program Elements & I'M SMART - SYRacuSE & SOBERCAB - MINNEAPOLIS \\
\hline Program Operation Period: & Year Round & Holiday Only \\
\hline Program Operated by: & $\begin{array}{l}\text { I'm Smart of Central New York } \\
\text { (private organization) }\end{array}$ & $\begin{array}{l}\text { Funded by Council of Hospital Corp. } \\
\text { using Airport Taxi Company }\end{array}$ \\
\hline Mileage Paid to Drivers: & $\$ 0.25 / \mathrm{mile}$ & $\begin{array}{l}\text { use of existing cab services (no extra } \\
\text { charges - regular fares) }\end{array}$ \\
\hline Amount of Insurance: & $\$ 3,000,000$ liability & $\begin{array}{l}\text { no extra insurance for cabs or } \\
\text { Council of Hospital Corp. }\end{array}$ \\
\hline Training Costs: & $\$ 1,200$ per year & none \\
\hline Rent: & $\$ 650.00 /$ month & use existing corporate facilities \\
\hline Advertising Costs: & free (pro bono) & $\begin{array}{l}\text { paid by operator - Council of } \\
\text { Hospital Corporations }\end{array}$ \\
\hline Number of Drivers: & 38 & $\begin{array}{l}50 \text { - Regular cab drivers who agree } \\
\text { to take SoberCab rides }\end{array}$ \\
\hline Office Staff: & $3-5$ & $\begin{array}{l}\text { small percent of time of existing } \\
\text { hospital employees and coordinator }\end{array}$ \\
\hline Cars: & privately owned & regular cabs \\
\hline Cost per Ride: & $\begin{array}{l}\text { no charge to individual user } \\
\$ 33.00 / \text { ride average to corporate, } \\
\text { establishment or insurance payer }\end{array}$ & $\begin{array}{l}\text { no charge to individual } \\
\$ 10.00 / \text { ride average to Council of } \\
\text { Hospital Corporations }\end{array}$ \\
\hline Communication: & phones and pagers donated & phones at member hospital \\
\hline Number of Rides: & 2,615 in 1992 & 692 in 1992 \\
\hline Area Covered: & 2 counties & 7 counties \\
\hline Square Miles Covered: & 820 square miles & unknown \\
\hline Member Organizations: & 342 (as of January 1993) & Local Hospitals \\
\hline Individuals with RSP Vouchers: & Approximately 41,000 employees & no vouchers needed \\
\hline
\end{tabular}




\section{METHODS AND RESULTS}

Evaluation of the year-round program, I'm Smart, started in October 1991, and ended in August 1993. Two waves of data collection were conducted allowing for a publicity campaign. The community of Albany, New York was used as a control site. Evaluation of the holiday program, SoberCab, occured mainly during the Christmas-New Year's Eve holiday, 1992, through the summer of 1993. A control holiday period, the July 4th weekend, 1993, was used as a comparison. Due to time constraints and other reasons discussed later, no special campaign was conducted in the Twin Cities area.

The methodology and samples employed will be discussed under each evaluation question. A summary of the data collection instruments, general analytic approaches and limitations for each evaluation question appears in Appendix A.

\section{To what extent is the driving community aware of the RSP?}

\section{Methodology - I'm Smart}

Data on name recognition and knowledge of I'm Smart was obtained from several different samples and instruments.

- DMV Surveys - Written questionnaires were distributed by DMV staff to individuals coming into two state Department of Motor Vehicles (DMV) offices in Syracuse, during the Fall of 1992 and in June, 1993. Surveys were also available to samples of individuals coming into DMV offices in a comparison area without a year-round RSP (offices in Albany, Schenectady and Troy, New York) during approximately the same period of time as in Syracuse. For the comparison area, the June 1993 survey was distributed only in the Albany, New York office. Individuals coming into DMV offices were used to obtain a sample of the driving population. The questionnaire, completed anonymously, included questions on demographics, drinking behavior, knowledge of a ride service program, recognition of the name of an RSP (four were listed including I'm Smart), knowledge of what an RSP is (open-ended), sources of information about I'm Smart and alternatives to driving after drinking (See Appendix B). Data from the DMV surveys are also employed to answer several other evaluation questions.

The samples of individuals coming to DMV offices were not obtained randomly. Respondents were both self-selected and determined by DMV staff participation. The survey forms were distributed at the "start here" desk along with other forms needed by the customer. They were asked to hand in the completed forms at the window where they transacted their business. Thus, the survey was brought together with paperwork identifying the client. This may have discouraged potential respondents or influenced responses to some of the questions, e.g., candid responses to items about income, drinking, and driving after drinking.

- Discussions With Customers at Alcohol-Serving Establishments - This approach was used to obtain samples of the alcohol drinking population. The on-site coordinator trained field research staff using "in-vivo" and role playing techniques. Trained field research staff as well as the coordinator of field research conducted these discussions in Syracuse during the fall of 1992 and June, 1993. Similar discussions were also done with a sample of customers of six alcohol-serving establishments in Albany, New York (comparison area) during March, 1993. The establishments were self-selected from those scouted, selected and approached by the coordinator of field research. In Syracuse, 
establishments were obtained that did and did not belong to I'm Smart. In addition to the possible self-selection bias of establishments, customers who agreed to talk with staff, usually as they were leaving, were also self-selected to some extent. Thus, biases in the sample of establishments and customers may exist. Several different types of establishments with respect to modal characteristics of customers were included in the sample (e.g., "blue collar", "yuppie", college students).

During the discussions, items such as demographic information, typical drinking behavior, drinking behavior during the evening, feelings of intoxication and ability to drive safely, name recognition of I'm Smart, previous use of I'm Smart, alternatives used to avoid driving after drinking, and methods of transportation to and from the establishment were raised (Appendix C). The focus of some of the discussions varied from the comparison area to Syracuse. Data from these discussions are also used to answer other evaluation questions.

When concluding these unstructured discussions the customers were given a BAC card which gave approximate blood alcohol content by weight and number of drinks. In the comparison site, customers were also given a sheet listing taxi companies and phone numbers. In Syracuse, customers were given the I'm Smart phone number. In both communities customers were encouraged to take alternative transportation if they felt unsafe to drive.

- $\quad$ RID Survey - A written survey, conducted by a citizen's group, Remove Intoxicated Drivers (RID), was given to attendees at the New York State Fair in Onondaga County, New York (the home of I'm Smart) in September, 1992. Many of the questions concerned ride services programs. Respondents were self-selected as they were individuals who visited the RID booth, and took the survey.

Questions on the RID survey included, awareness of a safe ride program in their community, knowledge of the program (open-ended question), county of residence, frequency of drinking, feeling unable to drive home safely in the past, what was done in those conditions and previous charge or conviction for an alcohol-related traffic offense. It should be noted that no question about I'm Smart was asked. (The state fair attracted individuals from throughout the state and elsewhere.) Name recognition and knowledge of I'm Smart was gleaned from responses to the open-ended question. (See Appendix D).

\section{$\underline{\text { Results - I'm Smart }}$}

\section{- DMV Surveys}

Table 3 presents data on RSP awareness and name recognition of I'm Smart from the DMV surveys in Syracuse and the comparison area.

The DMV surveys conducted in the two offices in Syracuse show that $51 \%$ in 1992 and $55 \%$ in 1993 had heard about a "ride service program" in their community. Differences between round one and round two respondents in Syracuse were not statistically significant $\left(\chi^{2}=1.5, \mathrm{df}=1, \mathrm{p}=.22^{1}\right)$. Combining the two

\footnotetext{
${ }^{1}$ This notation means that 22 times out of 100 this event would occur by chance.
} 
samples, 53\% of a sample of Syracuse DMV clients indicated they had heard of an RSP in their community.

Table 3

Syracuse and Comparison Area DMV Surveys, 1992 and 1993

Awareness of an RSP and Name Recognition of I'm Smart

\begin{tabular}{|c|c|c|c|c|}
\hline \multirow[b]{2}{*}{ QUESTION ASKED } & \multicolumn{2}{|c|}{ SYRACUSE } & \multicolumn{2}{|c|}{ COMPARISON AREA* } \\
\hline & 1992 & 1993 & 1992 & 1993 \\
\hline \multicolumn{5}{|c|}{ Have You Heard of a Ride Service Program in Your Area? } \\
\hline Yes & $\begin{array}{c}51 \% \\
(\mathrm{n}=270)\end{array}$ & $\begin{array}{c}55 \% \\
(n=205)\end{array}$ & $\begin{array}{c}31 \% \\
(\mathrm{n}=298)\end{array}$ & $\begin{array}{c}24 \% \\
(\mathrm{n}=57)\end{array}$ \\
\hline No and No Response & $\begin{array}{c}49 \% \\
(n=259)\end{array}$ & $\begin{array}{c}45 \% \\
(n=165)\end{array}$ & $\begin{array}{c}70 \% \\
(n=680)\end{array}$ & $\begin{array}{c}76 \% \\
(n=182) \\
\end{array}$ \\
\hline \multicolumn{5}{|c|}{ Which of the Following Programs Have you Heard About?** } \\
\hline Tipsy Taxi & $\begin{array}{c}1 \% \\
(\mathrm{n}=3)\end{array}$ & $\begin{array}{c}.3 \% \\
(n=1)\end{array}$ & $\begin{array}{c}6 \% \\
(n=59) \\
\end{array}$ & $\begin{array}{c}5 \% \\
(\mathrm{n}=11) \\
\end{array}$ \\
\hline Home Free & $\begin{array}{c}2 \% \\
(\mathrm{n}=9)\end{array}$ & $\begin{array}{c}1 \% \\
(\mathrm{n}=3)\end{array}$ & $\begin{array}{c}8 \% \\
(\mathrm{n}=80)\end{array}$ & $\begin{array}{c}4 \% \\
(n=9)\end{array}$ \\
\hline I'm Smart & $\begin{array}{c}55 \% \\
(\mathrm{n}=292) \\
\end{array}$ & $\begin{array}{c}58 \% \\
(\mathrm{n}=216)\end{array}$ & $\begin{array}{c}2 \% \\
(\mathrm{n}=20)\end{array}$ & $\begin{array}{c}2 \% \\
(\mathrm{n}=4)\end{array}$ \\
\hline Safe Shuttle & $\begin{array}{c}1 \% \\
(\mathrm{n}=7)\end{array}$ & $\begin{array}{c}2 \% \\
(\mathrm{n}=6)\end{array}$ & $\begin{array}{c}7 \% \\
(\mathrm{n}=71) \\
\end{array}$ & $\begin{array}{c}9 \% \\
(n=22)\end{array}$ \\
\hline $\begin{array}{l}\text { More Than One Name } \\
\text { Checked*** }\end{array}$ & $\begin{array}{c}3 \% \\
(n=18) \\
\end{array}$ & $\begin{array}{c}2 \% \\
(n=9)\end{array}$ & $\begin{array}{c}3 \% \\
(n=31) \\
\end{array}$ & $\begin{array}{c}2 \% \\
(\mathrm{n}=5)\end{array}$ \\
\hline No Names Checked & $\begin{array}{c}38 \% \\
(n=200) \\
\end{array}$ & $\begin{array}{c}37 \% \\
(\mathrm{n}=135) \\
\end{array}$ & $\begin{array}{c}73 \% \\
(n=717)\end{array}$ & $\begin{array}{c}79 \% \\
(n=188) \\
\end{array}$ \\
\hline Total $\mathbf{N}^{2}$ & 529 & 370 & 978 & 239 \\
\hline
\end{tabular}

- The first round of surveys was conducted in three offices, one each in the cities of Albany, Schenectady and Troy, New York. The second round of surveys was conducted in one office in Albany.

** During the second round this question included the words "in your community" after the word "programs". This was done to reduce some of the individuals who had checked other programs not in the Syracuse area or in New York State.

*** In Syracuse this includes respondents who checked I'm Smart and one or nore of the other RSPs listed. Seventeen of the 18 multiple responses included I'm Smart.

In terms of name recognition, 55\% of the DMV respondents during the fall of 1992 and $58 \%$ during June, 1993 checked that they had heard of I'm Smart. Combining the two samples, 57\% reported to have heard of I'm Smart. Only those who checked I'm Smart as their only choice among the four RSPs listed are included in these percentages. The few who checked I'm Smart plus one or more of the other listed RSPs were not included among those recognizing the name I'm Smart. The three other RSPs listed on

2 Columns will not always add to Total $\mathrm{N}$ due to multiple and missing responses. 
the questionnaire were names of RSPs in parts of the country far from New York State. Differences between the 1992 and 1993 samples in recognizing the name I'm Smart (comparing those who heard of I'm Smart versus all other responses, including no response) are not statistically significant $\left(\chi^{2}=.9\right.$, df $=1, p>.25$ ). Despite limitations imposed by the way the sample was obtained (i.e., non-random sample of individuals who visit DMV offices) the level of name recognition can be considered relatively high, with over half of the combined samples indicating that they had heard of I'm Smart. I'm Smart has been in operation since 1982 and much publicity and advertising as well as corporate and bar membership has made it known to the general driving population.

The percent of the sample in Syracuse who reported hearing of a ride service program was lower than the percent who checked one or more of the four listed RSPs. Of those who said they had not heard of a ride service program in the community but checked one or more of the four listed RSPs, well over 90\% checked I'm Smart. Thus, the name I'm Smart was more familiar to some individuals than the term "ride service program," and some respondents did not associate the term "ride service program" with I'm Smart. This may have been due to lack of understanding of the term "ride service program", despite recognition of the name I'm Smart.

Not surprisingly, a much lower percentage of the DMV respondents in the comparison area claimed to have heard of an RSP than in Syracuse (31\% in 1992; $24 \%$ in 1993; $53 \%$, combining both surveys). There are no year-round RSPs in the Albany-Schenectady-Troy area, but there may be a small New Year's Eve program. Most of those in the comparison area who claimed to have heard of an RSP checked one or more of the listed programs other than I'm Smart (program names that do not exist in New York State to our knowledge). I'm Smart received the lowest percent of the four RSPs listed - only 2\% of the combined 1992 and 1993 samples. Differences between Syracuse and Albany area respondents on awareness of an RSP and hearing of I'm Smart are statistically significant at better than the $99 \%$ level of confidence.

The DMV survey included an open-ended question concerning what the respondent knew about the RSP(s) they had checked in the previous question. During the second round of DMV surveys (1993) a new, structured question was added to the questionnaire which asked the respondent to check how they knew about the RSP. There were seven alternatives, including "other", and the instructions allowed the respondent to check as many as applicable. Only individuals who had heard of I'm Smart were used in the analyses of these questions. Table 4 presents data on how the respondent heard of the RSP from the 1993 DMV survey.

The most frequent sources of information about I'm Smart were bars, radio and television. Three other specific alternatives listed were indicated as sources of information by at least $25 \%$ - newspaper, family or friends, and the workplace. A large proportion of those who had heard of I'm Smart, (45\%) reported more than one source. This group checked an average of almost 3 responses (Average $=2.94$ ). Only $6,(3 \%)$ individuals who reported that they had heard of I'm Smart did not indicate any of the seven sources of information. The data shows that publicity about I'm Smart at point of drinking (bars), through the media and at work is effective in providing public awareness.

In addition to questions concerning awareness of a ride service program, name recognition, and sources of information about the RSP, an open-ended question was asked concerning what is known about the 
RSPs. This was designed to elicit level of specific knowledge as well as beliefs and attitudes regarding I'm Smart.

Table 4

Syracuse DMV Survey, 1993

Sources of Information About RSP

(Only Respondents Who Checked Hearing of I'm Smart)

\begin{tabular}{|l|c|c|}
\hline SOURCE OF INFORMATION* & NUMBER & PERCENT \\
\hline Television & 68 & 31 \\
\hline Radio & 78 & 35 \\
\hline Newspaper & 62 & 28 \\
\hline Work & 61 & 27 \\
\hline Bar & 77 & 35 \\
\hline Friend or Family & 57 & 26 \\
\hline Other & 10 & 5 \\
\hline No Response & 6 & 3 \\
\hline Multiple Responses & 101 & 4 \\
\hline \hline Total N: & 223 & \\
\hline
\end{tabular}

- Individuals who gave multiple responses are included in all categories which they checked.

Written responses were coded into several categories with up to two codes per response. Categories included:

- source of information about I'm Smart (mainly coded for the 1992 sample);

- description of some element of an RSP including those specific to I'm Smart;

- responses indicating that the respondent is or had been a member of I'm Smart or has used I'm Smart;

- general positive remarks about an RSP;

- negative remarks about an RSP;

- description of other anti-DWI programs;

- responses saying that they knew nothing, very little, or only the name was known; and

- other.

In 1992,205 or $66 \%$ of the respondents who checked that they heard of I'm Smart wrote a response that could be coded to the open-ended knowledge question. In 1993, 132 or 59\% wrote a response. Table 5 presents the coded responses. The percentages are based on the number of respondents who indicated that they had heard of I'm Smart, including those that did not respond to the knowledge question. 
The most frequent response is no response (37\% of the combined 1992-93 samples). An additional 15\% in the combined samples said they knew nothing, knew little or not much, or only heard of the name or knew that it was available. Thus, slightly over half who said they had heard of I'm Smart did not indicate any knowledge about I'm Smart or an RSP. Some responses coded in the other categories also did not indicate any information about what I'm Smart does or how it operates.

Table 5

Syracuse DMV Surveys, 1992 and 1993 combined

Coded Categories of Response to Knowledge Question About the RSP

(Only Those Respondents Who Indicated They had Heard of I'm Smart)

\begin{tabular}{||l|c|c|}
\hline KNOWLEDGE CATEGORY & 1992 SURVEY & 1993 SURVEY \\
\hline Indicates source of knowledge ** & $16 \%(\mathrm{n}=48)$ & $1 \%(\mathrm{n}=2)$ \\
\hline $\begin{array}{l}\text { Description of some element of an RSP } \\
\text { including those specific to I'm Smart }\end{array}$ & $23 \%(\mathrm{n}=72)$ & $32 \%(\mathrm{n}=72)$ \\
\hline $\begin{array}{l}\text { Respondent has been or is a member of I'm } \\
\text { Smart or used I'm Smart }\end{array}$ & $7 \%(\mathrm{n}=21)$ & $.4 \%(\mathrm{n}=1)$ \\
\hline $\begin{array}{l}\text { General positive remark about RSPs } \\
\text { Little or no knowledge stated or know name } \\
\text { only }\end{array}$ & $15 \%(\mathrm{n}=47)$ & $15 \%(\mathrm{n}=34)$ \\
\hline Other & $5 \%(\mathrm{n}=15)$ & $6 \%(\mathrm{n}=13)$ \\
\hline No response & $34 \%(\mathrm{n}=104)$ & $41 \%(\mathrm{n}=91)$ \\
\hline \hline Total N: & 309 & 223 \\
\hline
\end{tabular}

* The small number of respondents whose responses were coded in two categories are represented in both categories.

** Changes in the questionnaire between 1992 and 1993 could account for the differences in these percentages.

The most frequent written response indicated that the individual had some idea of what an RSP was, (description of some element of an RSP) although only a minority of responses in this category showed a knowledge of the specifics of I'm Smart. Responses included statements such as: "Call and they will take you home for a fee"; "For people who have had too much too drink - \& get a ride home"; "They'll drive you home in your car"; "Some employers pay for service"; "Free ride home if needed"; "Provided by volunteers \& without cost or question"; "Corporation use for employees"; "Company paid - can only be used in Onondaga County"; "The bar sponsors rides"; "Ride service for people who drink too much."; "Available at request if a member"; "Free to all employees at work - fantastic idea"; "Call from bar"; "They take people home"; "There is a charge"; "Company belongs to it"; and "They will give you a ride if you think you had too much to drink." Many of the responses classified as indicating knowledge of some element of an RSP show specific knowledge of I'm Smart, but most did not mention driving your car or membership requirements. 
These responses show that people know something about what a ride service program does although many do not know the details of I'm Smart, and some gave wrong information. Some responses indicate awareness that the service is employer or establishment based while others respond as if it is a free service available to all. In fact many RSPs are free. In addition to responses describing an RSP or I'm Smart specifically, several written responses indicated that the individual belonged to I' $m$ Smart or their employer provides I'm Smart or, in a very few cases, that the respondent had used I'm Smart. We can assume that respondents who indicated they or their company were members or had used I'm Smart have some detailed and accurate knowledge of the program. However, the results from the open-ended question showed that a relatively small minority of all who reported hearing of I'm Smart knew how the program operated, although a larger percent provided indications of general knowledge of what an RSP does. It is possible that the percent who have some knowledge of I'm Smart and how it operates is somewhat underestimated by this data. Some individuals, especially those whose responses were coded under "source of knowledge" and the "positive remark" category, may have known more about an RSP and I'm Smart in particular, but chose not to spend the time to organize and articulate a more complete response.

There are differences between the two surveys with regard to some of the categories. A smaller percentage of individuals in the 1993 survey answered the knowledge question by stating they or their employers were members of I'm Smart. A larger proportion of the responses in 1993 were coded as showing knowledge of some element of an RSP, but a greater percentage did not answer the knowledge question in 1993 than 1992.

The data shows that, although a substantial proportion of DMV clients who completed the survey had heard of I'm Smart, the important details of how this service operates (driving the user's car and membership requirements) were described by a relatively small percent of these individuals.

\section{- Discussions with Customers in Alcohol-Serving Establishments}

Table 6 presents data on name recognition of I'm Smart based on discussions with customers in alcoholserving establishments in Syracuse during 1992 and 1993. In addition, how the customer had learned of I'm Smart, how to use I'm Smart, and previous use of I'm Smart is also presented. The table also presents data from establishment customers in the comparison site of Albany, collected during March, 1993.

Combining data from 1992 and 1993 in Syracuse, 78\% of the customers had heard of I'm Smart. The difference between 1992 and 1993 samples is not statistically significant $(p=.33$ ). Very few of the customers talked with in the comparison area (Albany) reported hearing of I'm Smart (4\%).

Half the establishments in Syracuse where discussions occurred were members of I'm Smart and half were not members. Alcohol-serving establishments which belong to I'm Smart typically have an "I'm Smart" sign prominently posted. The difference in the percent of customers who had heard of I'm Smart between the two types of establishments was not statistically significant at the $p=.05$ level using the combined 1992 and 1993 samples. In the member establishments 82\% of the customers had heard of I'm Smart, compared to $76 \%$ in the non-member establishments. 
Table 6

Discussions with Alcohol-Serving Establishment Customers in Syracuse and Albany, 1992 and 1993

Name Recognition, Sources of Information About I'm Smart,

Knowledge of How to Use I'm Smart and Prior Use of I'm Smart

\begin{tabular}{|c|c|c|c|}
\hline QUESTION & $\begin{array}{c}\text { SYRACUSE - } \\
1992\end{array}$ & $\begin{array}{l}\text { SYRACUSE - } \\
1993\end{array}$ & $\begin{array}{l}\text { ALBANY - } \\
\text { 1993** }\end{array}$ \\
\hline \multicolumn{4}{|l|}{ Had the Customer Heard of I'm Smart? } \\
\hline Yes & $76 \%(\mathrm{n}=207)$ & $80 \%(\mathrm{n}=245)$ & $4 \%(\mathrm{n}=5)$ \\
\hline No & $24 \%(n=64)$ & $20 \%(n=61)$ & $96 \%(\mathrm{n}=133)$ \\
\hline \multicolumn{3}{|c|}{ What Were Their. Sources of Information About I'm Smart?* } & \\
\hline Signs/Posters (no further specification) & $24 \%(n=46)$ & $26 \%(n=64)$ & \\
\hline $\begin{array}{l}\text { Advertisements (no further } \\
\text { specification) }\end{array}$ & $7 \%(\mathrm{n}=13)$ & $9 \%(n=21)$ & \\
\hline TV/Radio & $2 \%(\mathrm{n}=3)$ & $4 \%(\mathrm{n}=10)$ & \\
\hline Friend/Family & $22 \%(n=43)$ & $18 \%(\mathrm{n}=43)$ & \\
\hline At Work & $26 \%(\mathrm{n}=50)$ & $12 \%(n=30)$ & \\
\hline Member of I'm Smart & $11 \%(n=22)$ & $15 \%(\mathrm{n}=36)$ & \\
\hline At Bar & $15 \%(n=29)$ & $20 \%(n=48)$ & \\
\hline Other & $6 \%(n=11)$ & $8 \%(n=19)$ & \\
\hline \multicolumn{3}{|l|}{ Did They Know How to Use I'm Smart?* } & \\
\hline Yes & $80 \%(\mathrm{n}=164)$ & $77 \%(n=187)$ & \\
\hline No or No Response & $20 \%(n=41)$ & $23 \%(\mathrm{n}=57)$ & \\
\hline \multicolumn{3}{|l|}{ Had They Ever Used I'm Smart?* } & \\
\hline Yes & $13 \%(n=27)$ & $16 \%(n=40)$ & \\
\hline No or No Response & $87 \%(\mathrm{n}=177)$ & $84 \%(\mathrm{n}=205)$ & \\
\hline Total N: & 271 & 306 & 138 \\
\hline
\end{tabular}

* Data only for customers who responded affirmatively to having heard of I'm Simart. Multiple response categories were allowed for sources of infomation about I'm Smart. This occurred for about 9\% of the customers.

** Albany, New York was used as a comparison community.

The proportion of the sample of customers in alcohol-serving establishments (representing some part of the population who drink in commercial establishments) who had heard of I'm Smart (78\%) is a much larger proportion than in the samples of DMV clients (57\%) and those who completed the RID survey (35\%). (See Table 7 for RID survey data.) These differences are statistically significant at high levels of confidence, $\mathrm{p}<.0001$. The differences reflect well on the publicity and the targeting of those who drink and may drive. Customers of commercial alcohol-serving establishments would more likely be targets of an RSP than broader populations of DMV clients or state fairgoers who include greater 
proportions of non-drinkers, infrequent drinkers and those that do not drink in commercial establishments than the population of customers of alcohol-serving establishments.

Several sources of information were mentioned by those who said they had heard of I'm Smart. Only $3 \%$ of those who had heard of the program mentioned no sources of information. The three most frequent sources reported during the first round were work, signs and posters, and friends or family. During 1993, the three most frequent sources were signs and posters, at a bar, and friends or family. Some of the categories may overlap. Signs and posters were likely to have been seen at an alcoholserving establishment. The "advertisements" category may be from radio, TV or newspapers. Those who heard of I'm Smart at work were likely to be members through their employers. Given these assumptions, the most frequent sources from which customers heard about I'm Smart are from the workplace, family and friends, and alcohol-serving establishments. Around $25 \%$ get information through posters and signs, most likely at alcohol-serving establishments or their place of employment. The only statistically significant difference between the 1992 and 1993 data was for the category, "at work" (chisquare $=12.1, \mathrm{df}=1, \mathrm{p}=.0005$ ). About $12 \%$ of the sample mentioned this in 1993 and about $26 \%$ in 1992. However, the percentages who mentioned I'm Smart membership as the source of knowledge was not statistically different between the two years.

Of those who heard of I'm Smart, 77\% in the 1993 sample and $80 \%$ in the 1992 sample said they knew how to use the service. This has important positive implications for use of the RSP when customers feel they may not want to drive their vehicle in an impaired state.

Customers who indicated hearing of I'm Smait were asked if they had ever used the service. About $13 \%$ of the customers in the 1992 and 16\% in the 1993 samples said they had used I'm Smart (the difference was not statistically significant, $\mathrm{p}=.43$ ) for a total of $15 \%$ for the combined samples. Looking at the total sample, (including those who said they had not heard of I'm Smart) 12\% reported using I'm Smart in the past.

In order to go beyond name recognition, many customers were asked if they knew what I'm Smart was. In 1992 this was asked only when there was an I'm Smart poster in the establishment. Of those who replied, about one-fifth (22\%) of the combined 1992-93 samples said they did not know what I'm Smart was. The largest percent responded affirmatively, $49 \%$ in 1992, and 63\% in 1993. In 1992, approximately $18 \%$ of those who answered this question mentioned that the program transports the driver and the driver's car, while only $4 \%$ of the individuals mentioned this in 1993. In 1992, about $10 \%$ responded with general information about what an RSP is or what purposes it serves. In 1993 these responses were given by $13 \%$ of those who responded. Reasons for these differences are not apparent.

\section{- $\quad$ RID Survey}

Table 7 presents data on awareness of a "ride service" or "safe ride" program and whether the individual mentioned I'm Smart (or a similar name) in response to an open-ended question asking what is known about the ride service or safe ride program. The data is presented by area of residence of the respondent using Onondaga County (the area where I'm Smart is most active), counties contiguous to Onondaga, and all others areas including the $19 \%$ who did not write their county of residence. Respondents were those who completed the questionnaire at the Remove Intoxicated Drivers (RID) booth at the New York State Fair, held in September, 1992 in Onondaga County. 
Residents of Onondaga County report more awareness of a safe ride or ride service program (68\%) than residents of counties contiguous to Onondaga (40\%) and residents of other areas or those who did not specify county of residence $(37 \%)$. The differences are statistically significant at a very high level of confidence $\left(\chi^{2}=86.5, \mathrm{df}=2, \mathrm{p}<.0001\right)$. The presence of I'm Smart, the length of time it has been operating, publicity about the program, and membership in the program undoubtedly has made ride service programs familiar to large numbers in Onondaga County. There is a substantial fall off in percent awareness of an RSP even in the counties contiguous to Onondaga. However, $38 \%$ of all respondents outside Onondaga County reported to have heard of an RSP in their community. There may be some influence from I'm Smart as well as programs in other locations throughout the state contributing to this level of awareness. Also, "ride service" is an ambiguous term which could easily be confused with programs other than RSPs, (e.g., services to help the elderly with grocery shopping).

Table 7

RID State Fair Survey, 1992

Awareness of an RSP and Mention of I'm Smart by Respondent Residence

\begin{tabular}{|c|c|c|c|}
\hline QUESTION & $\begin{array}{c}\text { ONONDAGA } \\
\text { COUNTY }\end{array}$ & $\begin{array}{l}\text { ConTIGUOUS } \\
\text { COUNTIES }\end{array}$ & $\begin{array}{c}\text { OTHER } \\
\text { RESIDENCE OR } \\
\text { No RESPONSE }\end{array}$ \\
\hline \multicolumn{4}{|c|}{ Aware of Ride Service or Safe Ride Program } \\
\hline Yes & $\begin{array}{c}68 \% \\
(n=216)\end{array}$ & $\begin{array}{c}40 \% \\
(n=76)\end{array}$ & $\begin{array}{c}37 \% \\
(n=247)\end{array}$ \\
\hline No or No Response & $\begin{array}{c}32 \% \\
(n=102)\end{array}$ & $\begin{array}{c}60 \% \\
(n=113)\end{array}$ & $\begin{array}{c}63 \% \\
(n=426)\end{array}$ \\
\hline \multicolumn{4}{|c|}{ Mentioned I'm Smart or Similar Name* } \\
\hline Yes & $\begin{array}{c}35 \% \\
(n=76)\end{array}$ & $\begin{array}{c}18 \% \\
(n=14)\end{array}$ & $\begin{array}{c}9 \% \\
(\mathrm{n}=22)\end{array}$ \\
\hline $\mathrm{No}^{* *}$ & $\begin{array}{c}47 \% \\
(n=102)\end{array}$ & $\begin{array}{c}58 \% \\
(n=44)\end{array}$ & $\begin{array}{c}66 \% \\
(n=162)\end{array}$ \\
\hline No Response to Question & $\begin{array}{c}18 \% \\
(n=38)\end{array}$ & $\begin{array}{c}24 \% \\
(\mathrm{n}=18)\end{array}$ & $\begin{array}{c}26 \% \\
(\mathrm{n}=63)\end{array}$ \\
\hline Total N: & 319 & 189 & 673 \\
\hline
\end{tabular}

- Only those people that were aware of a Ride Service or Safe Ride Program.

** Includes respondents who described I'm Smart relatively accurately but did not mention the name. This was done to try to make the data somewhat comparable to name recognition data from the DMV surveys and customer interviews.

An open-ended question following the one on awareness asked what was known about the program. All responses mentioning I'm Smart or a similar name (e.g., Get Smart, Smart) were coded. Again, a much larger proportion of Onondaga County residents who said they were aware of an RSP or safe ride program mentioned I'm Smart (35\%) than those from contiguous counties (18\%) or from other areas of residence and those who did not indicate county of residence $(9 \%)$. The differences were again statistically significant at a very high level of confidence $\left(\chi^{2}=48.7, \mathrm{df}=4, \mathrm{p}<.0001\right)$. Comparison of name recognition of I'm Smart from the RID survey is not comparable to that from the DMV surveys 
or discussions with customers since the questions were phrased quite differently. Somewhat over onethird of the Onondaga County residents who had heard of an RSP mentioned I'm Smart in their responses to the knowledge question. Some responses described I'm Smart in some detail without mentioning the name. Adding these responses would increase the percent who named I'm Smart to 43\% in Onondaga County.

Written responses to the open-ended question were coded into several categories. These categories and combinations of categories were used to determine degree of knowledge of I'm Smart similar to what was done for the DMV surveys. The focus of the analyses was Onondaga County residents. It should be noted that large percentages did not answer this question (44\% of the Onondaga County residents, $68 \%$ of the residents of counties contiguous to Onondaga County and $72 \%$ of residents of other areas plus those who did not indicate residence). Differences between Onondaga County residents and others likely reflect different levels of awareness of an RSP or safe ride service in their respective communities.

The most frequent written response among Onondaga County residents was coded as descriptions of the functions of an RSP, including descriptions of I'm Smart (23\% of the total Onondaga County sample). All percentages reported here are a function of all respondents indicating Onondaga County as their residence, including those who did not respond to the knowledge question. A few responses were not accurate descriptions of I'm Smart, but almost all involved basic elements of an RSP. The inaccuracies were mainly omission of membership and fees or implying the service is free to all. Almost all responses in this category indicated a basic understanding of an RSP. The second most frequently coded response (22\%) was an indication of awareness or availability of I'm Smart with no further description. It is not known how many of these respondents knew more about I'm Smart or what an RSP does. Other response catcgories included positive responses without describing an RSP (although a few said it got drunks off the road), describing other RSPs such as Students Against Drunk Driving (SADD), and naming or describing other anti-DWI programs or organizations including designated drivers. Responses in each of these categories were less than $5 \%$ of the sample. Very few individuals said anything negative about RSPs or I'm Smart.

\section{- $\quad$ Summary of Data on Awareness, Name Recognition and Knowledge}

A relatively large percentage of the driving public (approximately 56\%) as represented by clients of the DMVs in Syracuse show name recognition. In a survey conducted by an anti-DWI organization at the New York State Fair in Onondaga County, approximately $35 \%$ of the respondents living in Onondaga County mentioned I'm Smart and a total of $43 \%$ identified either its name or its function, in responding to a question about RSPs. About two-thirds of respondents (68\%) said they had heard of an RSP or safe ride program. Focusing on a more direct target population, approximately $78 \%$ of customers talked with in alcohol-serving establishments in Syracuse had heard of I'm Smart. It is even more impressive considering that the use of the service is available chiefly to employees of corporate members and to a lesser extent to customers of member alcohol-serving establishments.

Knowledge about I'm Smart as measured by open-ended questions on the written surveys and discussions with customers was limited. A relatively small proportion of those with name recognition provided specific accurate information about I'm Smart. Many who responded showed an understanding of the basics of the RSP, although most did not mention taking the user's vehicle or the corporate membership fee aspect of the program. 
Methodology - SoberCab

- University of Minnesota Survey - several questions relevant to SoberCab were included in a general population telephone survey sample of households in the Minneapolis - St. Paul area conducted by the University of Minnesota Survey Research Center between October and December, 1992 (Appendix E); and

- Discussions With Customers in Alcohol-Serving Establishments - A non-random selection of alcohol-serving establishments in the Minneapolis-St. Paul was made, and the permission of the establishment's owners was obtained. The on-site coordinator made contact with the owners and asked permission to approach customers between December 25, 1992 and January 2, 1993 and during the July 4th weekend 1993 (a time during which SoberCab does not operate). Discussion topics were similar, for the most part, to those in New York State, but there were some differences (Appendix C).

At the conclusion of the discussion the customers were given a BAC card and the SoberCab phone number (during the holiday period) or several taxi cab phone numbers (during the comparison period). Customers were encouraged to take alternative transportation if they felt unsafe to drive.

$\underline{\text { Results - SoberCab }}$

- University of Minnesota Telephone Survey

Name recognition was very high among the sample of 805 people interviewed by telephone during October through December, 1992 by the University of Minnesota Survey Research Center. Over fourfifths $(83 \%)$ reported that they were aware of a holiday season safe ride program called SoberCab. The survey was conducted during a period before the publicity campaign about SoberCab started. A similar question on a survey conducted in 1990 found close to $90 \%$ had awareness of SoberCab. Among those reporting awareness, $3 \%$ said they had used the service. Since these questions were added to a much larger, existing survey and space was limited, no questions on what was known about SoberCab or sources of information were asked.

\section{- Discussions With Customers in Alcohol-Serving Establishments}

A total of 232 customers in alcohol-serving establishments in the Twin Cities area were talked with during the period when SoberCab operated in 1992 (Christmas - New Year's Eve) and during a comparison holiday period when SoberCab did not operate (weekend of July 4, 1993). Table 8 presents data on name recognition, knowledge of how to use SoberCab, and previous use.

The customer's level of name recognition was very high; $88 \%$ said they knew of SoberCab during the Christmas - New Year's Eve period in 1992. Name recognition was also very high (99\%), at the time when SoberCab was not operating and there was no publicity about the service, during the July 4th weekend, 1993. The very high level of name recognition is consistent with that found in the general population telephone survey. However, not all those with name recognition knew how to use SoberCab; only $58 \%$ indicated they knew how to use the RSP in 1992. A larger percent (84\%) said they knew how to use SoberCab, in 1993. Eleven percent of the combined sample reported that they had used SoberCab. 
Table 8

Discussions with Alcohol-Serving Establishment Customers, Twin Cities, 1992 and 1993 Name Recognition, Knowledge of How to Use and Prior Use of SoberCab

\begin{tabular}{|c|c|c|}
\hline QUESTION & DECEMBER 1992 & JULY 1993 \\
\hline \multicolumn{3}{|c|}{ Did They Know About SoberCab? } \\
\hline Yes & $88 \%(n=132)$ & $99 \%(\mathrm{n}=81)$ \\
\hline No & $12 \%(n=18)$ & $1 \%(n=1)$ \\
\hline \multicolumn{3}{|c|}{ Did They Know How to Use SoberCab? } \\
\hline Yes & $58 \%(\mathrm{n}=87)$ & $84 \%(n=69)$ \\
\hline No or No Response & $42 \%(n=63)$ & $16 \%(n=13)$ \\
\hline \multicolumn{3}{|c|}{ Had They Used SoberCab Before? } \\
\hline Yes & $10 \%(\mathrm{n}=15)$ & $12 \%(n=10)$ \\
\hline No or No Response & $90 \%(n=135)$ & $88 \%(\mathrm{n}=72)$ \\
\hline Total N: & 150 & 82 \\
\hline
\end{tabular}

To what extent are those who are more likely to have need of an RSP (i.e., those who drink alcohol and those who drink and drive) aware of and have knowledge of the RSP?

\section{Methodology - I'm Smart}

Data relevant to this question was obtained from responses to the DMV surveys (Syracuse), discussions with customers of alcohol-serving establishments in Syracuse, and the RID survey of New York State Fair attendees from Onondaga County. The instruments and samples were described previously.

\section{$\underline{\text { Results - I'm Smart }}$}

\section{- $\quad$ DMV Surveys}

Several questions were asked concerning drinking behavior and driving after drinking. Comparisons were conducted between respondents who indicated that they had heard of I'm Smart and those who had not. All data uses the combined 1992 and 1993 samples. Table 9 presents a summary of the analyses. Those who drink, regardless of the frequency, were more likely to have heard of I'm Smart than non-drinkers. Less than half (47\%) of the non-drinkers had heard of I'm Smart while $66 \%$ of all individuals who reported drinking (including those saying they drank once a month or less) heard of I'm Smart. Only the difference between drinkers and non-drinkers was significant.

Similarly, respondents who admitted to feeling unable to drive safely at times after drinking were more likely to recognize the name I'm Smart (69\%) than those who did not (60\%). Many of the non-drinkers 
Evaluation Question: To what extent are those who are more likely to have need of an RSP aware of and have knowledge of the RSP?

(based on non-response to an earlier question) did not answer this question. Of the small percentage $(8 \%)$ who admitted to having received a citation or been arrested for a drunk driving offense, there was a higher level of name recognition (76\%) than those without an offense (63\%). Those who had heard of I'm Smart had a higher average estimated tolerance than those who had not (average number of drinks before they felt it would be too dangerous to drive $=2.9$ for the former and 2.4 for the latter). All differences mentioned here were statistically significant at better than the .05 level. When the nondrinkers were eliminated from the analyses, the same relationships to name recognition were maintained for feeling unsafe to drive after drinking, receiving a citation or arrest for DWI, and estimated tolerance, although the relationship to DWI was significant at the .09 level for the latter.

Table 9

Syracuse DMV Surveys, 1992 and 1993 Combined

Differences in Drinking Behavior and Drinking and Driving Behavior

Between Respondents who Had and Had Not Heard of I'm Smart

\begin{tabular}{||l|l|l||}
\hline \hline VARIABLE & DIRECTION OF RELATIONSHIP & p LEVEL \\
\hline Frequency of Drinking & $\begin{array}{l}\text { Drinkers were more likely to have heard of I'm Smart } \\
\text { than non-drinkers (66\% versus 47\%). }\end{array}$ & $\begin{array}{l}\mathrm{p}<.0001, \\
\chi^{2}=30.7, \mathrm{df}=4\end{array}$ \\
\hline $\begin{array}{l}\text { Felt Unable to Drive } \\
\text { Safely After Drinking }\end{array}$ & $\begin{array}{l}\text { Those who had felt unsafe to drive after drinking had a } \\
\text { higher rate of name recognition than those who had } \\
\text { not (excluding many of the non-drinkers), 69\% versus } \\
60 \% .\end{array}$ & $\begin{array}{l}\mathrm{p}=.01, \\
\chi^{2}=6.3, \mathrm{df}=1\end{array}$ \\
\hline $\begin{array}{l}\text { Ever Received Citation or } \\
\text { Been Arrested for DWI }\end{array}$ & $\begin{array}{l}\text { Those who had a DWI had a higher rate of name re- } \\
\text { cognition than those who had not (76\% versus 63\%). }\end{array}$ & $\begin{array}{l}\mathrm{p}=.04, \\
\chi^{2}=4.1, \mathrm{df}=1\end{array}$ \\
\hline $\begin{array}{l}\text { Number of Drinks in Two } \\
\text { Hours Before It Would be } \\
\text { Too Dangerous to Drive }\end{array}$ & $\begin{array}{l}\text { Those who had heard of I'm Smart had a higher } \\
\text { estimated tolerance, average 2.9 drinks, than those who } \\
\text { had not heard of I'm Smart, average 2.4 drinks. }\end{array}$ & $\begin{array}{l}\mathrm{p}=.004 \\
\mathrm{t}-\mathrm{test}\end{array}$ \\
\hline
\end{tabular}

The data from the DMV surveys provide indirect evidence that name recognition of I'm Smart is higher among those who may be more likely to have need of an RSP. It should be noted that despite the differences, all groups have a relatively high level of name recognition.

In addition to the data on drinking and drinking and driving, analyses on the relationships between demographic variables and name recognition were conducted. Table 10 shows these relationships.

Concerning the question about the effects of the publicity campaign targeted at minorities (See pages 67 to 69), it should be noted that those who identify themselves as African-American or Hispanic have the lowest level of name recognition compared to Whites (or white nationality groups), other racial groups, those who could not be classified, and the $25 \%$ who did not respond to the ethnic group question. 
Evaluation Question: To what extent are those who are more likely to have need of an RSP aware of and have knowledge of the RSP?

Table 10

Syracuse DMV Surveys - 1992 and 1993 Combined

Relationships Between Name Recognition of I'm Smart and Demographic Variables

\begin{tabular}{|l|l|l||}
\hline VARIABLE & DIRECTION OF RELATIONSHIP & $\begin{array}{l}\text { p VALUE, } \\
\text { STATISTICAL TEST }\end{array}$ \\
\hline Gender & Females had higher name recognition (63\%) than males (56\%) & $\mathrm{p}=.065, \chi^{2}=3.4$ \\
\hline Age & $\begin{array}{l}\text { Those who had name recognition were older (average }=37 \text { years } \\
\text { versus 34 years) }\end{array}$ & $\begin{array}{l}\mathrm{p}<.001, \\
\mathrm{t}=3.56\end{array}$ \\
\hline Marital Status & $\begin{array}{l}\text { Married individuals had higher name recognition than singles, } \\
\text { divorced people and those living with partners (65\% versus 53\%) }\end{array}$ & $\begin{array}{l}\mathrm{p}=.003, \\
\chi^{2}=13.7, \mathrm{df}=3\end{array}$ \\
\hline $\begin{array}{l}\text { Employment } \\
\text { Status }\end{array}$ & $\begin{array}{l}\text { Employed respondents had higher name recognition than those } \\
\text { not employed (64\% versus 42\%) }\end{array}$ & $\begin{array}{l}\mathrm{p}<.0001 \\
\chi^{2}=27.4, \mathrm{df}=1\end{array}$ \\
\hline $\begin{array}{l}\text { Total Household } \\
\text { Income }\end{array}$ & $\begin{array}{l}\text { People with higher incomes had a higher rate of name recognition } \\
\mathrm{p}\end{array}$ & $\begin{array}{l}\mathrm{p}<.0001 \\
\chi^{2}=27.3, \mathrm{df}=4\end{array}$ \\
\hline $\begin{array}{l}\text { Educational } \\
\text { Level }\end{array}$ & $\begin{array}{l}\text { High school graduates and those who had some college had the } \\
\text { highest level of name recognition (65\%), followed by college grads } \\
\text { and those with graduate school education (55\%). Those who had } \\
\text { not graduated from high school showed the lowest rate (35\%). }\end{array}$ & $\begin{array}{l}\mathrm{p}<.0001 \\
\chi^{2}=30.2, \text { df }=4\end{array}$ \\
\hline $\begin{array}{l}\text { Ethnic Group } \\
\text { Whites had highest name recognition (64\%) followed by those } \\
\text { who did not indicate an ethnic group (54\%) and those identifying } \\
\text { themselves as minorities - African-American, Hispanic, Native } \\
\text { American, Asian and other (42\%) }\end{array}$ & $\begin{array}{l}\mathrm{p}=.0001 \\
\chi^{2}=19.6, \\
\mathrm{df}=3\end{array}$ \\
\hline $\begin{array}{l}\text { Number of } \\
\text { Children }\end{array}$ & $\begin{array}{l}\text { Those who had heard of I'm Smart had a higher average number } \\
\text { of children (1.6) than those who had not (1.4) }\end{array}$ & $\begin{array}{l}\mathrm{p}=.03 \\
\mathrm{t}=2.14\end{array}$ \\
\hline
\end{tabular}

\section{- Discussions with Customers at Alcohol-Serving Establishments}

The level of name recognition of I'm Smart was very high among customers, 78\% of the combined 1992 and 1993 Syracuse samples. Analyses were performed to explore whether, even at this high level of name recognition, there were variables that differentiated those that did and did not say they had heard of I'm Smart. Variables included drinking during the evening of the interview, indicators of impairment, general drinking behavior, methods of transportation that evening, and a few demographic variables. Table 11 shows these relationships to name recognition.

General drinking behavior was not related to name recognition. Most of the variables measuring drinking behavior that night also were not related. The one exception is self-rated level of intoxication. The small number of individuals ( $8 \%$ of the total sample) who rated themselves most intoxicated on the five point scale (points 4 and 5) had a lower rate of recognition than those who rated themselves sober to moderately intoxicated (61\% for the most intoxicated to $80 \%$ for the others). Estimates of blood alcohol concentration (BAC) based on two formulas applied to information given by the customer on number of drinks, amount of time spent at the establishment and weight (or weight estimated by the researcher) produced no significant differences for those who had and had not heard of I'm Smart. (See Appendix $F$ for the formulas used.) 
Evaluation Question: To what extent are those who are more likely to have need of an RSP aware of and have knowledge of the RSP?

Table 11

Discussions with Alcohol-Serving Establishment Customers in Syracuse, 1992 and 1993 Combined

Relationships of Name Recognition of I'm Smart to other Variables

\begin{tabular}{|c|c|c|}
\hline VARIABLE & DIRECTION OF RELATIONSHIP & $\begin{array}{l}\text { p LEVEL, } \\
\text { STATISTICAL } \\
\text { TEST }\end{array}$ \\
\hline Gender & No Relationship & $p=.8$ \\
\hline Age & No Relationship & $p=.4$ \\
\hline Ethnic Group & $\begin{array}{l}\text { Whites had higher name recognition, } 80 \% \text {, than the very } \\
\text { small subsample of other ethnic classifications, } 56 \% \text {. }\end{array}$ & $\begin{array}{l}p \leq .001 \\
\chi^{2}=11.7 \\
d f=1\end{array}$ \\
\hline Employment Status & $\begin{array}{l}\text { Employed persons had a much higher level of name } \\
\text { recognition, } 82 \% \text {, than unemployed, } 57 \% \text {. }\end{array}$ & $\begin{array}{l}\mathrm{p}<.0001 \\
\chi^{2}=22.2 \\
\mathrm{df}=1\end{array}$ \\
\hline Live in Neighborhood & $\begin{array}{l}\text { Those who lived in the neighborhood of the } \\
\text { establishment had higher name recognition, } 83 \% \text {, than } \\
\text { those who did not, } 74 \% \text {. }\end{array}$ & $\begin{array}{l}p=.007 \\
\chi^{2}=7.0 \\
d f=1\end{array}$ \\
\hline Frequency of Drinking* & $\begin{array}{l}\text { No relationship - very small sample of reported non- } \\
\text { drinkers }\end{array}$ & $p=.6$ \\
\hline Frequency of Drinking in Bars* & No relationship & $\mathrm{p}=.8$ \\
\hline Typically Drink as a Couple & No relationship & $p=.4$ \\
\hline Typically Drink in a Group & No relationship & $p=.6$ \\
\hline $\begin{array}{l}\text { Number of Drinks Typically } \\
\text { Have* }\end{array}$ & No relationship & $\mathrm{p}=.8$ \\
\hline $\begin{array}{l}\text { Self-Rated Feelings of } \\
\text { Intoxication* }\end{array}$ & $\begin{array}{l}\text { Those rating themselves highest on a } 5 \text { point scale ( } 4 \\
\text { and 5) had a lower rate of name recognition }(61 \%) \text { than } \\
\text { those rating themselves } 1 \text { to } 3 \text { on the scale }(80 \%)\end{array}$ & $\begin{array}{l}p=.009 \\
\chi^{2}=11.5 \\
d f=3\end{array}$ \\
\hline Do You Feel Safe to Drive* & No relationship & $p=.3$ \\
\hline $\begin{array}{l}\text { Amount of Time Drinking } \\
\text { Today* }\end{array}$ & $\begin{array}{l}\text { Those who heard of I'm Smart were drinking for a } \\
\text { longer time than those who had not (average } 140 \text { versus } \\
126 \text { minutes). (Very large variances and large variance } \\
\text { between groups.) }\end{array}$ & $p=.1$ \\
\hline How Many Drinks Today* & No relationship & $p=.4$ \\
\hline $\begin{array}{l}\text { Estimated Blood Alcohol } \\
\text { Concentration (see text) }\end{array}$ & No relationship using two different formulas & $\begin{array}{l}p=.5 \\
p=.3\end{array}$ \\
\hline $\begin{array}{l}\text { How Did You Get Here } \\
\text { Tonight* }\end{array}$ & $\begin{array}{l}\text { Those who drove had a higher rate of name recognition, } \\
83 \% \text {, than those where someone else drove, } 71 \% \text {, and } \\
\text { those who arrived through other methods, } 78 \% \text {. }\end{array}$ & $\begin{array}{l}p=.004 \\
\chi^{2}=10.8 \\
d f=2\end{array}$ \\
\hline $\begin{array}{l}\text { How Do You Plan to Get } \\
\text { Home* }\end{array}$ & $\begin{array}{l}\text { Those who planned to drive had a higher level of name } \\
\text { recognition }(83 \%) \text { than those who did not }(74 \%)\end{array}$ & $\begin{array}{l}\mathrm{p}=.027 \\
\chi^{2}=7.1 \\
\mathrm{df}=2\end{array}$ \\
\hline
\end{tabular}

* Variables defining populations more likely to need an RSP. 
Those who drove to and were planning to drive from the establishment were more likely to have heard of I'm Smart than those who had someone drive them or had used other means of transportation. Perhaps those who did not drive do not usually drive to alcohol-serving establishments, and are somewhat less likely to be aware of the RSP.

Demographic variables were more likely to be statistically related to name recognition than were general drinking behaviors or current drinking and its effects. Interviewees who said they lived in the neighborhood were more likely to report hearing of I'm Smart than those that did not. Employment status produced the greatest differences in percent of name recognition. Those who reported being employed had an $82 \%$ rate of name recognition versus $57 \%$ of the unemployed. Since a major source of knowledge of I'm Smart is through employer members, this strong relationship would be expected.

\section{- $\quad$ RID Survey}

There were a few variables on the RID survey that would identify groups more likely to need an RSP (thought at times you might be unable to drive home safely, drinker versus non-drinker, frequency of drinking, prior charge for alcohol-related traffic offense, personal or family member victim of a drinking driver). Analyses only includes respondents who indicated Onondaga County as their residence $(\mathrm{N}=319)$. First, regarding awareness of an RSP or safe ride program, none of the variables measured were related to rates of awareness. Only one of these variables statistically differentiated those who named I'm Smart in their written response to the open-ended question of knowledge of an RSP or safe ride program. Those who reported that at times they thought they might be unable to drive home safely showed a higher rate of naming I'm Smart in their responses than those who did not (52\% to $36 \%, \chi^{2}=3.6, p=$ .055 , df $=1$ ). Data on naming I'm Smart is confined to the $56 \%$ of Onondaga County residents who produced a written response to the knowledge question.

Two demographic variables were measured on the RID survey: gender and age. Gender was not related to awareness of an RSP. Aware respondents were statistically significantly older than the unaware (average age of 38.6 years versus 32.8 years, $t=4.0, p<.001$ ). Among those who wrote a response to the open-ended knowledge question, neither gender nor age was related to naming I'm Smart.

\section{Methodology - SoberCab}

Items from the University of Minnesota general population telephone survey and discussions with customers of alcohol-serving establishments, described previously, were used to address the question of whether or not those more likely to have need of an RSP were aware of SoberCab.

$\underline{\text { Results - SoberCab }}$

\section{- University of Minnesota Telephone Survey}

The level of name recognition of SoberCab was very high, $83 \%$ of all respondents. Only one variable was included that was directly related to whether those who knew of the RSP may be more likely to at some time need the service. Respondents were asked whether they had driven during the holiday season when they felt they had too much to drink within the last 10 years. Slightly over $19 \%$ responded affirmatively. 
Evaluation Question: To what extent are those who are more likely to have need of an RSP aware of and have knowledge of the RSP?

Relationship to name recognition of SoberCab was statistically significant at the .05 level with a higher percent of name recognition among those who said they had driven after drinking too much than those who did not ( $89 \%$ to $82 \%$ name recognition).

Among demographic variables, those who appear to be somewhat more affluent (income above $\$ 20,000$, residents of single family homes, duplexes and townhouses, home owners, employed individuals, married with no children and single individuals) had a higher level of name recognition as did older individuals ( 54 and above). The differences were all statistically significant at the .05 level or better. These largely interrelated factors may reflect a population with high levels of awareness of many aspects of their community. The few respondents classified as other than White or African-American had a much lower level of name recognition than those who identified themselves as White or African-American. In addition to the variables in Table 12, educational level was related to name recognition at the .07 level of significance. The relationship was non-linear: respondents with some college had a higher level of name recognition than all other levels $(88 \%$ to $80 \%)$. Gender was not related to name recognition.

It is important to note that levels of name recognition were high among most subgroups within each variable despite statistical differences between groups.

Table 12

University of Minnesota Telephone Survey, Fall, 1992

Relationships of Demographic Variables to Name Recognition of SoberCab from All Listed Relationships Statistically Significant at the .05 Level or Greater

\begin{tabular}{||l|l||}
\hline VARIABLE* & DIRECTION OF RELATIONSHIP \\
\hline Age & $\begin{array}{l}\text { Respondents 54 years old and younger had a higher proportion reporting } \\
\text { awareness than older groups (86\% versus 71\%) }\end{array}$ \\
\hline Housing Unit Type & $\begin{array}{l}\text { Residents of single family homes, townhouses and duplexes were more likely } \\
\text { to have heard of the service than apartment dwellers or those in other } \\
\text { housing types (86\% versus 69\%). }\end{array}$ \\
\hline Housing Ownership & $\begin{array}{l}\text { Related to the findings on housing unit type, owners of their residences were } \\
\text { more likely to report awareness than renters (85\% versus 78\%). }\end{array}$ \\
\hline Employment Status & $\begin{array}{l}\text { Those working full-time showed a higher proportion who were aware than } \\
\text { those in other employment statuses (86\% versus 72\%). }\end{array}$ \\
\hline Household Income & $\begin{array}{l}\text { Respondents with reported incomes of } \$ 20,000 \text { or more were more likely to } \\
\text { report awareness of SoberCab than the lowest income groups (86\% versus } \\
77 \%) .\end{array}$ \\
\hline Household Composition & $\begin{array}{l}\text { Respondents who were married with no children had a lower rate of } \\
\text { awareness than those who were married with children and those who were } \\
\text { single with or without children (77\% versus } 86 \%) .\end{array}$ \\
\hline Race & $\begin{array}{l}\text { The small number classified as other than White or African-American } \\
\text { (N=30) had a much lower level of name recognition than Whites plus } \\
\text { African-Americans (56\% to 84\%). There were very few African-Americans } \\
\text { in the sample (N=9). }\end{array}$ \\
\hline \hline
\end{tabular}

* All listed variables were significantly related to name recognition at the .05 level or better. 

knowledge of the RSP?

\section{- Discussions with Customers in Alcohol-Serving Establishments}

Since name recognition was so high, some of the analyses produced very small expected cell sizes among those who did not know of SoberCab or very large standard errors, thus lowering the probabilities of finding statistically significant differences and stable estimates. A few variables statistically differentiated those who knew and did not know of SoberCab. Customers who drank most often (3-4 times a week or more often) plus those who drank infrequently (2-3 times a month or less) had a higher level of name recognition (94\%) than those who drank 1-2 times a week plus those who never drank (81\%). This noncontinuous relationship was significant $\left(\chi^{2}=5.0, \mathrm{df}=1, \mathrm{p}=.02\right.$ using Yates correction). Other variables that differentiated the two groups were age and estimates of blood alcohol content. Those who knew about Sober $\mathrm{Cab}$ had an average age of 32.7 while the few who did not had an average age of 27.6 $(\mathrm{t}=2.41, \mathrm{p}=.02$ using separate variance estimates). Customers who reported knowing about SoberCab had higher estimated BACs (calculated by the two formulas shown in Appendix F) than those who did not know of the RSP. Using each formula the mean BAC differences were statistically significant at $\mathrm{p}$ $=.01$ and $\mathrm{p}=.001$ using separate variance estimates.

There is only limited evidence that individuals who say they know of SoberCab may be more likely to need the service. Most of the variables that may be hypothesized to indicate high risk drinkers and drivers did not differentiate the two name recognition groups.

\section{How many individuals use the RSP and what are their characteristics?}

\section{Methodology - I'm Smart}

Data on the number of rides provided by I'm Smart was obtained in graphic form from the RSP for the years 1984 through 1991. I'm Smart's computerized file containing information on rides from September, 1989 through June, 1993 was also employed to provide precise data for the past 3.8 years. Data from logs maintained by drivers for May, July, September and December, 1992 and May 1993 was employed to obtain information on the number of riders per ride, the number of rides provided during each day of the week, and the numbers provided during the Christmas - New Year's Eve holiday period.

Information on characteristics of users of I'm Smart was obtained from four sources:

- Judgements by I'm Smart drivers (I'm Smart did not permit interviews with users) on age, ethnic group, judged socioeconomic level of the "drop-off" neighborhood, and level of intoxication (Appendix G). The latter was judged on a five point scale with points 1, 3 and 5 labelled, "no visible signs of intoxication", "moderate intoxication (e.g., silliness, reduced inhibition)" and "severely intoxicated (e.g., slurred speech, unsteady gait)" respectively. Drivers had opportunities to observe and interact with the riders when they picked them up, walked to the rider's car and during the trip. Observations were made during June and July, 1993. The drivers were experienced in interacting with these clients, and were simply oriented to the data we needed.

- Discussions with customers in alcohol-serving establishments - customers were asked if they had ever used I'm Smart; 
- Drivers' logs - data on gender of riders was available from the sample of logs mentioned above.

- I'm Smart computer data file - Some of the information about rides maintained in I'm Smart's computerized data base was employed to respond to the two evaluation questions (e.g., number of rides, method of payment).

\section{$\underline{\text { Results - I'm Smart }}$}

\section{Number of Rides}

Data on number of rides were obtained in graphic form from I'm Smart. This is shown in Figure 1 by year. The data represent the number of rides, not the number of riders. The information starts in 1984 and is complete through the end of 1992. The growth of number of rides is very strong, increasing steadily from somewhat under 300 in 1984 to approximately 1,400 in 1988 . Between 1988 and 1990 there was a sharp rate of increase in number of rides from approximately 1,400 to 2,976 in 1990 . There has been a small decrease from the peak number of rides in 1990 to 2,735 in 1991 and 2,615 in 1992. During the first five months of 1993 the number of rides provided was 1,013. Based on the percent of total rides for the first five months of the year for 1990, 1991 and 1992 and extrapolating to 1993, approximately 2,700 can be expected for the full year of 1993.

December is by far the busiest month for rides. Data from the I'm Smart computerized file show between 402 and 451 rides during December for the years 1990 through 1992.

Drivers' logs from May, July, September and December, 1992 and May, 1993, show the average number of riders per trip was 1.7 for 964 trips where data on number of riders was recorded. Over half (56\%) of the trips had only one rider while $31 \%$ had two riders and the remaining $13 \%$ between 3 and 8 riders. Using these estimates (and assuming that 4 is the average number of riders in the 3 to 8 rider category) a total of 2,700 rides (approximately the amount provided in 1991) provided safe transport to approximately 4,600 individuals.

Slightly over half (52\%) of the rides take place on Friday and Saturday (including early Sunday morning), based on a five month sample of 1,162 drivers' logs. An additional $21 \%$ of the trips take place on Thursday.

\section{Characteristics of Users}

\section{- I'm Smart Computer Data File}

Almost half $(47 \%)$ of the pick-ups were made between midnight and $3 \mathrm{am}$, with nearly all the remainder (45\%) between 8pm and midnight. Almost all riders were picked up from commercial alcohol-serving establishments. A large majority, $84 \%$, paid for the ride by a membership card, indicating they were employed by a member organization which paid for the service. Of interest is that $8 \%$ used a health insurance program that covers I'm Smart rides. Approximately $84 \%$ were picked up at an alcohol-serving commercial establishment or private club. Of the total number of rides, less than $1 \%$ were indicated as not related to alcohol consumption (e.g., ride from hospital, medical office). 
Figure 1

I'm Smart Total Rides for 1984-1992

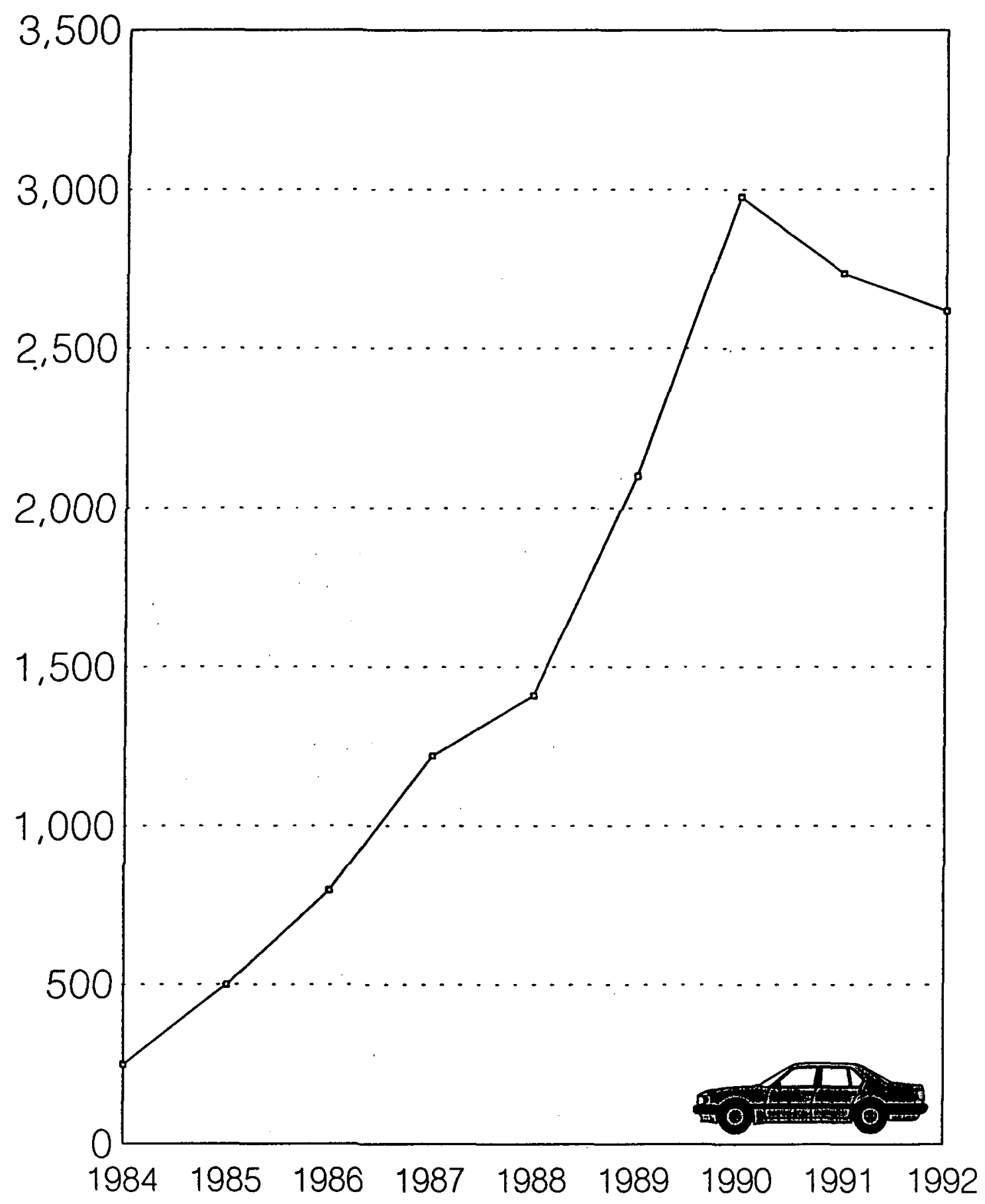


- Driver Judgements

Table 13 presents data on drivers' judgements of users. The majority of the users $(56 \%)$ were judged as 26 to 35 years of age. An additional $17 \%$ were judged as 36 to 40 , and about $16 \%$ as 20 to 25 years old. The smallest number of users (11\%) were judged as 41 or older.

Drivers judged the neighborhoods where they dropped the riders off. They judged the largest number of neighborhoods (45\%) as middle class and $31 \%$ as blue collar. Almost one-fifth were judged as above average or affluent $(20 \%)$. Very few neighborhoods were judged as poor (2\%).

Table 13

I'm Smart Drivers' Observations

Characteristics of I'm Smart Users as Judged by Drivers

\begin{tabular}{|c|c|c|}
\hline CHARACTERISTIC & NUMBER & Percent \\
\hline \multicolumn{3}{|l|}{ Approximate Age } \\
\hline $20-25$ & 20 & 16 \\
\hline $26-30$ & 41 & 32 \\
\hline $31-35$ & 31 & 24 \\
\hline $36-40$ & 21 & 17 \\
\hline Over 40 & 14 & 11 \\
\hline \multicolumn{3}{|l|}{ Ethnic Group } \\
\hline White & 115 & 88 \\
\hline Other & 3 & 2 \\
\hline Missing & 13 & 10 \\
\hline \multicolumn{3}{|c|}{ Socioeconomic Level of Drop-off Neighborhood } \\
\hline Poor & 3 & 2 \\
\hline Blue Collar & 40 & 31 \\
\hline Middle Class & 59 & 45 \\
\hline Above Average & 19 & 15 \\
\hline Affluent & 7 & 5 \\
\hline Missing & 3 & 2 \\
\hline \multicolumn{2}{|c|}{$\begin{array}{l}\text { Average Judgement of Visible Intoxication on scale of } 1 \text { (no } \\
\text { visible intoxication) to } 5 \text { (severely visibly intoxicated): }\end{array}$} & 3.3 \\
\hline Total N: & 131 & \\
\hline
\end{tabular}

Almost all riders were judged as being White, with about $10 \%$ omitting data on ethnic group. Only 3 of the $131(2 \%)$ riders were judged as members of minority racial groups (2 African-American and 1 
Native American). This is substantially less than the percent of minority populations of Syracuse and Onondaga County.

Driver judgements on visible intoxication showed half judged as moderately intoxicated (50\%). About one-third of the judgements were of severe visible intoxication (34\%). A small percent, $12 \%$, were judged as showing no signs of visible intoxication. Although not trained for this study, the drivers were accustomed to dealing with intoxicated passengers and reported no difficulty in judging intoxication.

\section{- $\quad$ Drivers' Logs}

Data from a sample of 961 drivers' logs where gender was indicated showed $80 \%$ of the trips included one or more males and $53 \%$ included one or more females. Some trips included both males and females, $27 \%$. The largest number of trips involved one male rider (40\%) followed by one male and one female rider (23\%) and one female rider (16\%).

\section{- Discussions With Customers in Alcohol-Serving Establishments}

Discussions with customers in alcohol-serving establishments in Syracuse during 1992 and 1993 produced a total of 67 individuals who, in response to a question "Have you ever used I'm Smart?", responded affirmatively. This number represented $12 \%$ of all customers talked with and $14 \%$ of customers who had heard of I'm Smart. Table 14 presents characteristics of customers who reported using I'm Smart in the past.

In terms of demographic factors measured, about half (54\%) of the previous users said they lived in the neighborhood of the establishment, almost all were employed (94\%), three-quarters (75\%) were male, and all but one were judged as White (very few racial/ethnic minorities were identified among all the customers the study's researchers talked with). The average age was 29 years. Slightly less than onequarter (24\%) were 25 or younger and the majority (69\%) between the ages of 26 and 35 .

With regard to general drinking behavior, previous users most frequently reported drinking 1 to 2 days per week (57\%), 34\% reported drinking more often, and $8 \%$ drank 2 or 3 days a month or less. A large majority ( $81 \%$ ) drank in bars 1 to 2 days a week or more often, with $28 \%$ reporting 3 days or more often. About 20\% reported drinking in bars 2 to 3 days a month or less. Slightly less than half (46\%) said they drank in bars during holidays. The average number of drinks reported as typical was 6 , with about $50 \%$ reporting 6 or more drinks. Few of the users report typically drinking alone, as a couple, or at friends' homes. Almost all (97\%) report typically drinking with a group.

Customer's drinking behavior that evening showed an average number of drinks as 5 , ranging from 0 to 14. The largest percentage ( $42 \%$ ) reported drinking three or four drinks. Under one-third (31\%) of the users reported drinking six or more drinks that evening. The median reported time spent drinking that evening was two hours. On a five point scale of self-reported feelings of intoxication (1 equals sober and 5 equals "drunk"), the average was 2.1 . Over one-fourth (28\%) rated themselves as sober. The largest group (42\%) rated themselves between sober and moderately intoxicated. Somewhat over one-fifth of the previous I'm Smart users rated themselves moderately intoxicated $(22 \%)$ while $8 \%$ rated themselves above moderately intoxicated. Three-quarters (75\%) said they felt safe to drive. 
Table 14

Discussions with Alcohol-Serving Establishment Customers in Syracuse, 1992 and 1993 Combined Characteristics of Those Who Reported to Have Used I'm Smart in the Past

\begin{tabular}{|c|c|c|}
\hline Characteristic & NUMBER & PERCENT \\
\hline \multicolumn{3}{|l|}{ Demographics } \\
\hline Male & 50 & 75 \\
\hline Employed & 63 & 94 \\
\hline Racial/Ethnic Minorities & 1 & 2 \\
\hline Live in Neighborhood & 36 & 54 \\
\hline Average Age: & 29 & \\
\hline \multicolumn{3}{|l|}{ General Drinking Behavior } \\
\hline Drink Three or More Days per Week & 23 & 34 \\
\hline Drink in Bars One or More Days per Week & 54 & 81 \\
\hline Typically Drink in a Group & 65 & 97 \\
\hline Average Number of Drinks on Typical Occasion: & 6 & \\
\hline \multicolumn{3}{|l|}{ Current Drinking Behavior } \\
\hline Six or More Drinks & 21 & 31 \\
\hline Average Number of Drinks During Evening: & 5 & \\
\hline Self-rating Moderately Intoxicated or Greater & 20 & 30 \\
\hline Felt Unsafe to Drive & 16 & 24 \\
\hline Plan to Drive Home & 35 & 52 \\
\hline Total N: & 67 & \\
\hline
\end{tabular}

The majority (55\%) of the previous users of I'm Smart said they drove to the establishment and $27 \%$ said a friend or family member drove. Nearly the same percentage (52\%) said they planned to drive home. None of the customers in the combined sample ( $\mathrm{N}=557)$ said they would call I'm Smart to get home that evening.

Slightly less than one-third (31\%) reported they had heard about I'm Smart from work and/or indicated that they were a member.

Among previous users, current feelings of being able to drive safely was positively and significantly related to feelings of intoxication, number of drinks and how they planned to get home. Those who said they felt unsafe to drive had a significantly higher average number of drinks, 7.2 , than those who said they felt safe, $3.7(\mathrm{t}=4.0, \mathrm{p}=.001)$, and they also felt more intoxicated than those who felt safe to drive (average 3.1 versus $1.8, t=4.0, p<.001$ ). Nineteen percent of the customers who reported they felt 
unsafe to drive said they were planning to drive upon leaving. All respondents received a BAC card and hand-out suggesting alternatives to driving after drinking.

In summary, customers of selected alcohol-serving establishments who reported previous use of I'm Smart drank often and drank often in bars (at least 1 to 2 days per week), typically drank an average number of 6 drinks and typically drank with a group. They were mainly male, almost all White and the majority were between the ages of 26 and 35. Slightly over half reported living in the neighborhood of the establishment. They reported an average number of 5 drinks that evening consumed over a median period of two hours. About $30 \%$ rated themselves moderately intoxicated or more and almost the same percentage rated themselves as sober. The largest group, about $41 \%$, rated themselves between sober and moderately intoxicated. About one-quarter said they did not feel safe to drive. The majority (55\%) drove to the establishment and were planning to drive home (52\%). Most of those who were not driving were riding with someone else (possibly one of their drinking companions, who may or may not have been less intoxicated).

Reported users were compared with customers interviewed who had not previously used I'm Smart. Very few of the variables statistically differentiated these groups at the .10 level of significance. Previous users report a statistically significant higher number of drinks typically imbibed than non-users (average $=6.1$ versus $5.25, \mathrm{t}=2.03, \mathrm{p}=.042)$. Users tended to drink more often $(1-2$ days per week or more) than non-users. However, the difference only approached the .10 level using Yates correction for $2 \times 2$ tables. This provides limited evidence that I'm Smart serves a population at elevated DWI risk.

Users and non-users also showed differences in sources of information about I'm Smart. Previous users were more likely to be members and heard about the service at work. Non-users were more likely to have heard of I' $m$ Smart through signs and posters and from a bar. This is to be expected, given that a very large majority of those who actually use I'm Smart (from the I'm Smart computer file) pay for the ride with a corporate membership card.

In general, from the sample of customers of alcohol-serving establishments, those who reported having used I'm Smart in the past differ little from the remainder of the customers with the exception that they are more often members of the service and have learned about it at work. They appear to be representative of drinkers interviewed at these establishments, although the users typically consume more drinks than the non-users.

Data from I'm Smart's computerized file provides additional data on users. The majority, 84\%, used a membership card indicating they were employed by a member organization which paid for the service. An additional $8 \%$ used a health insurance program that covers I'm Smart rides. Approximately $84 \%$ of the riders were picked up at an alcohol-serving establishment, other commercial establishment or private club. Less than $1 \%$ of the rides were indicated as health related (e.g., ride to or from hospital, medical office).

Methodology - SoberCab

- Number of Rides - The number of rides provided by SoberCab during the Christmas - New Year's Eve period for the past 2 holiday seasons (1991-92 and 1992-93) was obtained from the taxi company that provides the rides. 
- $\quad$ Characteristics of Users - The following four sources were used:

(1) Ride-along Discussions With Users - The Project Director rode four nights with three SoberCab drivers between December 26 and December 30, 1992 and talked with 17 users. Topics included those dealing with general and current drinking behavior, feelings of intoxication, previous use of SoberCab, how the person got to the place of drinking, alternatives to driving if SoberCab was not available, and demographics (Appendix C). In addition, a portable Intoxylizer 5000 was used to measure the BAC of the riders and the Project Director made judgements of impairment. Ride-alongs occurred between 9:50pm and 1:50am. Not all of the questions were responded to by the riders. This sample size is a limitation when generalizing the information to the population of SoberCab users.

(2) Interviews of Users by SoberCab Drivers - An additional 12 users were interviewed by SoberCab drivers on New Year's Eve. Driver's attempted to ask all patrons if they were willing to participate. If the patron agreed, the driver asked a short list of structured questions. Questions were asked about current drinking and demographic characteristics. The drivers also made judgements of intoxication level of the rider (Appendix $\mathrm{H}$ ).

(3) University of Minnesota Survey - Respondents were asked if they had ever used SoberCab in addition to demographic information and whether or not they had driven when feeling they had too much to drink over the past 10 years during the Christmas holiday period.

(4) Discussions with Customers in Alcohol-Serving Establishments - Customers were asked if they had ever used SoberCab.

\section{$\underline{\text { Results - SoberCab }}$}

\section{- $\quad$ Number of Rides}

The number of rides provided by Sober Cab during the 1991-92 and 1992-93 Christmas - New Year's Eve periods is shown in Table 15. The largest number of rides during the period are provided on the New Year's Eve - New Year's day 24 hour period, $44 \%$ for 1991-92 and 43\% for 1992-93.

Table 15

Number of SoberCab Rides for 1991-92 and 1992-93

\begin{tabular}{||l|c|c||}
\hline YEAR & TOTAL NUMBER OF RIDES & $\begin{array}{l}\text { \% OF TOTAL ON NEW YEAR'S EVE - } \\
\text { NEW YEAR's DAY }\end{array}$ \\
\hline $1991^{*}$ & 705 & $44 \%$ \\
\hline $1992^{* *}$ & 692 & $43 \%$ \\
\hline
\end{tabular}

* Includes New Year's Day for the following year.

** Includes New Year's Day, the evening of New Year's Day and Jan. 2, 1993. New Year's day fell on a Friday. 


\section{- Characteristics of Users}

(1) Ride-Along Discussions with Users - Table 16 shows data on the 17 users who talked with the Project Director. Almost all 17 riders were male, the average age was 31 and the median age was 32 . The ages ranged from 17 to 54. The underage rider was picked up at a motel party. Over three-quarters (77\%) were judged as White with the other four African-American, Hispanic and Native American. Over half ( 8 of the 15 who answered the question) were unemployed, three of whom were students.

Table 16

Ride-Along Interview of SoberCab Users

Characteristics of Riders

\begin{tabular}{|c|c|c|}
\hline ChaRACTERISTIC & $\begin{array}{c}\text { NUMBER } \\
\& \\
\text { PERCENT* }\end{array}$ & $\begin{array}{l}\text { NUMBER OF } \\
\text { INDIVIDUALS } \\
\text { PROVIDING } \\
\text { INFORMATION }\end{array}$ \\
\hline \multicolumn{3}{|l|}{ Demographics } \\
\hline Male & $88 \%(n=15)$ & 17 \\
\hline Employed & $46 \%(n=7)$ & 15 \\
\hline Ethnic/Racial minorities & $24 \%(n=4)$ & 17 \\
\hline Average age & 31 & 17 \\
\hline \multicolumn{3}{|l|}{ General Drinking Behavior } \\
\hline Drink three or more days per week & $71 \%(\mathrm{n}=12)$ & 17 \\
\hline Drink in bars one day per week or more & $73 \%(\mathrm{n}=10)$ & 14 \\
\hline Typically drink with a group & $67 \%(\mathrm{n}=11)$ & 15 \\
\hline Prior DWI arrests** & $47 \%(n=8)$ & 12 \\
\hline Average number of drinks on typical occasion & 7 & 14 \\
\hline \multicolumn{3}{|l|}{ Current Drinking Behavior } \\
\hline Average number of drinks during evening & 10 & 12 \\
\hline Average $\mathrm{BAC}$ reading from Intoxolizer 5000 & .096 & 13 \\
\hline Self-rating as moderately intoxicated or greater & $94 \%(n=15)$ & 16 \\
\hline $\begin{array}{l}\text { Users judged as showing one or more signs of } \\
\text { severe intoxication }\end{array}$ & $76 \%(n=13)$ & 17 \\
\hline Feel unsafe to drive & $94 \%(\mathrm{n}=16)$ & 17 \\
\hline $\begin{array}{l}\text { Users who said they had driven to get around } \\
\text { that evening }\end{array}$ & $29 \%(n=5)$ & 17 \\
\hline Total $\mathrm{N}$ & 17 & \\
\hline
\end{tabular}

* Percentages based on the number for whom data was obtained.

** Asked only of those who said they driven after they thought they had too much to drink. 
Most of the riders were frequent and relatively heavy drinkers. Twelve of 17 reported drinking 3 or more days a week and 3 said they drank 1-2 days a week. The average number of drinks typically consumed that evening was 7 for the 14 individuals for whom a quantitative answer was provided. Over 80\% (86\%) of the 14 riders who answered the question said they typically drank in bars and less frequently at home or at friends' homes. Five of the 12 riders who provided specific answers reported drinking in bars 3 days a week or more often. Almost three-quarters of those answering the question said they usually drank with a group.

Riders reported drinking an average of 6.8 hours that evening and a median of 5.4 hours with a range from 1 hour and 45 minutes to 13 hours and 30 minutes. Of the 12 riders who provided quantitative data, the average number of drinks reported was 10 with a median of 8 . The range was from 6 to 20 . All but one of the $16(94 \%)$ who responded, rated themselves as moderately intoxicated or greater. Six. rated themselves as more than moderately intoxicated. All but one of the 17 reported they felt unsafe to drive. Blood alcohol content readings were obtained for 13 riders. The average BAC was .096 with a range from .03 to .18 .

The Project Director, an experienced clinical psychologist who has worked with many individuals with alcohol problems, rated 15 of the 17 as having one or more visible signs of moderate intoxication. ${ }^{3}$ The average number of moderate signs per rider was 2.3 ranging from 0 to 5 . Thirteen of the 17 were rated as having one or more signs of severe visible intoxication with an average of 2.7 signs per person ranging from 0 to 7 . Eleven of the $17(65 \%)$ were judged as clearly intoxicated and $5(29 \%)$ as clearly impaired. Only one individual was judged as neither clearly intoxicated nor impaired.

Of great importance is that five of the 17 riders (29\%) said they had driven to get around that evening. Twelve of $16(75 \%)$ said they had driven after they thought they had too much to drink in the past. Eight admitted to prior DWI arrests (47\%).

(2) Drivers' Interviews with Users - The estimated average age of the 12 riders interviewed was 35 years with a median of 32 . The age range was from 22 to 65 . No data was collected on general drinking behavior. During the evening, riders reported drinking for an average of six hours ranging from 2 to 10 hours. The 12 riders reported an average of 8.5 drinks that evening with a median of 6.5 . The range was from 1 to 30 . Over $80 \%(83 \%)$ rated themselves as moderately intoxicated or greater. Drivers rated half as drunk and half as somewhat intoxicated. ${ }^{4}$ Only 2 of the 12 reported using SoberCab previously. Of the six who answered the question, five admitted to driving after having too much to drink. Half had heard of SoberCab through television with a few from radio or friends and none from bars.

(3) University of Minnesota Telephone Survey - From the telephone survey conducted by the University of Minnesota in the Twin Cities area between October and December, 1992, 19 of 805 (2\%) reported having used SoberCab. About two-thirds (65\%) of the users were male and were under age $34(67 \%)$ and 16 of the $19(84 \%)$ had some college or were college graduates. Almost all (18 of 19 users) worked full-time and 16 of the 19 reported household incomes of $\$ 30,000$ or more. About $40 \%$ of the users were

\footnotetext{
${ }^{3}$ Signs included: social behaviors (e.g., inappropriate closeness, silliness, reduced social inhibition, isolation, physical contact, disregard of social norms, hostility, confusion); speech (e.g., loudness, deliberate speech, profanity, slurring); and physical indicators (e.g., sweating, red eyes, poor dexterity, sloppy appearance, stumbling, fumbling).

4 Drivers were made aware of the signs of visible intoxication (see footnote 3) but were asked to make broad qualitative judgements on the interview form ("drunk", "somewhat intoxicated" and "not visibly intoxicated").
} 
single and $32 \%$ married with children. About one-third of the users $(35 \%)$ resided in counties outside those where the Twin Cities of Minneapolis and St. Paul are located.

(4) Customers in Alcohol-Serving Establishments - Discussions with customers of alcohol-serving establishments included the topic of whether the individual had ever used SoberCab. Twenty five interviewees, $11 \%$ of the combined 1992-1993 samples, said they had used SoberCab previously. Table 17 shows data on these past users.

About two-thirds of the 25 previous users were males (64\%), most were employed (80\%) and all but one was judged as White (4\%). The representation of previous minority users was less than their percentage in the area $(18 \%-22 \%$ in the Twin Cities). Their average age was 35 years with a median of 30 . Twothirds (67\%) were between the ages of 24 and 32 .

Table 17

Discussions with Alcohol-Serving Establishment Customers, Twin Cities, Combined Experimental and Control Characteristics of Previous Users of SoberCab

\begin{tabular}{|c|c|c|}
\hline Characteristic & NUMBER & PERCENT ${ }^{*}$ \\
\hline \multicolumn{3}{|l|}{ Demographics } \\
\hline Male & 16 & 64 \\
\hline Employed & 20 & 80 \\
\hline Racial/ethnic minorities & 1 & 4 \\
\hline Average age & 35 & \\
\hline \multicolumn{3}{|l|}{ General Drinking Behavior } \\
\hline Drink three or more days per week & 14 & 56 \\
\hline Drink in bars one or more days per week & 23 & 92 \\
\hline Typically drink in a group & 15 & 60 \\
\hline Average number of drinks on typical occasion & 6 & \\
\hline \multicolumn{3}{|l|}{ Current Drinking Behavior } \\
\hline Six or More Drinks & 7 & 28 \\
\hline Average number of drinks during evening & 5 & \\
\hline Self-rating moderately intoxicated or greater & 12 & 48 \\
\hline Felt unsafe to drive & 7 & 28 \\
\hline Plan to drive home & 9 & 36 \\
\hline Total $\mathrm{N}$ & 25 & \\
\hline
\end{tabular}

* Percentages are based on the total sample of 25 . 
With regard to general drinking behavior, almost all (92\%) previous SoberCab users indicated drinking one day a week or more, with $56 \%$ drinking three or more days per week. Almost half of the previous users reported drinking in bars 3 or more days per week while an additional $44 \%$ drank 1 to 2 days a week in bars. The average number of drinks typically consumed was 6 with a median of 6 , and a range from 2 to 12 drinks.

The average number of drinks for that evening, reported by previous users of SoberCab, was 5 , with a median of 4 . The range was from $1-15$. On a five point scale of intoxication ( 5 = "I feel drunk"), the average self-rating was 2.5 with a median of 2.5 . About one-half (48\%) rated themselves as moderately to very intoxicated. The interviewers judged 20 of the 25 as exhibiting one or more signs of moderate visible intoxication with an average of 3 signs. Five of the 25 were rated as showing one or more visible signs of severe intoxication. A large majority $(68 \%)$ said they felt they were able to drive safely and seven (28\%) did not feel safe. (One previous user did not answer the question.) Somewhat over onethird (36\%) said they planned to drive home. One said they would use SoberCab to get home and there were no responses from three of the 25 previous users.

Comparisons between those customers who reported to have used versus those who reported not to have used SoberCab did not produce statistically significant differences on most variables measured.

\section{Are users those who are targeted by the program (i.e., individuals who are impaired and have driven to the location where they drink)?}

\section{Methodology - I'm Smart}

Data relevant to this question comes from observations and judgements by drivers and characteristics of customers of alcohol-serving establishments obtained from interviews. Data was previously reported about characteristics of users (pages 30 to 36 ).

\section{$\underline{\text { Results - I'm Smart }}$}

I'm Smart provides rides only to those who have a car at the place of pick-up. Users thus automatically meet one of the two criteria stated above: they have driven to the place of drinking. Furthermore, the user can be considered to feel impaired since (1) having a car, he/she is not simply in need of transportation, and (2) unless feeling impaired, people are unlikely to want strangers driving their cars. Therefore, it can be assumed that a large percent of I'm Smart users are impaired and have driven to where they drink. The data on actual users obtained from drivers' observations confirms this assumption. Of the 127 users judged by drivers with regard to intoxication, about $87 \%$ were judged as moderately or severely intoxicated ( $34 \%$ severely intoxicated).

Indirect data relevant to the question was obtained from customers of alcohol-serving establishments who reported using I'm Smart in the past. They drank relatively often (about one-third drank 3 or more days per week and $28 \%$ drank at bars three or more days per week). Almost $80 \%$ drank at bars at least once per week. Data from the evening of the discussion show over half reporting to have driven to the establishment (55\%), almost $30 \%$ feeling moderately to severely intoxicated and almost one-quarter (24\%) feeling unsafe to drive. Data on previous users did not differ, statistically, from customers who had not used I'm Smart, with the exception of average number drinks they typically have, suggesting a 
substantial at-risk population who do not use the RSP. Previous users of I'm Smart show a higher reported typical number of drinks than non-users (average $=6.1$ for previous users to 5.3 for non-users).

\section{Methodology - SoberCab}

Data from the discussions with SoberCab users by the Project Director and some of the drivers as well as data from customers of alcohol-serving establishments who reported previous use of SoberCab are employed to answer the question. Much of this data has been presented in the section on "Characteristics of Users" (see pages 37 - 41).

\section{$\underline{\text { Results - SoberCab }}$}

\section{- $\quad$ Ride-Along Discussions with SoberCab Users}

The data described above show that a large percent of SoberCab users are alcohol impaired. However, only five of the 17 users $(29 \%)$ talked with during the ride-along said they had gotten around that evening by driving. Thus, less than one-third meet the criteria of having driven to the place of drinking. Sober $C a b$ does not require the user to have a vehicle and no questions are asked about that. Based on the direct data from a small sample of users, only a relatively small percent may be considered members of the target group, because most did not drive to where they were picked up. However, not driving to the drinking establishment may not always represent program abuse. Some people may plan to use Sober $\mathrm{Cab}$ and therefore arrange other transportation to the establishment, not wishing to leave their cars overnight in a bar parking lot in sub-freezing weather. These are individuals who, absent Sober Cab, may have driven.

Some SoberCab users had prior, sometimes multiple, DWI offenses, lost their licenses and no longer drive. Providing a safe ride to such impaired individuals may, to a small extent, prevent the individual from becoming involved in pedestrian and other accidents, especially since some patrons reported they would have walked home in sub-freezing temperatures on icy sidewalks.

\section{- User Interviews by Drivers}

Evidence, presented previously, support the ride-along data. Most of the 12 users interviewed by drivers were likely impaired and had much to drink. However, information on means of transportation to the drinking establishment(s) was not obtained.

\section{- Discussions with Previous Users Among Customers in Alcohol-Serving Establishments}

Discussions with customers of alcohol-serving establishments who reported past use of SoberCab drink frequently, and frequently in bars. They also indicated a relatively high number of drinks on a typical occasion (average $=6$ ). Their general drinking behavior could place some of them at risk of driving impaired. Although the sample of previous users based on discussions with customer looks quite different than the sample of current users, especially in terms of current drinking behavior, the data provides evidence that they may well have been impaired when they used SoberCab in the past. 
- University of Minnesota Survey

Based on the University of Minnesota telephone survey of Twin Cities population, those who reported using SoberCab $(\mathrm{N}=19)$ included a higher percent $(7 \%)$ who said they had driven during the holidays during the past 10 years when they felt they had too much to drink than those who had not used SoberCab (2\%). The difference was statistically significant at $\mathrm{p}<.001$.

\section{Summary}

Users of I'm Smart are likely to be targets of a ride service program. They must have a car at the location of pick-up in order to use the service. Data from judgements of intoxication by drivers indicate that the very large majority are judged as moderately or severely intoxicated. The decision to use the RSP implies that the user feels unsafe. For SoberCab, the data for a small sample of current users also show almost all with many indications of moderate to severe impairment. However, only a minority of this very small sample said they had driven. Thus, many of SoberCab's users may not fit the criteria of an impaired person who had driven a vehicle.

\section{Is the RSP conducted in an efficient and convenient manner?}

Convenience here is defined as the ability of the user or potential user to easily access and pay for the ride, and for the ride to come within a reasonably short period after the call is made.

\section{Methodology - I'm Smart}

Data relevant to this question comes from the sample of drivers' logs mentioned previously - and from questions on a written survey sent to a sample of corporate members of I'm Smart. Descriptive information on procedures for accessing the RSP will also be presented. The most relevant information from drivers' logs are times from call for service to arrival (wait time) and the number of "no loads" (the driving team arrives at a location, but no customer is there). The latter is a measure of efficiency.

\section{$\underline{\text { Results - I'm Smart }}$}

\section{- Description of Procedures}

Most local individuals who work for employers who are members of I'm Smart are given a card with the number to call. The card is also a method of payment. One health insurance plan also covers rides by I'm Smart and the insured has a card that will be accepted as payment by the driver. Alcohol-serving establishments who are members are given five free passes per year to use as they wish. The pass may be given to customers. Establishments that belong to I'm Smart have signs and posters that provide the telephone number. The user must have the card to show who will pay for the ride (usually the user's employer who belongs to I'm Smart). The high fee for non-members (approximately $\$ 60$ ) is likely an inconvenience for those without membership or not drinking in a member establishment. It should be noted that the RSP is not designed for the general public (unless they are willing to pay the fee for the ride), but for those covered by employers, insurance or the establishment, and who have a vehicle at the pick-up location. For those with member cards, the service is easily accessed. The very large majority of users pay with their member card. 
Wait Time

Another important convenience factor is wait time - the time from the call to I'm Smart to the time the pick-up is made. Longer waits may motivate some potential users to leave and drive their vehicle. In order to measure this aspect of convenience, a sample of drivers' logs was used that had information on both the time when the call was received and the time of arrival at the pick-up location. The dispatcher contacts a driver pair immediately after the call, so there is minimal delay between call and the drivers' departure. A total of 1,165 logs were sampled from the months of May, July, September and December of 1992 and May 1993. All logs found for these months were used. Only 335 of the logs (29\%) had information recorded about time of call to I'm Smant and time of pick-up. Whether or not the sample is biased due to the missing data is not known.

Data on wait time will not include pre-arranged pick-ups (where the customer calls several hours in advance) since this would artificially inflate the statistics dealing with wait time for the customer. A total of 227 logs were used in the analyses. The average recorded time from call to arrival at pick-up location was about 21 minutes and the median 18 minutes. The range was from 1 to 76 minutes. Sometimes a pick-up is made by the driving team who have already made a drop-off and a call is received for a customer who is nearby. Thus there are some very short (under 10 minutes) wait times. Over $80 \%$ of the arrivals (83\%) were within 30 minutes of the time the call was recorded. Forty-four percent of the arrivals were within 15 minutes. There were small differences between trips made on weekdays and weekends. Average and median times between call and arrival were slightly lower on weekends than weekdays (Average $=20.5$ minutes for weekend trips versus average $=22.7$ minutes on weekdays). This is attributable to more teams on call on weekends. Based on this data I'm Smart appears to be quite convenient for users in terms of wait time.

I'm Smart accepts pre-arranged pick-ups where the customer will be picked up several hours after the call. Pre-arranged calls represent a convenience to individuals or groups who believe, in advance, they will want a safe ride for themselves and their vehicle. Of importance, is that some people use I'm Smart to plan their activities (drinking behavior?).

From the sample of drivers' logs, a total of $208(18 \%)$ of all calls were pre-arranged. For over threequarters $(76 \%)$ of the pre-arranged rides where data was available, time of pick-up or arrival was at the pre-arranged time or earlier. Only $9 \%$ of these rides were more than 10 minutes late.

In terms of efficiency from the perspective of I'm Smart, data on no loads was recorded from the same sample of drivers' logs. "No loads" are instances in which the drivers arrived at the location but no person was transported. In the sample of 1,165 logs, 133 or $11 \%$ were no loads. Information written on the logs show that the majority (approximately 70\%) of the no loads were instances where I'm Smart arrived but the customer was not there. Some of these happened when the arrival time was after the establishment had closed. The other major reason for a no-load was cancellation of the order after the crew had started on their trip to the pick-up location (approximately 14\%). In a few instances the customer did not want a ride, did not have a vehicle, was too intoxicated to be safely transported, or was hostile to the crew. 


\section{- $\quad$ Survey of Corporate Members}

Several questions on a survey sent to corporate members of I'm Smart dealt generally with convenience and efficiency. Included with the survey, which was initiated by I'm Smart, was a letter from the Director of I'm Smart and a brochure of a new program he was creating (Appendix I). One question on the survey asked the respondents to rate the efficiency of the RSP for employees. Of the 63 responding organizations (38\% response rate), seven did not rate this item due to insufficient information and four did not answer the question. Of the 52 remaining corporate respondents, $49(94 \%)$ rated efficiency good or outstanding. Another rating item asked about the convenience of the system to management. Of the 57 who made a rating, almost all (93\%) rated I'm Smart as good or outstanding with the largest number rating convenience as outstanding. Thus, among the $38 \%$ of the corporations who returned the survey, I'm Smart was believed to be efficient for employees and convenient to management by over $90 \%$ who rated these items.

\section{Methodology - SoberCab}

No specific record of wait times was available. Data on "no loads" were available from the taxi company who provided the Sober $\mathrm{Cab}$ rides during the 1991-92 and 1992-93 periods. Data from the discussions with customers in alcohol-serving establishments regarding knowledge of how to use SoberCab is used as a measure of customer convenience. A brief description of the procedures for accessing the RSP is presented.

\section{$\underline{\text { Results - SoberCab }}$}

Data on wait time was not recorded. The operations manager of the taxi company estimated that the average time is between 20 and 30 minutes except on New Year's Eve - New Year's Day when the time may be as long as 45 minutes to one hour. Only about one-third of the drivers for the taxi company accept SoberCab rides. Approximately 55\% of all calls to SoberCab during their period of operation come on New Year's Eve - New Year's Day. During this busiest period, SoberCab lacks convenience in terms of time from call to pick-up for a substantial number of individuals who want to use the service. Evidence that some customers do not wait that long is shown below in the number and percent of no loads on New Year's Eve - New Year's Day.

Publicity about the RSP and drinking and driving is concentrated in the period shortly before and during the Christmas - New Year's period. Information, signs and table tents with the SoberCab phone number are sent or delivered to many licensed establishments. The pick-up procedure involves a call to the Sober $\mathrm{Ca}$ number. The only restrictions are that pick-up must be made from a commercial establishment and the drop-off location cannot be another alcohol-serving establishment. A very large percentage of the general population reached via the telephone survey conducted by the University of Minnesota and customers of alcohol-serving establishments have heard of SoberCab. However, not all those who were talked with in alcohol-serving establishments who had heard of SoberCab reported knowing how to use it; only $73 \%$ stated that they knew how to use the service.

From site visits and discussions with customers in alcohol-serving establishments, it was observed that some establishments did not have the SoberCab number available for patrons who were leaving. Some individuals may have been inconvenienced or discouraged from calling if the number was not readily available. 
From the viewpoint of SoberCab, there is inefficiency in the system, especially during the New Year's Eve - New Year's Day period. SoberCab distinguishes between cancellations and no loads, since the taxi company receives the same fee for no loads as for pick-ups, but not for cancellations. In 1991-92, 27\% of the total number of calls during the holiday period resulted in a cab being sent but no SoberCab pickup was made (no loads). On New Year's Eve - New Year's Day the percent of no loads as a function of the total number of calls was 39\%. In 1992-93 the percent of no loads as a function of all calls was $29 \%$ during the entire operating period. On New Year's Eve - New Year's Day there were 34\% no loads.

There were also calls for SoberCab where the request was canceled and a cab was not dispatched (cancellations). On New Year's Eve - New Year's Day in 1992-93 this amounted to 20\% of all calls. For the entire SoberCab operating period (December 25 - January 2, 1992-93), 14\% of all SoberCab calls resulted in non-dispatch.

\section{Is the program self-sustaining?}

\section{Methodology - I'm Smart}

In order to assess the funding base of I'm Smart, the survey sent to corporate members from I'm Smart and interviews with a small number of owners of alcohol-serving establishments who belong to I'm Smart provide indirect evidence of the program's ability to sustain itself. Opinions concerning the RSP from DMV surveys as well as from talks with customers in alcohol-serving establishments are also be utilized. The survey of corporate members included satisfaction ratings of 10 aspects of I'm Smart. Respondents were also asked whether I'm Smart had been used for company events, the number of employees covered by I'm Smart services, the estimated percent of employees who have used the ride service, and openended questions asking for additional comments and suggested improvements.

\section{$\underline{\text { Results - I'm Smart }}$}

I'm Smart is a profit-making business that has been operating since 1982 . The profitable nature of the business speaks to their ability to be self-sustaining. The membership and fee structure was described in Section III (page 6). The stability of the number of member organizations who pay a fee and pay for rides is an argument for the continuation of the program.

There are several major customer groups served by I'm Smart: (1) corporate member organizations, including public sector organizations and private clubs which receive awareness training and corporate party management training as well as the ride service; (2) alcohol-serving establishments which receive server training and other liability-reducing services; (3) individuals who use the service; and (4) a health insurance company which provides their policy holders with the ride service.

Customers from alcohol-serving establishments in 1992 were asked their opinions of I'm Smart only if they indicated they had previously used the service. Almost all expressions were positive and only three individuals were critical. In the 1993, opinions were asked of all who said they had heard of I'm Smart. A very large majority (about $85 \%$ of those who responded) produced positive statements, usually of a general nature such as saying it was a "good idea" or "good" with some providing stronger positive statements such as "wonderful" and "great". The most frequent negative comments referred to the costs of using the ride service, saying it was too expensive for those who did not have a corporate card. Over 
one-fifth (23\%) mentioned cost as a negative factor. However, many of those who were critical also thought that the RSP was a good idea. Very few responses were solely negative toward the service.

On the DMV survey, those who answered the open-ended question concerning what is known about I'm Smart often made a positive remark. There were very few negative statements about the RSP.

In 1993, interviews were conducted with owners of seven member alcohol-serving establishments concerning their use and views of I'm Smart. Six of seven had positive comments about the program, but four believed the membership costs were too high. Some said they occasionally pay for an I'm Smart ride if the customer is not a member, but most said that the customers usually pay or have company memberships. A few mentioned that non-member customers would be hesitant to spend the money to use I'm Smart. The owners' principal motivation is the perception that I'm Smart protects against possible liability actions and lowers insurance costs. One said his membership in I'm Smart assisted his defense in a law suit as a result of server training, development of a written policy, and documentation. Others expressed their concern about people getting hurt in crashes and wanting to prevent DWI, and some indicated that I'm Smart provided a convenient way to handle difficult situations with intoxicated customers. One owner thought it was a good program but not worth the cost to him, since he could use cabs for patrons at less cost. Another related an incident with an I'm Smart driver running a stop sign and questioned how drivers are trained and what happens if there is an accident. The seven establishments had good things to say about the program, but also had concerns, especially whether it was worth the monetary costs to them.

Opinions about I'm Smart from corporate members were measured by means of a questionnaire sent by I'm Smart to 168 of these organizations, not including the licensed establishments who sell alcohol. Returns were received from 63 of these organizations, a $38 \%$ return rate. Of the 55 respondents who answered the question on number of employees covered by I' $m$ Smart the range was 0 to 4,500 with a median of 50 employees. About one-eighth of the sample listed under 10 employees covered, and $31 \%$ over 100 employees. About two-thirds of the organizations (65\%) had used I'm Smart for company events. This was somewhat more frequent among the organizations with over 50 employees.

Table 18 presents the data on ratings of 10 aspects of the I' $m$ Smart program from the survey. From the viewpoint of management of the 63 responding organizations, each of the 10 were rated as outstanding or good by $70 \%$ or more. There were very few negative responses to any of the 10 aspects of I'm Smart. A few organizations had reservations about employee trust in confidentiality of the ride service, and some questioned the costs versus benefits.

Seventeen of the 63 respondents wrote comments to one of the open-ended questions. Almost all were positive, indicating satisfaction and importance of the program to the organization and its employees. Some praised the professionalism of the service and noted its positive reputation. Several organizations mentioned that none or only a few individuals had used the service or the service was used rarely for company events. However, the implications of these responses were not negative for the program. Two responses were negative, one about cost and the other concerning feelings of employees that the company might be monitoring their use of the RSP and promoting alcohol use.

Based on the survey data of member organizations and opinions of potential users among customers of alcohol-serving establishments, I'm Smart has a satisfied customer base as well as many potential customers with positive opinions about the service. The major negative opinion among the customers 
and the alcohol-serving establishment members interviewed involved the cost of using the ride service. In addition, the number of organizations who belong to I' $m$ Smart has been relatively steady over the past few years, indicating a stable and continuing financial base.

Table 18

Survey of I'm Smart Corporate Members

Percent of Respondents Rating Each Dimension of I'm Smart on Each Scale Point

\begin{tabular}{|c|c|c|c|c|c|}
\hline \multirow[b]{2}{*}{ DimEnsion } & \multicolumn{5}{|c|}{ Percent Rating } \\
\hline & Outstanding & Good & $\begin{array}{c}\text { OK with } \\
\text { Some } \\
\text { Reservations }\end{array}$ & $\begin{array}{c}\text { Serious } \\
\text { Reservations, } \\
\text { Unsatisfactory }\end{array}$ & $\begin{array}{c}\text { Insufficient } \\
\text { Information, } \\
\text { Missing }\end{array}$ \\
\hline Program Goals and Strategies & 59 & 35 & 2 & 0 & 5 \\
\hline Employee Awareness Sessions & 25 & 46 & 8 & 0 & 21 \\
\hline $\begin{array}{l}\text { Corporate Host Risk Management } \\
\text { Planning }\end{array}$ & 22 & 43 & 6 & 2 & 27 \\
\hline $\begin{array}{l}\text { Stand-by Service for Company } \\
\text { Events }\end{array}$ & 56 & 29 & 2 & 0 & 14 \\
\hline $\begin{array}{l}\text { Efficiency of Ride Service for } \\
\text { Employees }\end{array}$ & 41 & 37 & 5 & 0 & 17 \\
\hline $\begin{array}{l}\text { Convenience of System to } \\
\text { Management }\end{array}$ & 52 & 32 & 6 & 0 & 10 \\
\hline $\begin{array}{l}\text { Confidentiality for Ride Service } \\
\text { Users }\end{array}$ & 73 & 14 & 2 & 0 & 11 \\
\hline Trust and Confidence of Employees & 54 & 27 & 10 & 2 & 8 \\
\hline Employee Satisfaction & 54 & 29 & 6 & 0 & 11. \\
\hline $\begin{array}{l}\text { Cost versus Benefits (Value for the } \\
\text { Money) }\end{array}$ & 48 & 27 & 13 & 5 & 8 \\
\hline Total N: & 63 & & & & \\
\hline
\end{tabular}

\section{SoberCab}

Sober $C a b$ and its predecessor had been operating for about 10 years. The 24 member hospitals of the Council of Hospital Corporations contribute to supporting SoberCab. The cost has been small for any one hospital, generally no more than $\$ 1,000$ per year depending on the amount of the hospital's revenue. The total cost was $\$ 18,000$ in 1990 , which included costs for newspaper ads. Most of the other publicity is provided free of charge. The phones are staffed by volunteers from the hospitals who may receive some compensatory time for their efforts. Management of the program constituted a very small amount of the time for two employees, one from the Council and one from a different hospital each year. The administration of the program was part of their duties. The company that provides the rides, Airport Taxi and their drivers, have a ready-made and well-established source of income during the holiday period which maintains motivation. Thus, it appears easy to financially maintain the program. 
However, in December 1993 the Council of Hospital Corporations announced its discontinuation of support three weeks before Sober $C a b$ was scheduled to begin its 1993 holiday service. The manager of the taxi company that provides the rides immediately contacted the media, resulting in TV, newspaper and Minnesota Public Radio (MPR) features on the problem. The response to the need for support was almost immediate. The Twin Cities bar and restaurant association offered financial support for SoberCab, but this proved unnecessary when the Fingerhut Companies, Inc., the large Twin Cities mail-order company, assumed complete financial sponsorship including publicity provided through their marketing department. Fingerhut has provided a year-round safe ride service, "Take-a-Taxi", for their employees for 17 years. In addition to Fingerhut, one of the previous hospital sponsors, Riverside Hospital, agreed to continue to provide space and phone bank facilities. Mothers Against Drunk Driving assumed responsibility for recruiting and coordinating volunteers to staff the phone bank. The Minneapolis Star Tribune, in addition it its feature article publicizing the need for funding, printed a follow-up editorial announcing Fingerhut's sponsorship and publishing the MADD and Airport Taxi numbers for phone bank volunteers to call. It is believed that the very high level of name recognition and positive reputation of Sober $\mathrm{Cab}$ aided in the immediate community response to the withdrawal of funds.

Would the users of the RSP employ means of transportation, other than driving their own vehicle, in absence of the RSP?

\section{$\underline{I ' m \text { Smart }}$}

No information was available to directly answer this question since there is no period when I'm Smart is not available and discussions with users were not permitted.

\section{Methodology - SoberCab}

The ride-along discussions with users by the Project Director included a question concerning what they would do if SoberCab was not available and what alternatives to driving they had used in the past. The latter question was also asked of customers in alcohol-serving establishments who reported they had used Sober $C a b$ in the past.

$\underline{\text { Results - SoberCab }}$

Of the 17 users of SoberCab talked with during ride-alongs by the Project Director, 10 responded to the question of use alternatives when SoberCab was not available. Two of the 10, (20\%), said they drove when SoberCab was not available. Others cited alternatives such as family or friends, taxi, public transportation and walking. Sober $\mathrm{Cab}$ users were also asked what alternative means had they used when they thought they had too much to drink. Thirteen of the 17 riders responded. The most common alternatives mentioned were use of family, friends or a designated driver $(\mathrm{N}=7)$, and taxis $(\mathrm{N}=5)$. Walking and "other" were responses of three users (multiple responses were coded).

Based on the small sample of users, few reported they would have driven if SoberCab was not available. In addition, users reported to have employed alternative methods to driving in the past when they felt they had too much to drink.

Customers in alcohol-serving establishments who said they had used SoberCab in the past $(\mathrm{N}=15)$, were asked how do they got home when Sober $C a b$ was not available. Responses were obtained from 20 of the 
Evaluation Question: Would the users of the RSP employ means of transportation, other than driving their own vehicle, in absence of the RSP?

25 past users. Seven of the $20(35 \%)$ said they drove. The most frequent alternatives reported were a friend or family member drove (55\%) and use of a taxi (40\%). Three past users (15\%) said they walked, and two (10\%) reported using public transit. This limited data indirectly supports the findings that most Sober $C a b$ users would have used alternatives to driving in absence of the RSP.

\section{What alternatives to driving after drinking do drinkers report using?}

The use or non-use of available RSPs needs to be evaluated within the context of what alternatives to driving after drinking drinkers report using.

\section{Methodology - I'm Smart}

Questions included in the DMV and RID surveys in New York State and in discussions with customers in alcohol-serving establishments in Syracuse and Albany asked about alternatives used to driving after drinking (DMV survey), or when feeling unable to drive safely, or when feeling intoxicated. Analyses of customer discussions compared plans for transportation that evening between those who reported feeling unsafe to drive and those who did not, as well between those who felt intoxicated (moderate or above) and those who did not.

\section{Results - I'm Smart}

\section{- $\quad$ DMV Surveys}

Table 19 presents data from the DMV surveys in Syracuse and Albany (combined 1992 and 1993 samples in both areas) to the question "Which of the following have you ever done to avoid driving after drinking?" Ten choices were presented and the respondent could check as many as applicable. Only individuals who had indicated, on a previous question, that they drank alcoholic beverages during the last 12 months were included in the analysis. Also excluded from the analyses was the option "Never done anything to avoid driving after drinking" leaving nine alternatives.

In Syracuse, $59 \%$ of those who answered the question gave multiple responses. The mean number of responses was 2.39 with a range of 1 to 7 . Forty-one percent $(41 \%)$ gave three or more responses. In the DMV samples from Albany (the comparison area), $65 \%$ of those who answered the question gave multiple responses. Their average number of responses was 2.77 ranging from 1 to 8 . Half (50\%) checked three or more alternatives. Of greater import is the fact that the large majority of those who said they drank alcoholic beverages during the last 12 months reported using at least one of the listed alternatives to driving after drinkings. In Syracuse, $13 \%$ did not check any of the alternatives and in Albany $14 \%$ did not. Some of these drinkers may not have been in situations where driving decisions occurred. In addition to the non-respondents, $8 \%$ of the Syracuse respondents and $4 \%$ of those in the Albany area checked that they had never done anything to avoid driving after drinking.

Respondents in both the I' $m$ Smart and comparison areas reported asking others for a ride, using a designated driver who did not drink alcoholic beverages, and staying overnight as a guest most frequently

\footnotetext{
5 However, the question was phrased in a manner so as to indicate an indefinite time frame "Which of the following have you ever done .....". No information on recency or frequency of use of these alternatives was obtained.
} 
among the alternatives listed. Use of an RSP was checked by a very small percent of the respondents, a higher percent in Syracuse than in the Albany area as would be expected (5\% versus 2\%). A small percent also said they used public transportation (5\% in Syracuse, $11 \%$ in the Albany area).

Table 19

Syracuse and Albany Area DMV Surveys - 1992 and 1993 Combined

Reported Alternatives to Driving After Drinking

Only those people that have drank in the last 12 months*

\begin{tabular}{||l|c|c||}
\hline ALTERNATrVE & SYRACUSE & ALBANY ** \\
\hline Called a cab & $17 \%(\mathrm{n}=87)$ & $31 \%(\mathrm{n}=201)$ \\
\hline Asked for a ride & $48 \%(\mathrm{n}=249)$ & $57 \%(\mathrm{n}=373)$ \\
\hline Stayed overnight as a guest & $43 \%(\mathrm{n}=223)$ & $51 \%(\mathrm{n}=333)$ \\
\hline Walked & $23 \%(\mathrm{n}=122)$ & $33 \%(\mathrm{n}=218)$ \\
\hline Took public transit & $5 \%(\mathrm{n}=25)$ & $11 \%(\mathrm{n}=74)$ \\
\hline Called an RSP & $5 \%(\mathrm{n}=24)$ & $2 \%(\mathrm{n}=12)$ \\
\hline Designated a driver who would not drink & $53 \%(\mathrm{n}=275)$ & $52 \%(\mathrm{n}=342)$ \\
\hline Waited until the effects wore off & $27 \%(\mathrm{n}=143)$ & $25 \%(\mathrm{n}=167)$ \\
\hline $\begin{array}{l}\text { Never done anything to avoid driving after } \\
\text { drinking }\end{array}$ & $8 \%(\mathrm{n}=41)$ & $4 \%(\mathrm{n}=29)$ \\
\hline Other & $6 \%(\mathrm{n}=33)$ & $6 \%(\mathrm{n}=38)$ \\
\hline \hline Total N: & 522 & 657 \\
\hline
\end{tabular}

* Only includes respondents who checked at least one of the 10 listed alternatives.

** Comparison City. 1992 round conducted in Albany, Schenectady, and Troy, New York. 1993 round conducted in one office in Albany.

Although there were differences in the percent checking the various alternatives between the Syracuse and Albany area samples, the importance of the data is that many drinkers report using alternatives to driving after drinking and many have used several alternatives. An RSP is not among the frequently used means to avoid driving after drinking and does not appear to be among the common, more "natural" methods used. Two of the most frequently reported alternatives to driving after drinking appear to be linked to the social situation in which drinking takes place, (e.g., asking someone for a ride, using a nondrinking designated driver). A large percent of the respondents stay overnight where they are after drinking (which might have occurred in drinking situations outside their community). Walking from the place of drinking was reported by $23 \%$ in Syracuse and $33 \%$ in the Albany area. (Many places where drinking occurs may be close to the drinker's home). Calling a cab is also a popular response, more so among the Albany area respondents. About one-quarter of the sample in each area $27 \%$ in Syracuse and $25 \%$ in the Albany area) said they had waited until the effects of the alcohol had worn off.

The DMV samples who drink appear to have used many alternatives to driving after drinking at some time. The very small percent in Syracuse who said they used an RSP may be, in part, due to the membership requirements for cost-free use. Another interpretation of the relatively low use of the RSP 
is that people prefer to use alternatives to driving that are more familiar to them (e.g., friends, family, designated driver, taxi).

\section{- $\quad$ RID Survey}

The survey of fairgoers at the New York State Fair held in Onondaga County included a question on alternatives to driving when the respondents felt they might be unable to drive home safely. Some of the alternatives were similar to those used in the DMV surveys but several were not included. The question was not strictly comparable to the one on the DMV survey. It was worded differently and in a different context on the RID questionnaire than on the DMV surveys.

Of the 484 fairgoers who reported at times feeling unable to drive home safely, $96 \%$ checked one or more of the alternatives to driving. The average number of alternatives checked was 1.5 , with $33 \%$ reporting use of more than one alternative. Table 20 presents the number and percent indicating each alternative.

The striking aspect of this table, especially in comparison with the DMV survey data, is the number and percent of respondents who said they drove when thinking they may have been unable to drive safely. Over one-third of the RID survey respondents $(35 \%)$ reported to have driven when believing they may have been unable to drive safely. Since only $6 \%$ of the DMV survey respondents in Syracuse and the Albany area combined checked that they never had done anything to avoid driving after drinking, the key word is probably "never." This suggests that a third of the population represented by the respondents may sometimes drive when alcohol-impaired, but that most use alternative transportation on some occasions.

Table 20

RID State Fair Survey

Alternatives When Feeling Unable to Drive Safely

(Only respondents who indicated that at times they felt unable to drive home safely)

\begin{tabular}{|l|c|c|}
\hline ALTERNATrve & NUMBER & PERCENT \\
\hline I drove anyway & 161 & 35 \\
\hline I had a friend or relative drive & 236 & 51 \\
\hline I took a cab & 42 & 9 \\
\hline I used public transportation & 13 & 3 \\
\hline I used a "safe ride" service & 11 & 2 \\
\hline I rode with a designated driver & 145 & 31 \\
\hline I didn't go home & 115 & 25 \\
\hline \hline Total N: & 463 & \\
\hline
\end{tabular}


Other common alternatives were use of a designated driver (31\%), driving with a friend or relative (51\%), and not going home (25\%). As in the DMV surveys, an RSP or public transportation was used by a very small percent of the respondents. Even among respondents who resided in Onondaga County, only $3 \%$ said they had used an RSP when they believed they may have been unable to drive safely.

The data shows that in Onondaga County, where I'm Smart operates, RSP use is an uncommon alternative to driving when feeling unable to drive safely. Other alternatives (including driving) are much more frequently reported.

\section{- $\quad$ Discussions with Customers in Alcohol-Serving Establishments}

Customers in Syracuse were asked three questions concerning alternatives: (1) transportation plans for that evening; (2) previous use of I'm Smart; and (3) other known alternatives. Of greatest interest are plans of those who rate themselves as unsafe to drive and who rate themselves as moderately intoxicated. Table 21 presents data on all three questions and Table $21 \mathrm{~A}$ shows transportation plans as a function of reported feelings of being able to drive safely and feelings of intoxication.

The majority of customers (52\%) said they were driving, and an additional $36 \%$ said they were riding with a designated driver, a friend or a family member. Most of the others (9\%) said they were walking. No individual in the sample said they planned to use I'm Smart. About one-eighth (12\%) said they had used I'm Smart in the past. When asked about other known alternatives, the largest number mentioned taxis or public transportation (41\%).

Individuals who rated themselves as moderately intoxicated or greater (most rated themselves as moderately intoxicated) were much less likely to plan to drive (28\%) than those rating themselves as less than moderately intoxicated $(62 \%)$. This difference was statistically significant $\left(\chi^{2}=52.8, \mathrm{df}=1, \mathrm{p}\right.$ $<.0001)$. Similar results were seen for the question on whether or not the customer felt safe to drive $\left(\chi^{2}=124.1, \mathrm{df}=1, \mathrm{p}<.0001\right)$. Those who reported not feeling safe to drive were much less likely to plan to drive (14\%) than those who felt safe to drive (86\%). Other indicators showed similar relationships. Drivers had a lower average number of drinks than non-drivers, were drinking for a shorter period of time, and had lower estimated BAC (based on number of drinks reported, amount of time drinking and weight). All differences were statistically significant at the .02 level of significance or greater, with most differences significant at greater than .001 .

It should be noted that almost all who drove to the establishment also said they were driving home. Thus, differences in indications of impairment did not necessarily, at the time, lead to decisions not to drive.

In Albany, customers were asked whether they had ever felt too intoxicated to drive. Of those responding $(\mathrm{N}=127), 91 \%$ said yes - a very high percent, with serious implications. Customers were also asked to estimate the number of times they drove when feeling too intoxicated to drive safely. The average number of times was 41 and the median was 10 . The range was $0-500$ based on the 102 customers who provided an estimate. About $25 \%$ reported having driven while too intoxicated 50 or more times. 
Table 21

Discussions with Alcohol-Serving Establishment Customers in Syracuse, 1992 and 1993 Combined Planned Means of Getting Home, Previous Use of I'm Smart and Knowledge of Other Alternatives

\begin{tabular}{||l|r|c||}
\hline \hline QUESTION & NUMBER & PERCENT \\
\hline Transportation Plans for the Evening & 297 & 52 \\
\hline Driving & 205 & 36 \\
\hline Designated driver, friend or family member driving & 5 & 1 \\
\hline Taxi & 49 & 9 \\
\hline Walk & 6 & 1 \\
\hline Other & 15 & 3 \\
\hline No response & 67 & 12 \\
\hline Used I'm Smart in the Past & & \\
\hline Known Alternatives to Driving & 232 & 41 \\
\hline Taxi or public transportation & 111 & 20 \\
\hline Call someone to drive & 83 & 15 \\
\hline Walk & 15 & 3 \\
\hline I'm Smart or RSP & 50 & 9 \\
\hline Other & 577 & \\
\hline \hline Total N: & & \\
\hline
\end{tabular}

Table 21A

Discussions with Alcohol-Serving Establishment Customers in Syracuse, 1992 and 1993 Combined Planned Means of Getting Home by Self-Reported Indicators of Impairment

\begin{tabular}{||c|c|c|}
\hline \hline INDICATOR OF IMPAIRMENT & PLAN TO DRIVE & $\begin{array}{c}\text { OTHER MEANS OF } \\
\text { GETTING HOME }\end{array}$ \\
\hline Self-Rating of Intoxication & & $38 \%(\mathrm{n}=145)$ \\
\hline Less Than Moderately Intoxicated & $62 \%(\mathrm{n}=241)$ & $72 \%(\mathrm{n}=119)$ \\
\hline Moderately Intoxicated or Greater & $28 \%(\mathrm{n}=47)$ & \\
\hline Feel Safe to Drive & & $32 \%(\mathrm{n}=132)$ \\
\hline Yes & $68 \%(\mathrm{n}=275)$ & $86 \%(\mathrm{n}=129)$ \\
\hline No & $14 \%(\mathrm{n}=21)$ & 265 \\
\hline \hline Total N: & 297 & \\
\hline
\end{tabular}


The customers were asked how they usually got home when they felt too intoxicated. A large percentage of those who said they felt too intoxicated to drive nevertheless said they drove (71\%). Alternatives reported were using a friend, family member or designated driver (25\%), taking a cab (15\%) and walking $(10 \%)$.

The Albany customers were asked if they knew of other alternative ways of getting home safely. The two most common responses were taxi (51\% of those who answered) and using an available friend, family member or designated driver (44\%). Some (18\%) said they knew of alternatives but did not specify any. Under $10 \%$ of the interviewees said they knew of no alternatives.

The customers were then asked why they did not use the alternatives they had mentioned. Only about $55 \%(\mathrm{~N}=76)$ replied, the majority $(62 \%)$ of those said the alternative was too inconvenient or too much trouble. Only one other coded response was given by more than $10 \%$ of those answering the question: the belief that using the alternative was not manly or was a threat to perceived status $(11 \%)$.

This shows that customers of alcohol-serving establishments in Albany generally do not use alternatives to driving when feeling intoxicated. However, many knew of alternatives but were reluctant to use them, mainly because they felt it was inconvenient, troublesome, or a threat to status.

\section{Methodology - SoberCab}

Customers in the Twin Cities establishments were asked if they had ever driven after they thought they had too much to drink. They were also asked how many times they thought they did it in their lifetime, and what alternative means they had used.

\section{$\underline{\text { Results - SoberCab }}$}

Eighty-seven percent $(n=202)$ of the customers said they had driven after they had too much to drink. The average number of times was 39 and the median 10 . The range was $0-500$. Over one-fifth (22\%) said they had driven impaired 50 or more times. Both the percentage of customers who said they had driven when feeling they had too much to drink and the average number of times this occurred was somewhat similar to the data obtained from customers in Albany, New York. (Customers in Syracuse were not asked this question.)

About two-thirds of those who answered the question concerning alternatives (67\%) said they used family, friends or a designated driver, $50 \%$ reported to have used taxis, and $26 \%$ to have walked. Less than $10 \%$ mentioned other alternatives to driving. Only two individuals indicated that they had never used an alternative and only one mentioned use of an RSP. Many customers gave multiple responses.

These data suggest that many establishment drinkers drive after drinking and do so with some regularity, but most also use alternative transportation on some occasions. Thus, this population is not closed to the idea in general, but may be resistive on situational bases.

\section{Summary}

In summary, a very large percent of customers of alcohol-serving establishments in Albany and the Twin Cities and a smaller percent of those who completed the RID survey in New York State admit to driving 
when feeling they had too much to drink, and many estimate they have done this on many occasions. They reported using taxis and available friends/family/designated drivers most often as alternatives. Walking and calling someone for a ride were reported much less often. Using an RSP was mentioned by a very small percent of the samples as alternatives to driving while intoxicated although a large percent of customers in Syracuse and the Twin Cities knew of the RSPs. The membership requirements of I' $m$ Smart and the seasonal nature of SoberCab may be major contributors to the lack of reported use of an RSP for times the customers felt unsafe to drive. DMV survey respondents from Syracuse and the Albany areas mention use of designated drivers, asking someone for a ride, staying overnight, and walking as alternatives to driving after drinking. Very few DMV survey respondents said they did nothing to avoid driving after drinking at some time.

RSPs seem to be an infrequent alternative to driving considered by the various samples used in the study. Social factors and relationships of the driver to others appear to play the most significant role in using alternatives to driving (e.g., use of family, friends or a designated driver, asking for a ride) on either a pre-arranged or spontaneous basis.

In summary, the implications of the data on knowledge and use of alternatives to driving among those who have driven when feeling unsafe implies encouragement of what appears more "natural" methods such as using family and friends, designated drivers, and calling cabs. In addition, there appears to be a need to encourage the use of RSPs - to provide the motivations and stimuli needed to act on the knowledge most have of these programs so that it becomes an alternative that is among those considered more often when individuals feel unsafe to drive and their preferred alternatives are unavailable.

Data from discussions with customers as well as other studies (Molof and Kimball, 1992; Molof, 1993) show that individuals who say they are driving have statistically significantly lower indications of intoxication or impairment than those who are not driving. In this study, differences are consistent for self-reported ratings of intoxication, feeling safe to drive, number of drinks during the evening, and time spent drinking in the Twin Cities and Syracuse. The implications are that people plan for drinking and that those who drink more or who believe they will become intoxicated are less likely to drive to the location of drinking, and that individuals who do not drive have fewer constraints on their drinking behavior.

\section{- How many alcohol-related trips are reduced due to the use of the RSP?}

This is perhaps the most direct and relevant question to ask in evaluating the effects of an RSP. RSP rides cannot be assumed to have saved an alcohol-related trip. RSP users may be largely drawn from a population who would use other alternatives to driving absent the RSP.

Given the data available in this study, an alcohol-related trip is defined as an individual driving a vehicle who is impaired based on one or more indicators of impairment: (1) self-report of feeling intoxicated or unsafe to drive; (2) judged as intoxicated by RSP drivers or ride-alongs; or (3) showing high estimated blood alcohol content. It should be noted that an individual with one or more of the above indications of impairment who did not drive to the location of drinking or would have probably used another means of transportation, other than the RSP or driving a vehicle, would not be considered as saving an alcoholrelated trip by use of the RSP. This is a narrow definition of an alcohol-related trip. The purpose of this definition is to pinpoint the potential effects of an RSP within a context in which some impaired users do not drive or probably would not have driven from the location at which they had been drinking. 
Methodology - I'm Smait

Drivers who made observations and judgements on a sample of users were asked to judge the level of visible intoxication of riders.

\section{Results - I'm Smart}

Only $12 \%$ of the users were judged as showing no signs of visible intoxication (although some or all of these individuals may have felt impaired or unsafe to drive). About $86 \%$ of the users in the sample may be considered to have made an alcohol-related trip in absence of I' $m$ Smart. (Judgements on intoxication were not recorded for a few riders.) Users were not questioned about how they would travel if I'm Smart were not available, but it can be assumed that individuals are unlikely to call I' $m$ Smart to drive them and their auto unless feeling impaired. Given this assumption a very high percent, perhaps close to $100 \%$ of the rides provided by I'm Smart, prevent an alcohol-related trip. However, the lack of data on possible use of alternatives other than driving or I'm Smart prevents a more definitive statement.

Some evidence from discussions with customers in alcohol-serving establishments in Syracuse and Albany provide indirect data that awareness of dangers of drinking and driving may be greater in Syracuse and the use of alternatives to driving greater among those who feel intoxicated and/or unsafe to drive. Table $22^{\circ}$ shows the data on how customers plan to get home (drive versus other means) and two self-report indices of impairment (self-reported level of intoxication and whether they feel safe to drive).

Self-reported ratings of intoxication show that Syracuse customers who felt moderately intoxicated or greater were much less likely to say they were planning to drive home than individuals with similar ratings in Albany (49\% to 79\%). Very few customers who rated themselves as a 4 or 5 on the scale of feelings of intoxication were planning on driving ( 7 in Syracuse and 5 in Albany). A chi-square test of the percent who said they would drive showed the difference was statistically significant $\left(\chi^{2}=12.7\right.$, df $=1, p<.001$, combining scale points 1 and 2; and 3,4 and 5). It should be noted that a substantial percent of both samples who rated themselves moderately intoxicated or greater said they were planning to drive home. The average self-ratings of intoxication for those who planned to drive and those that did not was 1.72 and 2.38 in Syracuse and 2.09 and 2.49 in Albany. An analysis of variance of the main effects of location was statistically significant $(\mathrm{F}=36.3, \mathrm{df}=1, \mathrm{p}=.012$ ) with Albany drivers showing a higher mean selfrating of intoxication. There was also a statistically significant main effect of how the individual plans to get home ( $\mathrm{F}=65.6, \mathrm{df}=1, \mathrm{p}<.001)$. Drivers have a lower average self-rating of intoxication, (1.79) than those who do not plan to drive, (2.40). However, the interaction between location and whether or not the person is driving on self-ratings of intoxication does not reach statistical significance.

Among the Syracuse customers who said they did not feel safe to drive at the time of the interview, $14 \%$ reported planning to drive home. In the comparison community (Albany), among customers who said they did not feel safe to drive, $24 \%$ planned to drive home. While this difference appears large, the difference was not statistically significant $\left(\chi^{2}=1.9, \mathrm{df}=1, \mathrm{p}=.17\right.$ using Yates correction).

Evidence from the samples of customers in alcohol-serving establishments show that there was a lower percent of alcohol-related trips in Syracuse. It is important to note that among those who reported they felt unsafe to drive a much lower percent said they would drive than those who rated themselves somewhat intoxicated or greater. Some individuals, although aware that they are somewhat intoxicated, may not feel unsafe to drive. 
The differences between customers at the two locations cannot be attributed to the use of I'm Smart rides in Syracuse; no customer said they were planning to go home by using I'm Smart that evening in either the 1992 or 1993 samples. The fewer alcohol-related trips (based on self report of level of intoxication and feelings of being unsafe to drive) in Syracuse may be a function of greater awareness of the dangers of driving while intoxicated and the consequent use of alternatives to driving. This may in part be a function of I'm Smart's training and publicity programs and other activities over the years. (Most customers in Albany reporting how they generally get home when they felt too intoxicated to drive said they drove, $71 \%$ ).

Table 22

Discussions with Alcohol-Serving Establishment Customers in Syracuse and Albany, 1992 and 1993 Planned Means of Getting Home for by Various Indicators of Impairment

\begin{tabular}{|c|c|c|c|c|}
\hline \multirow[b]{3}{*}{ INDICATOR OF IMPAIRMENT } & \multicolumn{2}{|c|}{ SYRACUSE } & \multicolumn{2}{|c|}{ ALBANY* } \\
\hline & \multicolumn{2}{|c|}{ Planning to Drive } & \multicolumn{2}{|c|}{ Planning to Drive } \\
\hline & Yes & No & Yes & No \\
\hline \multicolumn{5}{|l|}{ Feelings of Intoxication } \\
\hline Scale Points 1 and $2($ Sober $=1)$ & $\begin{array}{c}62 \% \\
(\mathrm{~N}=241) \\
\end{array}$ & $\begin{array}{c}38 \% \\
(\mathrm{~N}=145) \\
\end{array}$ & $\begin{array}{c}55 \% \\
(\mathrm{~N}=41)\end{array}$ & $\begin{array}{c}45 \% \\
(\mathrm{~N}=34) \\
\end{array}$ \\
\hline Moderately Intoxicated (Scale Point $=3$ ) & $\begin{array}{c}33 \% \\
(\mathrm{~N}=40) \\
\end{array}$ & $\begin{array}{c}68 \% \\
(\mathrm{~N}=83) \\
\end{array}$ & $\begin{array}{c}53 \% \\
(\mathrm{~N}=19) \\
\end{array}$ & $\begin{array}{c}47 \% \\
(\mathrm{~N}=17) \\
\end{array}$ \\
\hline $\begin{array}{l}\text { More than Moderately Intoxicated (Scale } \\
\text { Points } 4 \text { and 5) }\end{array}$ & $\begin{array}{l}16 \% \\
(\mathrm{~N}=7)\end{array}$ & $\begin{array}{c}84 \% \\
(N=36) \\
\end{array}$ & $\begin{array}{c}26 \% \\
(\mathrm{~N}=5) \\
\end{array}$ & $\begin{array}{c}74 \% \\
(\mathrm{~N}=14)\end{array}$ \\
\hline \multicolumn{5}{|l|}{ Feel Safe to Drive } \\
\hline Yes & $\begin{array}{c}68 \% \\
(\mathrm{~N}=275) \\
\end{array}$ & $\begin{array}{c}32 \% \\
(\mathrm{~N}=132) \\
\end{array}$ & $\begin{array}{c}66 \% \\
(\mathrm{~N}=54) \\
\end{array}$ & $\begin{array}{c}34 \% \\
(\mathrm{~N}=28)\end{array}$ \\
\hline No & $\begin{array}{c}14 \% \\
(\mathrm{~N}=21)\end{array}$ & $\begin{array}{c}86 \% \\
(\mathrm{~N}=129)\end{array}$ & $\begin{array}{c}24 \% \\
(\mathrm{~N}=12)\end{array}$ & $\begin{array}{c}77 \% \\
(\mathrm{~N}=39)\end{array}$ \\
\hline Total N & \multicolumn{2}{|l|}{562} & \multicolumn{2}{|l|}{133} \\
\hline
\end{tabular}

* Comparison City.

\section{Methodology - SoberCab}

Data from the Sober $C a b$ users who talked with the Project Director $(\mathrm{N}=17)$ and the 12 additional users interviewed by the Sober $C a b$ drivers is used to provide evidence concerning the number of alcohol-related trips saved. Data from customers at alcohol-serving establishments who reported using SoberCab in the past is also mentioned.

\section{$\underline{\text { Results - SoberCab }}$}

Sixteen of the 17 users of Sober $C a b$ rated themselves as unsafe to drive and also rated themselves as moderately intoxicated or greater. The Project Director rated 15 of the 17 as showing signs of moderate 
visible intoxication and 13 of the 17 as showing one or more signs of severe visible intoxication. Only one rider was not judged as clearly intoxicated or impaired. These judgements were supported by the number of drinks reported that day and BAC readings. Thus, almost all of the 17 riders met several criteria of being impaired. However, only five of the $17(29 \%)$ said they got around that evening by driving. Based on this very limited sample it can be said that alcohol-related trips are saved for about $30 \%$ of the users. (SoberCab does not require the user to have a car. The very large majority of the riders are picked up at commercial establishments and are driven to residences. The only questions asked of those who call the volunteers are the location of pick-up and drop-off.) In addition, of the few customers in alcohol-serving establishments who answered a question about what they would do if SoberCab was not available, few mentioned they would drive.

Drivers' interviews with an additional 12 riders on New Year's Eve showed 10 users rating themselves as moderately intoxicated or greater. Drivers rated half as somewhat intoxicated and half as drunk. A question on how the users got around that evening was not asked by the drivers, but they did ask how the rider got around after drinking when SoberCab was not available. Four of the $12(33 \%)$ indicated that they drove. This percent is similar to that found by the Project Director in talking with SoberCab users $(29 \%)$. Based on the very limited sample and reports of users, it can be estimated that about $30 \%$ to $35 \%$ of the Sober $C a b$ rides save alcohol-related trips. This data also shows that a majority of those who use SoberCab have not driven to the location of drinking.

\section{Do the RSPs reduce alcohol-related motor vehicle crashes?}

\section{Methodology - I'm Smart}

Data from the New York State Department of Motor Vehicles was obtained on the number of motor vehicle accidents classified as alcohol-related for the years 1974 through 1991. Data was provided for the total state, upstate New York (excluding the five boroughs of New York City), Onondaga County, Schenectady County and Albany County (the latter two were the comparison counties). The motor vehicle accidents classified as alcohol-related are probably a more stable and comprehensive indicator of driving under the influence than DWI arrests or motor vehicle fatalities associated with alcohol. Arrest data may be influenced by levels of law enforcement activities and numbers of fatalities may show large variation from year to year based on small changes.

Regression analyses for number of alcohol-related accidents was performed for upstate New York (minus the counties of Onondaga, Albany and Schenectady), Onondaga County (I'm Smart) and each of the comparison counties (Albany and Schenectady) for the 1982 to 1991 period.

\section{$\underline{\text { Results - I'm Smart }}$}

Figure 2 presents a graph showing the total number of reported alcohol-related motor vehicle accidents for the period 1974 - 1991 for New York, upstate New York, Onondaga, Albany and Schenectady counties. 


\section{Figure 2 \\ Alcohol Involved Accidents \\ New York State}

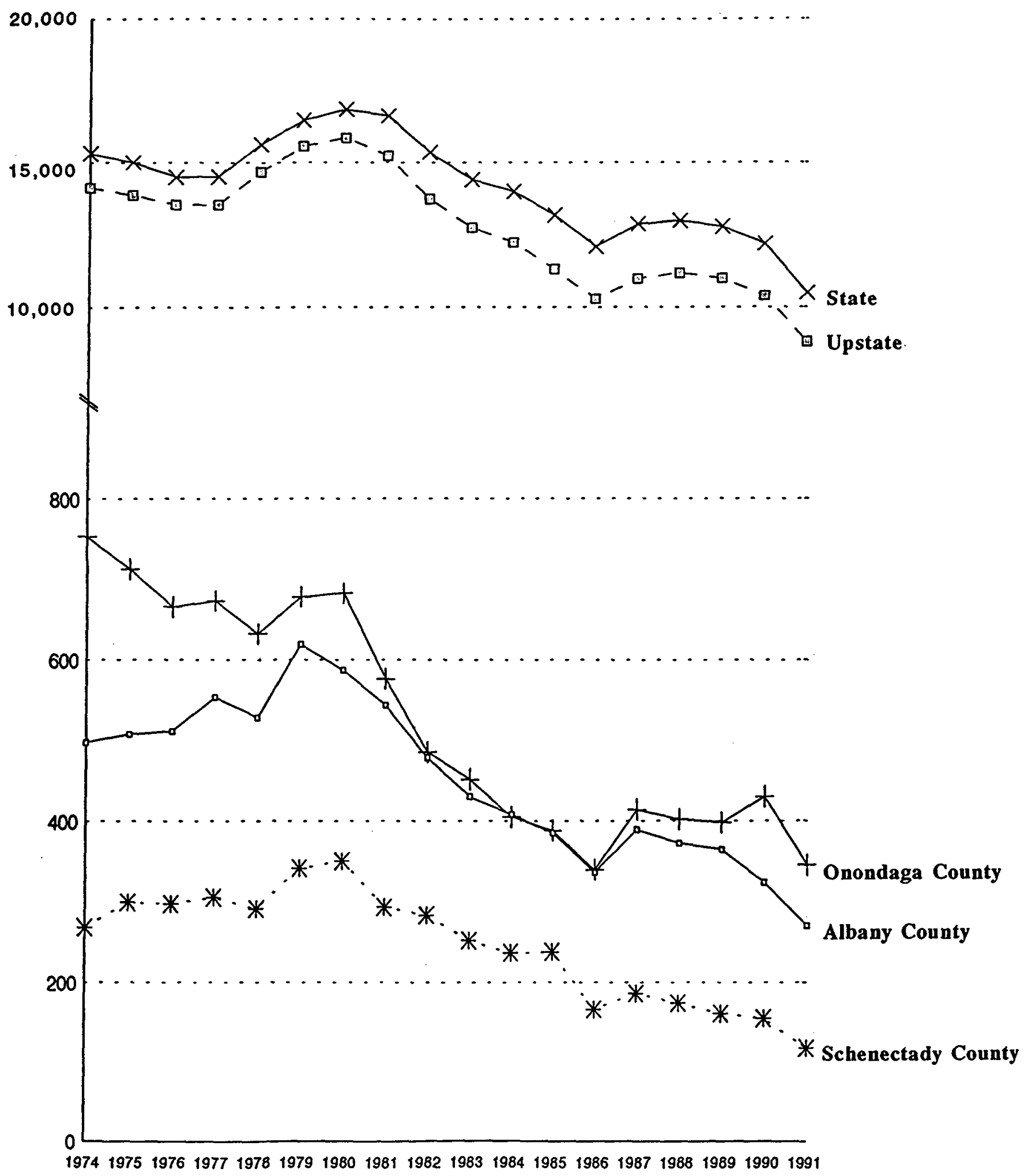


Figure 2 shows that a definite downturn in the number of alcohol-related vehicle accidents started in 1981 for upstate New York, Onondaga County and Schenectady County. In Albany County the downturn started in 1980. These downward trends continue through 1986 for upstate New York, Onondaga, Albany and Schenectady counties. In 1987 the number of reported alcohol-related motor vehicle accidents increased and then tended to "flatten" for the next two years in upstate New York and Onondaga County and appeared to resume the downtrend in Albany and Schenectady counties in 1988. A more pronounced downtrend in alcohol-related accidents resumed in 1990 for Albany County and for upstate New York, and in 1991 for Onondaga and Schenectady counties.

It is important to note that a statewide program called "STOP-DWI" which returns DWI fine monies to the counties to fund anti-drunk driving efforts and provides resources for comprehensive programs dealing with various aspects of alcohol and drug-impaired driving was implemented late in 1981 and continues. I'm Smart started in 1982. Thus, any effects of I'm Smart would be confounded with the influence of the "STOP-DWI" programs as well as other variables (e.g., number of vehicle miles traveled, enforcement levels).

Regression analyses of the trends shows statistically significant downward slopes starting in 1982 through 1991 for Onondaga County $(p=.01)$, upstate New York $(p=.03)$ and the average for Albany and Schenectady counties $(p=.0001)$ using all three geographic areas in the analyses (Albany, Schenectady and Onondaga County totals were subtracted from the upstate New York totals). ${ }^{6}$ The year 1982 was selected to correspond to the year when I'm Smart started in Onondaga County. As mentioned previously, these trends started one year earlier for each area under consideration except for Albany County where the trend started two years earlier, in 1980.

Separate regression analyses of trends between 1974 and 1981 were also conducted. The slopes for lines representing alcohol-related motor vehicle accidents were not statistically different from zero for upstate New York, Albany County or Schenectady County. Onondaga county showed a statistically significant $(p=.0001)$ decreasing slope during this period. This was chiefly due to the sharp decreases from 1974 to 1975 and from 1980 to 1981.

Using the 1982-1991 period there were no statistically significant differences in the slopes between Onondaga and Albany counties $(p=.23)$ or between Onondaga and Schenectady counties $(p=.85)$. However, the differences in trends between each of the three counties and upstate New York was statistically significant, showing a greater downtrend in alcohol-related motor vehicle accidents in the individual counties.

The regression analyses do not provide any statistical evidence that I'm Smart provided a unique contribution to the decrease in numbers of alcohol-related accidents in Onondaga County. Downtrends were seen in the two comparison counties, as well as for the entire upstate New York area (minus Onondaga, Albany and Schenectady counties and New York City) and all started prior to 1982, the first year of I'm Smart. The downtrend since 1982 in Onondaga County was not statistically different than similar trends in the two comparison counties (Albany and Schenectady). Furthermore, there was a general downtrend in alcohol-related vehicle accidents in Onondaga County between 1974 and 1981, prior to the initiation of I'm Smart. In addition, the number of rides provided by I'm Smart since 1984 (the

\footnotetext{
${ }^{6}$ The regression analyses of trend lines did not account for possible autocorrelations among the various time periods.
} 
first year for data on number of rides) did not appear to be related to the changes in number of alcoholrelated vehicle accidents throughout the period.

\section{Methodology - SoberCab}

Data on total and alcohol-involved accidents were obtained, with alcohol-involved accidents (AIA) as a percent of total accidents used as the criterion variable. This variable was chosen by the Project Director to operationalize the contribution of alcohol to total accidents during each time period examined, which reduces the influence of several potentially confounding factors. (For example, the contribution of weather and law enforcement activity to total and alcohol-related accidents might differ between the comparison areas and comparison periods.) Property-damage, injury-producing, and fatal accidents were combined for the comparisons. These data were available and provided to us for (1) the city of Minneapolis from its Public Works Transportation Department for the 1989-92 period, and (2) the state and all counties from the Minnesota Department of Public Safety for the 1987-92 period. Our "statewide" data excludes data from Hennepin and Ramsey counties (where St. Paul and Minneapolis are located and the very large majority of SoberCab rides occur), with data from these counties combined and then compared with the "statewide" data to assess the possible effects of SoberCab. However, no data was available for a period prior to the initiation of SoberCab and its predecessor to conduct a before and after analysis.

Results - SoberCab

Using these data aggregated over the 4-year or 6-year periods, the following comparisons were made (see Table 23):

- Percent of alcohol-involved accidents in Minneapolis during SoberCab week versus the rest of the year when SoberCab is unavailable. Over the four years, these data showed an 11.75 AIA percent during Sober $\mathrm{Ca} b$ week versus a 13.75 AIA percent during the other 51 weeks. However, SoberCab serves a much larger area than metropolitan Minneapolis (c. 370,000 population), and the data necessary for all needed comparisons was not available.

- ALA percent in the two principal Twin Cities counties (Hennepin and Ramsey, c. 1.5 million population) during SoberCab week versus the rest of the year. These percents were nearly identical (averages $=6.53$ and 6.60 ) and their difference was non-significant. It is interesting that these are about half the rate in the more concentrated urban area.

- ALA percent in the two principal Twin Cities counties versus the rest of the state during SoberCab week. The 2-county percent was significantly lower than the rest of the state (averages $=6.53$ versus $8.32, p=.003$ ). However, this difference prevailed all year as well (averages $=6.60$ versus $9.19, \mathrm{p}<.001$ ), suggesting no special effect attributable to SoberCab.

- ALA percent in the two principal Twin Cities counties during SoberCab week versus three other highrisk holiday periods: Memorial Day weekend, July 4th, and Labor Day weekend. These findings are very interesting. The AIA percent was substantially and significantly higher during the three comparison holiday periods than the Christmas-New Year's Eve holidays for the 2-county area (averages $=12.3$ versus $6.53, \mathrm{p}=.001$ ). However, this finding cannot be attributed to SoberCab, 
since an equivalent difference between these holiday periods occurred statewide (averages $=17.76$ versus $8.32, p<.001)$.

Table 23

Percent of all accidents that are alcohol-related for Hennepin/Ramsey Counties and Statewide (excluding Hennepin and Ramsey Counties).

All year, Christmas-New Year's, and Other Drinking Holidays.*

\begin{tabular}{|c|c|c|c|c|c|c|}
\hline YEAR & $\begin{array}{r}\text { ALI } \\
\text { Hennepin/ } \\
\text { Ramsey }\end{array}$ & Statewide** & \multicolumn{2}{|c|}{ Christmas - NeW YeaR'S } & $\begin{array}{c}\text { OTHER } \\
\text { Hennepin/ } \\
\text { Ramsey }\end{array}$ & $\begin{array}{l}\text { IOLIDAYS } \\
\text { Statewide** }\end{array}$ \\
\hline 87 & 7.71 & 11.09 & 7.39 & 9.27 & 15.40 & 19.41 \\
\hline 88 & 6.42 & 9.35 & 6.54 & 7.61 & 8.43 & 18.36 \\
\hline 89 & 6.72 & 9.21 & 6.55 & 9.54 & 13.66 & 17.98 \\
\hline 90 & 7.03 & 9.50 & 5.84 & 7.01 & 13.14 & 18.61 \\
\hline 91 & 5.73 & 7.77 & 7.30 & 9.83 & 12.31 & 16.83 \\
\hline 92 & 6.00 & 8.22 & 5.56 & 6.66 & 10.87 & 15.35 \\
\hline Average & 6.60 & 9.19 & 6.53 & 8.32 & 12.3 & 17.76 \\
\hline
\end{tabular}

* Memorial Day Weekend, 4th of July, and Labor Day Weekend

** Statewide excluding Hennepin/Ramsey Counties.

Despite the absence of data prior to the institution of SoberCab, trends in number of accidents over the last six years between the Twin Cities and the rest of Minnesota, and between holiday periods within the Twin Cities were compared. Figures 3 and 4 show the number of alcohol-related crashes for the 1987 to 1992 period for Ramsey and Hennepin Counties and for the rest of the state minus these two counties. Figure 3 shows the data for the period of time of SoberCab's operation and Figure 4 for the entire year. Figure 3 shows similar trends during SoberCab's operational period for the two counties and the remainder of the state with the exception of a sharp upturn in alcohol-related crashes for the rest of the state from 1988 (plus New Year's period 1989) to 1989 (plus New Year's period 1990) and the decrease from 1989 to 1990 . For Hennepin and Ramsey counties combined, the increase in alcohol-related crashes was much smaller from 1988 to 1989 and remained about the same for the 1990 period.

Figure 4 shows the total year trend in alcohol-related crashes between 1987 and 1992 for Hennepin and Ramsey counties combined and for the remainder of the state. Again the trends during this period are similar. Of more relevance is the comparison of trends for the entire year versus the period of SoberCab operations for Hennepin and Ramsey counties. The lower lines in Figures 3 and 4 show similar trends with the exception of the upturn in number of alcohol-related crashes during the Christmas - New Year's Eve period in 1992-1993 versus the total year of 1992.

Another comparison involves other holiday periods when SoberCab does not operate. Based on NHTSA fatality data, the Memorial Day, July 4th, and Labor Day periods were chosen as comparisons to the Christmas-New Year's Eve period. Figure 5 shows the 1987-1992 trends in alcohol-related crashes in 
Figure 3

Minnesota Alcohol-Related Crashes

Christmas-New Year's Eve Period* 1987-1992

Hennepin and Ramsey Counties Combined vs. Remainder of State

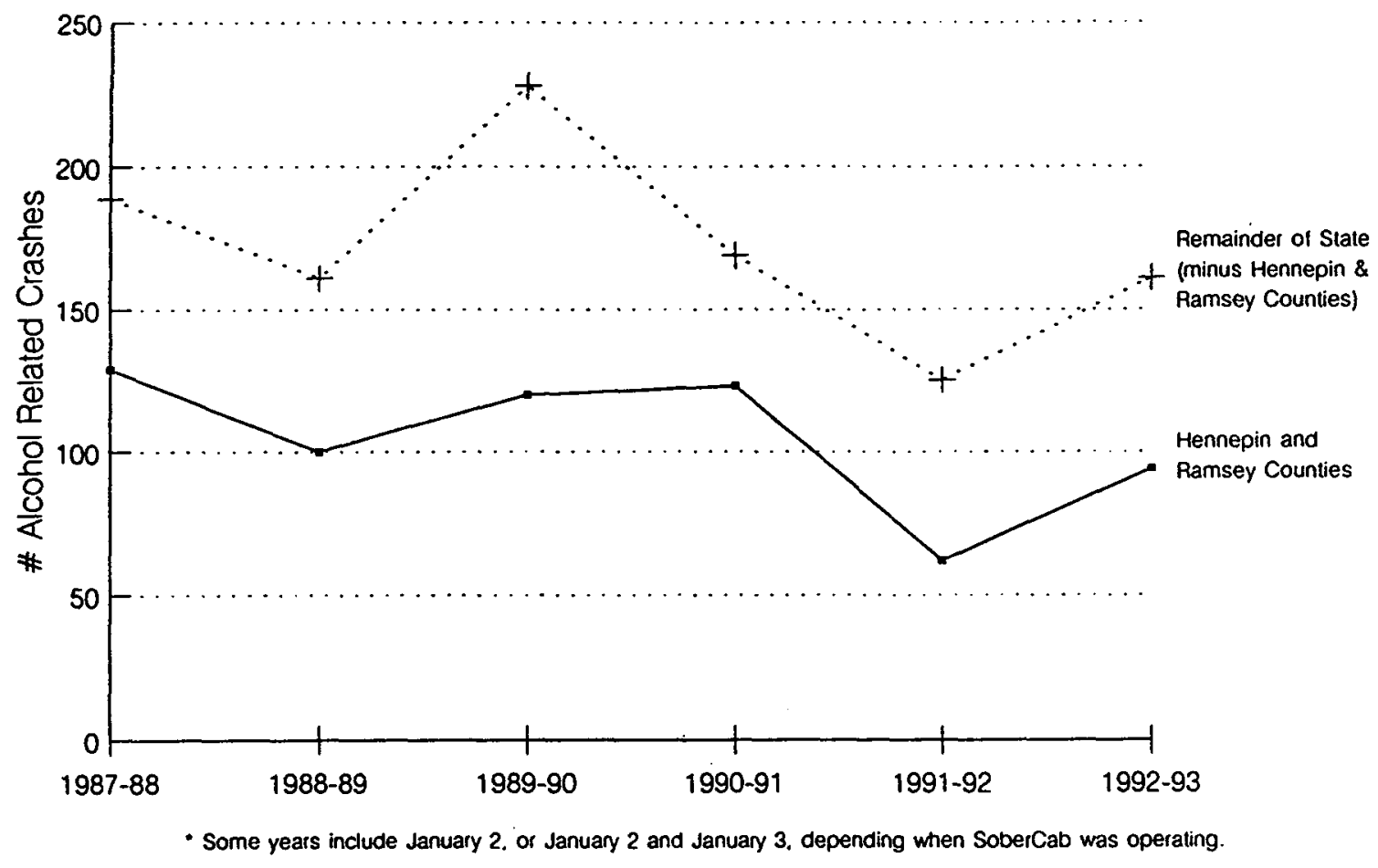

Hennepin and Ramsey counties versus the remainder of the state for the combined other three holiday periods. In addition, a line showing the alcohol-related crashes for the Christmas-New Year's Eve period for Hennepin and Ramsey counties combined is presented to compare to the other three holiday periods when SoberCab does not operate.

Comparing Hennepin plus Ramsey counties with the remainder of the state during the other three holiday periods shows a trend over the 1987-1992 period with the exception of a decrease in crashes in 1988 in the two counties versus the remainder of the state. Comparing trends for the Christmas-New Year's Eve period and the other three holiday periods combined in the two target counties does not show an effect during the latter period except for a decrease in Hennepin-Ramsey counties for 1991. Again, the 1987-1992 period did not show an obvious effect of SoberCab on alcohol-related crashes. However, a period of time prior to the inception of the RSP would be needed to make a meaningful assessment.

These findings indicate no statistically demonstrable impact of the SoberCab holiday RSP on alcoholinvolved accidents. However, they do reflect two unexpected and unexplained findings: (1) the AIA percent is consistently and substantially lower year-round and during all holiday periods in the Twin Cities area than throughout the rest of Minnesota; and (2) the AIA percent is consistently and substantially lower in Minnesota during the Christmas-New Year's Eve holidays than other high-risk holiday periods. However, in absolute numbers the Christmas holidays produce twice the total accidents and as many alcohol-involved accidents as the other three holidays combined. 
Figure 4

Minnesota Alcohol-Related Crashes

Total Year 1987-1992

Hennepin and Ramsey Counties Combined vs. Remainder of State

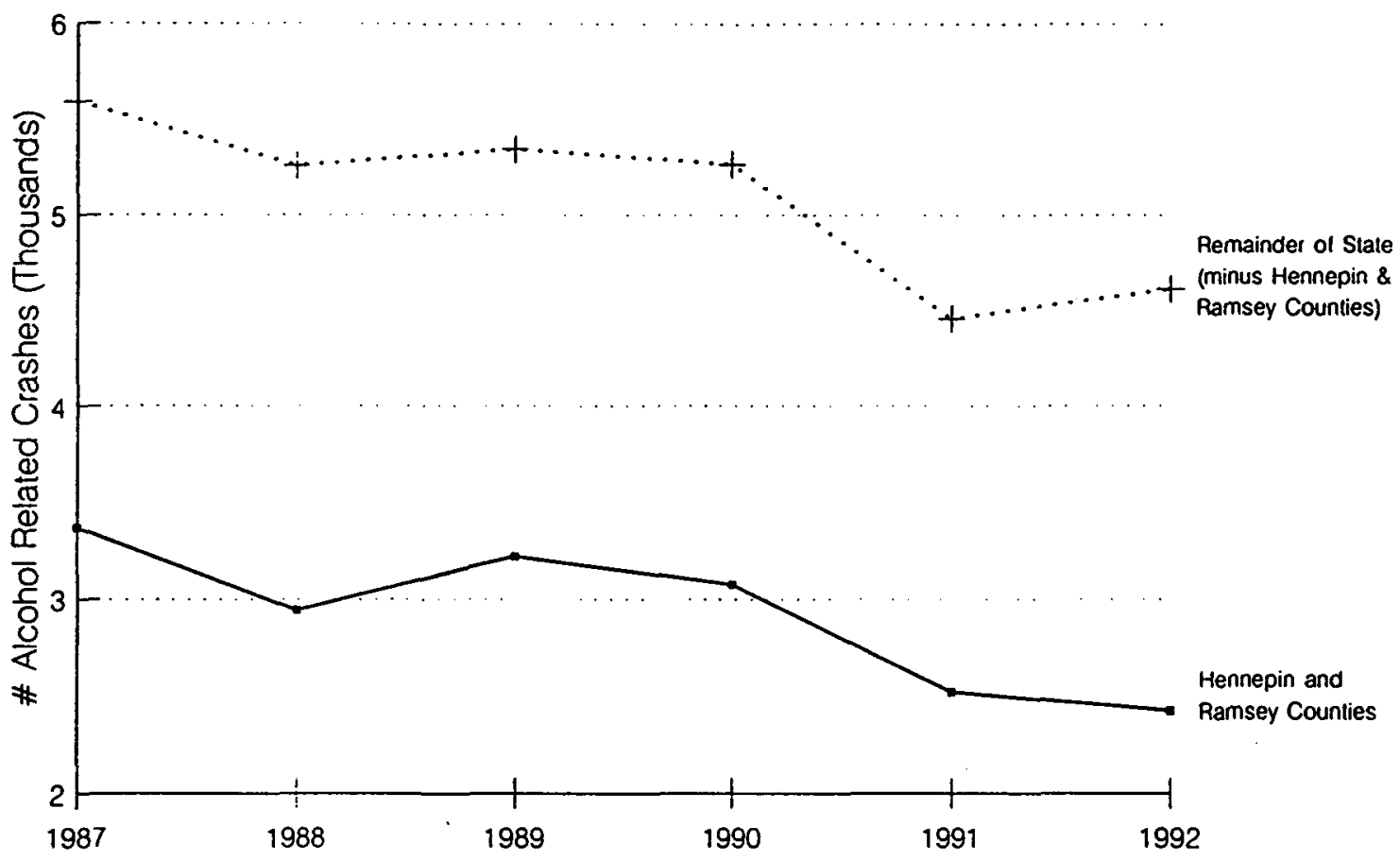

Summary

The effects of RSPs on reducing DWI incidents is very difficult to demonstrate due to the small potential effects of RSPs on DWI statistics from rides that reduce alcohol-related trips. For example, if each ride provided by I' $m$ Smart saved one alcohol-related trip, approximately 2,600 to 3,000 in each of the last three years, what percent of these trips would have become a DWI? Given a $.5 \%$ probability (an estimate higher than that provided in studies reported by NHTSA; Fell, 1993) of all impaired trips resulting in a DWI arrest ${ }^{7}$ and a lower percent for alcohol-related crashes, injuries or fatalities, only about 13 to $15 \mathrm{DWI}$ arrests would be reduced during a period of one year plus a few more crashes and probably no fatalities. Since DWI arrests are the most common DWI statistic, the decrease attributable

\footnotetext{
7. NHTSA estimates that the probabilities of a driver being arrested with a BAC level at or above the legal limit is 1 in 200 to 1 in 2,000 depending on location. These estimates were based on several samples of roadside BAC surveys (Fell, 1993). The percent of those in the surveys found to have BAC levels at or above the legal limit were used to estimate the number of trips made by legally intoxicated drivers. The number of DWI arrests made was divided into the estimated number of alcohol-related trips to derive the probabilities. The limits of the sampling for the several roadside surveys make these numbers somewhat speculative. The proportion would probably increase slightly if alcohol-related crashes and fatalities were added to DWI arrests. However, by any calculation, few trips involving drivers with BACs above the legal limit show up in any DWI statistics. Based on a national telephone survey of drivers done by Schulman, Ronca and Bucuvalas, Inc. for NHTSA in 1991 (NHTSA, 1992), 71\% of the drinkers said they drove within two hours of drinking at least once within the past year. Multiplying the percent of the driving sample who reported driving within two hours after drinking by the average number of times this occurred and by the estimated number of drivers in the country provided an estimate of the total number of drinking driving trips made. The number of drivers arrested for DWI in the country was divided by this estimate to produce an estimate of 1 arrest per 233 alcohol-related trips (.4\%). It should be noted that these estimates do not only involve legally impaired drivers but would include all legally impaired drivers within the sample of those who drove within two hours of drinking since may drivers using this criterion would not be legally impaired.
} 
Figure 5

Minnesota Alcohol-Related Crashes

Comparisons of Cristmas-New Year's Eve Period* with Other Holiday Periods Combined Hennepin and Ramsey Counties Combined versus Remainder of State

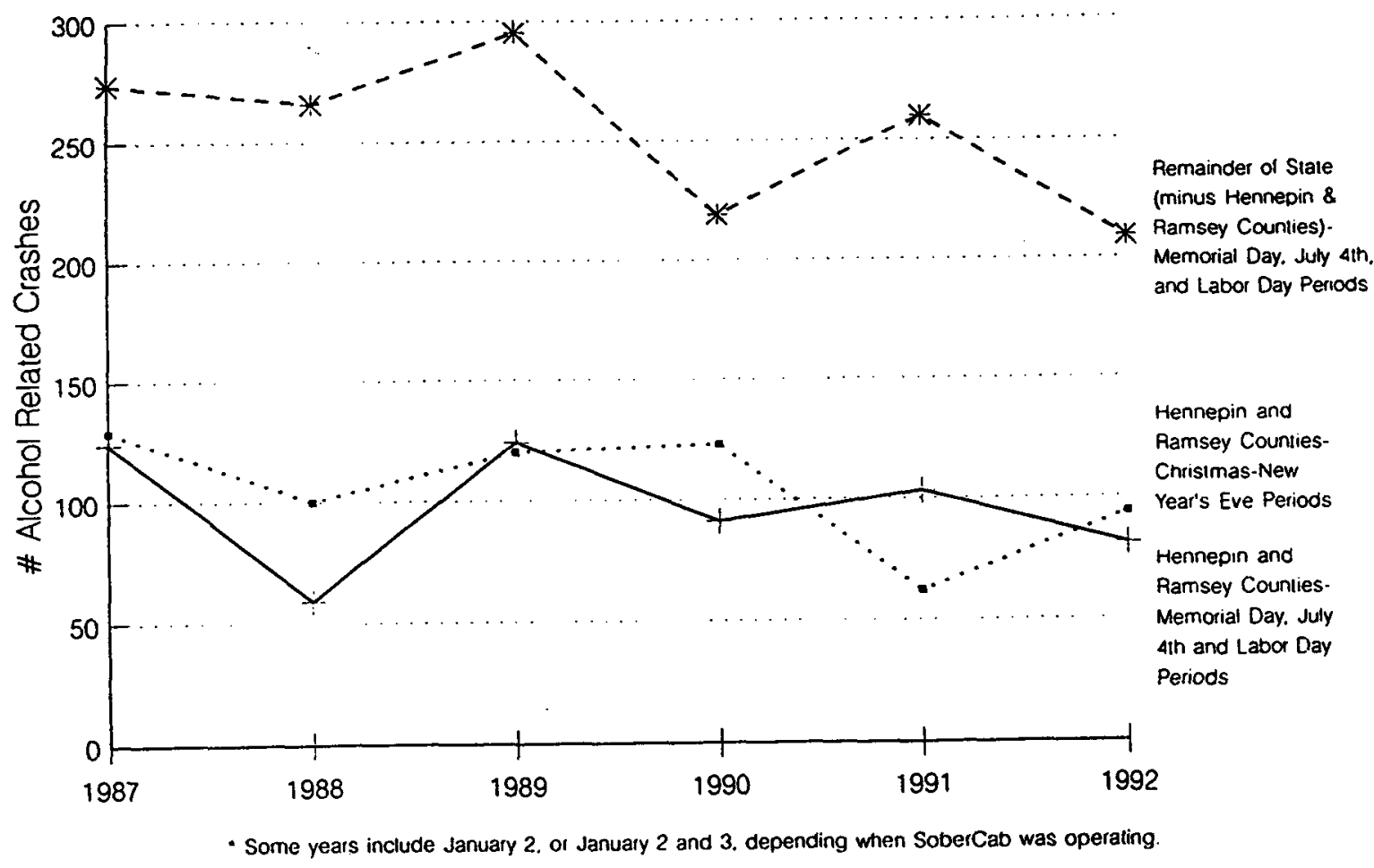

to I'm Smart would not likely be statistically detectable given the number of arrests and the variability of this data. An even lower proportion of alcohol-related crashes, injuries and fatalities could be expected from reducing 2,600 to 3,000 alcohol-related trips in one year since the probabilities of these events are probably lower than $.5 \%$ for arrest of an impaired driver. Extrapolating from the ratio of the number of DWI arrests to the estimated number of impaired drivers (about .5\%) and using the ratio of the number of DWI arrests to the number of alcohol-related crashes in Onondaga County (approximately 5 to 1 during 1979-1991) we estimate close to a $.1 \%$ probability of an impaired driver being involved in a reported alcohol-related crash. Thus, looking at DWI statistics over time from Onondaga County or comparing Onondaga County with comparison areas without an RSP (e.g., the Albany area or the rest of the state) would be unlikely to detect changes brought about by reducing alcohol-related trips through rides given by I'm Smart. A similar argument for Sober $\mathrm{Cab}$ is much stronger since only about $30 \%$ to $35 \%$ of the Sober $C a b$ rides may prevent alcohol-related trips as discussed above. In addition, the time frame is so short (one-week) and the number of alcohol-related crashes small, that changes are unlikely to be detected in any of the DWI statistics as a function of the rides provided by the RSP.

An inability to show that the RSPs statistically contribute to reduction in alcohol-related crashes does not deny the utility of these programs as part of a general traffic safety strategy. Undoubtedly some arrests, crashes, injuries and fatalities have been saved over the years by the rides provided. The publicity and awareness fostered by the two RSPs have probably contributed to greater traffic safety in the community. However, the statistical effects, if any, of rides provided by RSPs are very unlikely to be detected in analyses of trends in DWI statistics. 
Evaluation Question: Did a targeted publicity campaign change awareness and knowledge of I'm Smart among the population to whom the publicity was directed?

Did a targeted publicity campaign change awareness and knowledge of I'm Smart among the population to whom the publicity was directed?

The issue of use by ethnic, racial, age, and lifestyle minorities was examined within the context of the overall question: who uses the RSP. We elected to investigate this issue in Syracuse rather than the Twin Cities for several reasons due to time and resource contraints.

(1) According to I'm Smart, few members of minority groups including African-American, Hispanic, and Native American have used the ride service program. Although SoberCab uses far more drivers than I'm Smart and serves a much larger, demographically diverse metropolitan area, identification of minority use and minority establishments was much more difficult.

(2) Data from the DMV surveys showed that those who identified themselves as African-American and Hispanic showed the lowest name recognition (41\% compared to $64 \%$ for Whites). The University of Minnesota survey sample included only one percent African-American, one percent Asian, and one percent "other." Of nine African-American respondents, eight (89\%) knew of SoberCab Thus, our general population sample in the Twin Cities did not provide us information on minority use and awareness comparable to the Syracuse DMV surveys.

(3) The year-round RSP, I'm Smart, provided more opportunity for extended publicity and extended measurement of minority RSP use, as well as pre-post comparison data from the two DMV surveys on minority awareness.

Both study sites have comparable demographics, so the publicity manipulation did not need to be conducted in both sites to determine the effects. Therefore, Syracuse was chosen as the site for increased/improved publicity. A special publicity campaign was developed by I'm Smart using information gathered from the DMV surveys and customers of alcohol-serving establishments. It was carried out by the RSP to inform these groups and others (gay men, lesbians, university students and various religious groups) about I'm Smart. Previously there had been no specific targeting of these communities.

A general awareness campaign was conducted in December 1992. The special populations-targeted awareness campaign was conducted from March through May, 1993. Both had two objectives: to increase awareness of DWI risks, and to increase awareness of I'm Smart as an alternative to driving after drinking. Six special populations were targeted: Latinos, African-Americans, Native Americans, gay men and lesbians, university students, and religious communities (e.g., there are distinct Irish Catholic and Italian Catholic communities in Syracuse). In March, meetings were arranged with leaders from each community to craft community-specific messages, and promotional materials were then developed including brochures in both English and Spanish.

During April, a media campaign was conducted to coincide with a local "Alcohol Awareness Month" including distribution of brochures and flyers, and use of broadcast (Public Service Announcements (PSAs) and interviews), print (editorials, feature articles), and outdoor (billboards) media. This involved: (1) for Latinos, four billboards in their community, coverage on a community program and a talk show on two radio stations, and coverage in a daily and a weekly newspaper; (2) for African-Americans, three community billboards, PSAs on five radio stations and an interview show on another, and print coverage in a weekly newspaper and the NAACP Newsletter; (3) for the gay \& lesbian community, broadcast 

population to whom the publicity was directed?

coverage on a Sunday discussion program and print coverage in two weekly and one bi-monthly publications; (4) for Native Americans, coverage in the bi-monthly North American Indian Club of Syracuse Newsletter; (5) for the university community, coverage in Syracuse University's Daily Orange student newspaper and the university radio station; and (6) for religious communities, coverage in two monthly religious papers, The Jewish Observer and The Catholic Sun. Point-of-purchase displays and flyers were distributed throughout the targeted communities, and the program participated in several community events.

During May, I'm Smart conducted a concentrated follow-up campaign with companies employing minorities to provide employee awareness seminars and encourage member organizations to make use of the I'm Smart monthly bulletin.

\section{Methodology - I'm Smart}

Measurement instruments were not available to us in order to assess the effectiveness of the publicity campaigns targeted towards gay men and lesbians, the religious communities, and the student population. The following two methods were used to measure changes in knowledge and use of I'm Smart by ethnic minority group members only: (1) DMV surveys conducted in the Fall of 1992 and June 1993; and (2) informal discussions with customers of alcohol-serving establishments conducted during the fall of 1992 and June 1993.

Statistical analyses of differences between the 1992 and 1993 discussions with customers are limited by the small number of subjects identified as African-American, Latino or Native American. Neither university affiliation, religious preference, nor sexual orientation was asked on the DMV surveys or of the customers in alcohol-serving establishments.

\section{$\underline{\text { Results- I'm Smart }}$}

\section{- $\quad$ DMV Surveys}

In the 1992 survey, 30 individuals or $6 \%$ of the sample identified themselves as African-American, Hispanic (Latino) or Native American. About two-thirds of these individuals identified themselves as African-American. In the 1993 survey, the number was 21 and the percent of the total sample was the same as in 1992, 6\%. Sixteen of the 21 identified themselves as African-American. In each year, slightly over one-quarter of the total sample did not answer the open-ended question on ethnic group (27\% in 1992 and $28 \%$ in 1993).

There are no statistically significant changes from 1992 to 1993 among individuals classified as AfricanAmerican or Hispanic in awareness of an RSP in the community nor the percent who reported having heard of I'm Smart. There was an increase of about 6\% from 1992 to 1993 in awareness of an RSP. Within that group, nearly $5 \%$ checked having heard of I'm Smart, but the changes were much too small to indicate that the differences did not come from the same population in terms of awareness and name recognition.

In 1992, none of the 9 African-Americans and Hispanics who reported hearing of I'm Smart described what an RSP was in response to the open-ended knowledge question. In 1993, 5 of the 10 African- 
Evaluation Question: Did a targeted publicity campaign change awareness and knowledge of I'm Smart among the population to whom the publicity was directed?

Americans and Hispanics who heard of I'm Smart described the elements of an RSP in answering the question. Thus, members of the two minority groups studied who had heard of I'm Smart appeared to know more about an RSP or I'm Smart after the publicity campaign.

\section{- Discussions with Customers in Alcohol-Serving Establishments}

Combining the 1992 and 1993 samples, a total of 14 individuals were identified as African-American or Hispanic. This was $2 \%$ of the total sample of 577 customers. There was no change in the percent of African-American and Hispanic customers who said they had heard of I'm Smart (50\% in 1992 and 50\% in 1993).

It is important to note that the 1993 DMV surveys and discussions with customers were conducted shortly after the end of the targeted publicity campaign. This created a serious limitation on measuring evaluation impacts due to the short time allowed for the publicity intervention followed by the second wave of data collection. As a result, one must be cautious in the interpretation of the data for the publiticy campaign.

\section{RESEARCH SUMMARY AND CONCLUSIONS}

Based on the results presented in the previous section, several major conclusions can be drawn about each of the RSPs in the study and about both programs. Each program has a long history for this type of service. I'm Smart has been operating for about 11 years and SoberCab for 10 years. They have demonstrated their viability. For I'm Smart the number of rides provided has shown a strong upward trend through 1990. The number of SoberCab rides provided has been stable for the past few years. Both programs have adequate funding through the private sector and I'm Smart is operated as a for-profit business.

\section{I'm Smart}

Name recognition is relatively high among a general population of drivers who went to the Department of Motor Vehicles offices in Syracuse. Among Onondaga County residents who completed a questionnaire at the RID booth at the New York State Fair, about two-thirds of the respondents had heard of a ride service program and 35\% named I'm Smart. As expected, a much higher proportion of Onondaga County residents had heard of an RSP and I'm Smart than fairgoers who resided elsewhere, including contiguous counties. Among customers in a sample of alcohol-serving establishments there was much higher name recognition, approximately $78 \%$. On the DMV and RID surveys, a relatively small percent of those with name recognition described, in writing, what I'm Smart or an RSP does. On the DMV surveys slightly over $30 \%$ of those who said they had heard of I'm Smart described I'm Smart, the basic elements of an RSP, indicated they had used the RSP or were members. About one-third in the 1992 sample and $40 \%$ in the 1993 sample did not respond to the open-ended question about knowledge. Many who did describe I'm Smart or an RSP did not mention the membership requirement. On the RID survey, slightly less than $25 \%$ who said they had heard of an RSP wrote a description which showed an understanding of what an RSP was or described I'm Smart. 
Among customers of alcohol-serving establishments who reported having heard of I'm Smart, slightly under $80 \%$ said they knew how to use the service (although more detailed data on what they knew about I'm Smart was not collected for most customers).

Thus, name recognition is high, especially among those who may be considered to be more likely to need an RSP (customers in alcohol-serving establishments), most of whom also said they knew how to use the service. Name recognition among larger populations measured by DMV and RID surveys is relatively high but much lower than among establishment customers.

There is some evidence from the DMV surveys that those who potentially may need an RSP, measured by drinking behavior, have a somewhat higher level of name recognition than others. Those who drink alcoholic beverages were more likely to have heard of I'm Smart than those who did not. Respondents who said they had at times felt unsafe to drive after drinking and the few who said they had a DWI arrest or citation had higher levels of name recognition than those who did not. Those with higher estimates of their own level of tolerance before it would become unsafe to drive were also more likely to have heard of I'm Smart. On the RID survey, among Onondaga County residents, those who said they had at times felt unsafe to drive after drinking were more likely to have named I'm Smart in response to an open-ended question than those who did not.

Discussions with customers in alcohol-serving establishments did not show statistically significant relationships between name recognition and measures which may be thought to indicate potentially greater need for an RSP, such as general drinking behavior or measures of drinking behavior that evening. However, customers who said they drove to the establishment had a higher level of name recognition than those who did not. This is an important consideration in terms of those who potentially may need the service.

Among the demographic variables that were related to name recognition, employment status showed the strongest relationship in both the DMV and establishment customer samples. This is to be expected since many individuals know of and use I'm Smart through their employers. Whites were more likely to have heard of I'm Smart than African-Americans and Hispanics in both the DMV and customer samples.

The utilization of rides provided by I'm Smart shows a strong upward trend over the years. Between 2,600 and 3,000 rides were given during each of the years, 1990 through 1992, with the peak in 1990. Increases in number of rides were dramatic from 1984 through 1990 . The number of organizations belonging to I'm Smart has been relatively stable over the past few years. Thus, the greater number of rides may reflect greater knowledge and acceptance among those eligible for the service.

Among a sample of I'm Smart users, drivers judged about $86 \%$ as somewhat or very intoxicated. This data, along with the fact that users must have a vehicle that is driven by I'm Smart, indicates that a very large proportion of users feel impaired, and all are drivers; thus, alcohol-related trips are "saved".

I'm Smart is generaiyy operated in an efficient manner based on a small sample of drivers' logs where wait time could be calculated. Logs where call and pick-up time were recorded showed an average wait time of 21.5 minutes, with a median time of 18 minutes and a modal time of 15 minutes. Only $11 \%$ of the calls resulted in a no pick-up. As a convenience to users, I'm Smart will accept pre-arranged pick-up times if the customer calls in advance. Almost $18 \%$ of the rides were pre-arranged based on the sample of drivers' logs. I'm Smart also provides ride services from private residences, corporate offices, medical facilities, and corporate parties. Payment for rides for members were most often made with a corporate 
membership card. In general, it can be said that I'm Smart is convenient for individuals who work for member organizations.

I'm Smart has been operating for about 11 years. It is well established in the community and is a profitable business venture depending on no public funds. As such, it provides a potentially attractive model to businesses in other communities. It has shown itself to be self-sustaining through paid memberships by a well-diversified group of organizations (private, public, profit and non-profit) as well as alcohol-serving establishments. The total number of member organizations has been stable over the past few years. A questionnaire to corporate members of I'm Smart (public and private) showed very positive opinions of the various services provided, including all aspects of the safe ride service. The RSP has received much favorable publicity over the years as well as recognition beyond the community. I' $m$ Smart has employees who sell the service to various organizations in the community. There were very few negative comments made by DMV and RID survey respondents. Among seven owners of member alcohol-serving establishments who were interviewed, several expressed concern with the costs, but still felt it was useful to them and to their customers.

Data obtained from the DMV surveys, RID survey and customers of alcohol-serving establishments showed that I'm Smart or an RSP is very infrequently mentioned as an alternative that the individual has used or plans to use. Most drinkers have used alternatives when they felt unsafe to drive after drinking, but most have also driven impaired. The most frequent alternatives checked in the surveys were designated driver, family or friends and calling someone to drive them. Some also say they have used taxis, walked or stayed overnight. These alternatives appear to be more "natural" methods than an RSP to avoid driving when intoxicated or feeling unsafe to drive. The data implies that, in addition to knowledge of I'm Smart, there needs to be a change in the thinking of potential users that addresses their resistance to using I'm Smart if use is to increase substantially.

\section{- SoberCab}

Level of name recognition for SoberCab was exceptionally high, both among a general population sample from a telephone survey and among customers of alcohol-serving establishments. Based on the telephone survey, those who were employed, had higher incomes, were older, were married and were White were statistically more likely to have heard of Sober Cab. Customers of alcohol-serving establishments with name recognition had higher estimated $\mathrm{BAC}$ as calculated by two different formulae based on reported number of drinks, time spent drinking and weight. In general, based on data from customers, there is limited evidence that there is higher name recognition among those who may be at higher DWI risk.

SoberCab has provided some 700-1200 rides each year during the 1989 through 1992 Christmas-New Year's Eve periods. The largest number of rides (43\% to $44 \%$ of the total) are provided during the New Year's Eve - New Year's Day period.

Based on a small sample of discussions with SoberCab users, almost all were judged as impaired. The users judged themselves unsafe to drive and almost all had been drinking extensively that evening. Another, smaller sample of users were judged by drivers as somewhat intoxicated or drunk. From the former sample only 5 of $17(29 \%)$ said they had driven that evening. Thus, only that percent of alcoholrelated trips were saved according to our definition. Most users questioned said they would not drive even if SoberCab were not available. Sober $C a b$ does not appear to be the only viable alternative to driving among impaired individuals who use the service. Of the small number of users $(N=10)$ who responded to the questions of using alternatives to Sober $C a b$ only two said they would drive. This limited 
evidence shows that a large proportion of SoberCab users would not have driven even if the RSP was not available. Thus, only a relatively small percentage of SoberCab rides may save alcohol-related trips.

SoberCab, like I'm Smart, has been in operation for almost 10 years. It has remained self-sustaining. For several years the costs for rides and some advertising have been divided among 24 hospitals who also provide the volunteers to answer the phones. The low cost per hospital, the relatively high number of rides during a short period and its recognition among a very large percent of the population bodes well for its continuation.

With regard to evaluation of SoberCab's effectiveness using DWI data, the considerations discussed on page 65 apply. In addition, only about $30 \%$ of the users said they had driven to where they were picked up. Given approximately 700 rides and about $30 \%$ alcohol-related trips saved and a probability of an alcohol-related trip resulting in a DWI of .5 in 100, there is little chance of detecting any effects due to the RSP. Alcohol-related crashes during the 1987-1992 period did not show strong differences during the Christmas - New Year's Eve period between the two counties where SoberCab chiefly operates and the remainder of the state. However, no data prior to the start of the RSP was available to allow meaningful evaluation of effects on alcohol-related crashes.

\section{General Conclusions and Recommendations}

Both RSPs studied are successful in terms of name recognition on the part of the general public and the drinking and driving public, including those who may be at elevated risk for DWI. Both operate in the private sector requiring no public funds. In addition to providing rides, both RSPs aid in maintaining and increasing awareness of drinking and driving and the use of alternatives. I'm Smart does this through training of corporate members, and servers and managers of member alcohol-serving establishments. SoberCab provides holiday season publicity about drinking and driving and using SoberCab as an alternative.

Despite the high level of name recognition among the general public, the driving public and the drinking public, relatively few use the services. Based on the survey and interview data, there are several more frequently utilized alternatives to drinking and driving. The most frequent alternatives mentioned were those that occur in the social context of drinking (e.g., use of a designated driver, family or friends). These alternatives, as well as commercial taxis should be encouraged. To increase the use of RSPs in drinking driving decisions they need to become conscious, attractive, easily accessible, and affordable alternatives. Since name recognition as well as knowledge of what an RSP does is widespread, this knowledge needs to be incorporated into the individual's decision-process that makes it a higher frequency alternative to driving. The membership aspect of I'm Smart limits its use as an alternative for a large number of individuals who have heard of it, understand the service, and think well of the idea, but do not belong to member organizations.

The I'm Smart model includes important prevention services, which makes this an attractive model to replicate. The organization has developed relationships with the private and public sectors and enjoys an excellent reputation in the community. By creating these linkages, the prevention model is shared among many stakeholders and may contribute to a safer community.

In order to make RSPs a more frequently used alternative to driving, there needs to be expanded accessibility. Convenience of the service, especially short wait times, transporting the users' vehicle, and rigorous confidentiality should be stressed through publicity messages. 
Supplementary funding sources such as health organizations, alcohol and drug treatment agencies, insurance companies, the hospitality industry, manufacturers and distributors of alcoholic beverages, local government agencies, transportation companies, and service clubs might be recruited to enlarge the funding base, thereby reducing costs and making membership more accessible.

For a holiday RSP, suggestions for increasing usage include additional vehicles for New Year's Eve to provide shorter wait times and to reduce no loads. This might require special incentives for taxi drivers who do not now participate in SoberCab. Again, it is important to translate knowledge or name recognition of the service into a viable decision alternative for those who otherwise may have driven. The Sober $C a b$ number needs to be conspicuously posted in each drinking establishment.

RSPs are useful parts of an overall traffic safety strategy for communities even if their efforts cannot be statistically demonstrated in terms of DWI events (arrests, crashes, injuries and fatalities). The publicity and services provided must be considered as an integral part of the program in addition to the rides provided.

\section{RESEARCH ISSUES AND RECOMMENDATIONS}

Research should focus on the decision context within which drinking and driving occurs. Further research should investigate how drinking-driving decisions are made by various types of individuals in various situations. Within this framework, the role of RSPs as an alternative should be investigated. This study found that very few individuals appeared to consider RSPs as an alternative to driving. Research needs to focus on how name recognition and knowledge of RSPs can be translated into viable alternatives for individuals to consider, especially among those who would be most likely to drive and not use other alternatives. This would include examination of alternative media and content of messages as well as how

RSPs can operate so as to maximize utilization by those who otherwise would have driven while feeling intoxicated or unsafe to drive. Research is needed that explores perceived or actual barriers to using RSPs in more depth than was possible in the present study. 


\section{REFERENCES}

Caudill, B.D., Kantor, G.C. and Ungerleider, S. (1990) Driving while intoxicated: Increased deterrence of alternative transportation for the drunk driver. J. of Substance Abuse, 2, 51-67.

Fell, James - National Highway Traffic Safety Administration, Personal Communication 1993

Harding, W., Apsler, R. and Goldfein, J. (1988a). The assessment of ride service programs as an alcohol countermeasure: Final technical report. Washington, D.C.: United States Department of Transportation, National Highway Traffic Safety Administration. DOT HS 807290.

Harding, W., Apsler, R. and Goldfein, J. (1988b). A users guide to ride service programs. Washington, D.C.: United States Department of Transportation, National Highway Traffic Safety Administration. DOT HS 807146.

Molof, M. J. and Kimball, C. (1992). Server training models to reduce driving under the influence: An economic study, Final progress report to the National Institute on Alcohol Abuse and Alcoholism. Eugene, OR: Integrated Research Services, Inc.

Molof, M.J. (1993). Evaluation of the Oregon alcohol server training program, Report on interviews with customers of licensed alcohol-serving establishments in Oregon. Eugene, OR: Integrated Research Services, Inc.

National Highway Traffic Safety Administration (May 1992). Fact Sheet, Influence of BAC Limits on Drinking driving Decisions. Washington, D.C.: United States Department of Transportation.

Segal, R. \& Sisson, B.V. (1985). Medical complications associated with alcohol use and the assessment of risk of physical damage. In T.E. Bratter and G.G. Forrest (Eds.) Alcoholism and Substance Abuse: Strategies for Clinical Intervention. Free Press: New York. 
Appendix A

Summary of the Evaluation Questions, Data Collection Instruments/Sources of Data Analytic Approaches and Limitations on Answers

\begin{tabular}{|c|c|c|c|}
\hline EVALUATION QUESTION & $\begin{array}{l}\text { INSTRUMENTS - } \\
\text { DATA SOURCES }\end{array}$ & ANALYTICAL APPROACHES & LIMITATIONS \\
\hline $\begin{array}{l}\text { Level of Community } \\
\text { Awareness }\end{array}$ & $\begin{array}{l}\text { Syracuse DMV Surveys; } \\
\text { RID Survey; Univ of } \\
\text { Minnesota Survey; Inter- } \\
\text { views with customers of } \\
\text { alcohol-serving } \\
\text { establishments } \\
\end{array}$ & $\begin{array}{l}\text { Descriptive estimates of } \\
\text { name recognition; percent } \\
\text { who indicate knowledge of } \\
\text { what RSP does; Comparison } \\
\text { among different samples }\end{array}$ & $\begin{array}{l}\text { Representativeness of } \\
\text { DMV, RID and Custo- } \\
\text { mer samples; Knowledge } \\
\text { of RSP obtained through } \\
\text { written answers to open- } \\
\text { ended questions } \\
\end{array}$ \\
\hline $\begin{array}{l}\text { Awareness by Groups at } \\
\text { Elevated Risk for DWI }\end{array}$ & Same as above & $\begin{array}{l}\text { Comparisons between indi- } \\
\text { viduals with various levels of } \\
\text { drinking; Comparisons of in- } \\
\text { dividuals who have and have } \\
\text { not reported driving when } \\
\text { feeling unsafe after drinking; } \\
\text { Comparison of customers } \\
\text { with different levels of } \\
\text { indices of intoxication. }\end{array}$ & $\begin{array}{l}\text { Same as above; } \\
\text { Inaccuracies of self- } \\
\text { reported drinking and } \\
\text { drinking and driving } \\
\text { behavior; Inaccuracies of } \\
\text { self-reported intoxication } \\
\text { and data used to } \\
\text { estimate BAC. }\end{array}$ \\
\hline $\begin{array}{l}\text { Level of RSP Ridership } \\
\text { and Characteristics of } \\
\text { Riders }\end{array}$ & $\begin{array}{l}\text { RSP records; Ride-along } \\
\text { interviews with users } \\
\text { (SoberCab); Drivers' } \\
\text { observations of users (I'm } \\
\text { Smart and SoberCab) }\end{array}$ & $\begin{array}{l}\text { Description of number of } \\
\text { rides, number of different } \\
\text { pick-up locations and other } \\
\text { characteristics of the rides; } \\
\text { Description of trends in } \\
\text { number of rides; Description } \\
\text { of characteristics of users. }\end{array}$ & $\begin{array}{l}\text { Small sample of Sober- } \\
\text { Cab users; Limited data } \\
\text { about I'm Smart users } \\
\text { due to policy of confi- } \\
\text { dentiality; Inaccuracies } \\
\text { of drivers' judgements; } \\
\text { Inaccuracies of riders } \\
\text { self-report (SoberCab). }\end{array}$ \\
\hline $\begin{array}{l}\text { Are Users of the RSPs } \\
\text { Targets of the Program? }\end{array}$ & $\begin{array}{l}\text { RSP system descriptions; } \\
\text { Data on riders stated above } \\
\text { including limited data on } \\
\text { how SoberCab users would } \\
\text { have gotten home in } \\
\text { absence of the RSP. }\end{array}$ & $\begin{array}{l}\text { Estimate of the percent of } \\
\text { riders who are not at high } \\
\text { risk of alcohol-related } \\
\text { crashes (not intoxicated or } \\
\text { would not have driven). }\end{array}$ & Same as above. \\
\hline $\begin{array}{l}\text { Is the RSP Conducted in } \\
\text { an Efficient and } \\
\text { Convenient Manner? }\end{array}$ & $\begin{array}{l}\text { Procedures for accessing } \\
\text { and dispatching rides; I'm } \\
\text { Smart drivers logs (time } \\
\text { from call to pick-up); I'm } \\
\text { Smart computer file (no } \\
\text { pick-up, method of pay- } \\
\text { ment); SoberCab records; } \\
\text { Mail survey of I'm Smart } \\
\text { corporate members. }\end{array}$ & $\begin{array}{l}\text { Means and variability of } \\
\text { time from call to pick-up } \\
\text { (I'm Smart); Percent of all } \\
\text { calls where there is no pick- } \\
\text { up; Ratings related to } \\
\text { efficiency and convenience } \\
\text { from corporate members of } \\
\text { I'm Smart. }\end{array}$ & $\begin{array}{l}\text { No data on time from } \\
\text { call to pick-up for } \\
\text { SoberCab; Limited } \\
\text { sample of respondents to } \\
\text { I'm Smart corporate } \\
\text { member survey. }\end{array}$ \\
\hline $\begin{array}{l}\text { Are the Programs Self- } \\
\text { Sustaining? }\end{array}$ & $\begin{array}{l}\text { Funding sources for each } \\
\text { RSP including number of } \\
\text { corporate and establishment } \\
\text { members of I'm Smart; Mail } \\
\text { Survey of corporate mem- } \\
\text { bers of I'm Smart; Inter- } \\
\text { views with member estab- } \\
\text { lishments of I'm Smart; }\end{array}$ & $\begin{array}{l}\text { Estimates of stability of } \\
\text { funding sources (corporate } \\
\text { memberships for I'm Smart } \\
\text { and hospital funding for } \\
\text { SoberCab); }\end{array}$ & $\begin{array}{l}\text { Use of past and present } \\
\text { information to make } \\
\text { predictions. }\end{array}$ \\
\hline
\end{tabular}




\begin{tabular}{|c|c|c|c|}
\hline EVALUATION QUESTION & $\begin{array}{l}\text { INSTRUMENTS - } \\
\text { DATA SOURCES }\end{array}$ & ANALYTICAL APPROACHES & LIMITATIONS \\
\hline $\begin{array}{l}\text { Would RSP Users Employ } \\
\text { Means of Transportation } \\
\text { Other than Driving Their } \\
\text { Vehicle, in Absence of the } \\
\text { RSP? }\end{array}$ & $\begin{array}{l}\text { Talks with users of } \\
\text { SoberCab. }\end{array}$ & $\begin{array}{l}\text { Percent of SoberCab users } \\
\text { who report they would have } \\
\text { used means other than } \\
\text { driving a vehicle. }\end{array}$ & $\begin{array}{l}\text { Limited sample of } \\
\text { SoberCab users. No } \\
\text { direct data from users of } \\
\text { I'm Smart. }\end{array}$ \\
\hline $\begin{array}{l}\text { What Alternatives to } \\
\text { Driving After Drinking do } \\
\text { Drinkers Report Using? }\end{array}$ & $\begin{array}{l}\text { Discussions with alcohol- } \\
\text { serving establishment } \\
\text { customer; DMV surveys in } \\
\text { Albany and Syracuse; RID } \\
\text { survey; Data on use of alter- } \\
\text { native means to driving } \\
\text { after drinking from users } \\
\text { and customers in the Twin } \\
\text { Cities. }\end{array}$ & $\begin{array}{l}\text { Estimate of percent of DMV } \\
\text { survey respondents and } \\
\text { alcohol-serving } \\
\text { establishment customers who } \\
\text { say they use alternative } \\
\text { means to driving after } \\
\text { drinking. }\end{array}$ & $\begin{array}{l}\text { Indirect data on use of } \\
\text { alternative means; } \\
\text { Inaccuracies in reporting } \\
\text { by respondents on DMV } \\
\text { surveys and customers } \\
\text { and SoberCab users. }\end{array}$ \\
\hline $\begin{array}{l}\text { How Many Alcohol- } \\
\text { Related Trips are Reduced } \\
\text { Due to the use of the } \\
\text { RSP? }\end{array}$ & $\begin{array}{l}\text { Discussions and } \\
\text { observations of RSP users } \\
\text { and establishment } \\
\text { customers; DMV surveys; }\end{array}$ & $\begin{array}{l}\text { Percent of riders who did } \\
\text { not drive and/or judged } \\
\text { neither intoxicated nor im- } \\
\text { paired; Differences between } \\
\text { Syracuse and Albany areas } \\
\text { in the percent of individuals } \\
\text { who report they use alterna- } \\
\text { tives to driving after } \\
\text { drinking. }\end{array}$ & $\begin{array}{l}\text { Data on user intoxica- } \\
\text { tion or impairment } \\
\text { based on judgements of } \\
\text { drivers; Very small } \\
\text { sample (SoberCab); No } \\
\text { requirement for Sober- } \\
\text { Cab users to have a car } \\
\text { in order to obtain a ride. }\end{array}$ \\
\hline $\begin{array}{l}\text { Do RSPs Reduce Alcohol- } \\
\text { Related Crashes? }\end{array}$ & $\begin{array}{l}\text { Alcohol-related accident } \\
\text { statistics from the New } \\
\text { York State DMV, the state } \\
\text { of Minnesota, and the city } \\
\text { of Minneapolis. }\end{array}$ & $\begin{array}{l}\text { Regression analyses of } \\
\text { trends for Onondaga } \\
\text { County, two comparison } \\
\text { counties and upstate New } \\
\text { York. Data from the } \\
\text { Christmas - New Year's Eve } \\
\text { period for the SoberCab area } \\
\text { and the rest of the state. }\end{array}$ & $\begin{array}{l}\text { No data from Minnesota } \\
\text { prior to initiation of the } \\
\text { RSP. The number of al- } \\
\text { cohol-related trips saved } \\
\text { that would have resulted } \\
\text { in a recorded accident } \\
\text { may be too small to be } \\
\text { statistically detected. }\end{array}$ \\
\hline $\begin{array}{l}\text { Did a Targeted Publicity } \\
\text { Campaign by I'm Smart } \\
\text { Change Awareness and/or } \\
\text { RSP use in Specific Target } \\
\text { Communities? }\end{array}$ & $\begin{array}{l}\text { Data from I'm Smart } \\
\text { publicity activities; Before } \\
\text { and after DMV surveys; } \\
\text { Before and after data from } \\
\text { customers of alcohol-serving } \\
\text { establishments. }\end{array}$ & $\begin{array}{l}\text { Changes in name } \\
\text { recognition of I'm Smart and } \\
\text { knowledge of the program } \\
\text { before and after the } \\
\text { publicity campaign. }\end{array}$ & $\begin{array}{l}\text { Limited number of iden- } \\
\text { tified ethnic minorities } \\
\text { among the DMV and } \\
\text { customer samples; Gay } \\
\text { men, lesbians, students, } \\
\text { and religous group } \\
\text { members not identified } \\
\text { in the measurements; No } \\
\text { follow-up period after } \\
\text { publicity campaign. }\end{array}$ \\
\hline
\end{tabular}




\section{NEW YORK DRIVER INFORMATION SURVEY (E)}

Thls questionnalre is part of a study to determine attitudes and behaviors from the driving publle This survey will prorlde us Informatlon related to en Important public safety program. Your answers are completely conndentlal, so please do not loclude your name. Plense note that your partlcipatton is completely voluntary, and you are in no may obllgated to answer these questlons. We appreclate your assistance In completing thls survey and ask that you enswer all questions as aceurately as possible.

1. Age:

2. Ser: $M$

3. Marial Strnus: Married ___ Single __ Divoreed __ Living with Partner___

4. Number of Children:

3. Zip Code al Home Address:

6. Employed? Yes

7. Occupation or Type of Work:

8. Which of the following caregories best describes your rotal household income before paxes in 1991 ? - Less than $\$ 5,000$ - $\$ 30,000$ 10 $\$ 49,999$ - $\$ 100,000$ or more

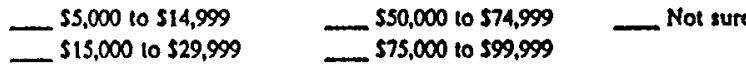

9. Why did you come to the Motor Vehicle Deparment Office Ioday? (Check all that apply.) — To register vehicle for first lime __ To take a drive lest

- To renew vehicie registration To obtain an identification card

To transfer ownership of vehicle To get a copy of ditving record

To obtain new driver's license To apply for license following suspenslon or revocation To renew driver's license

Other (specily):

10. Educntion:

Education:
No formal schooling
- First through 7 th grade
- Some college
- Four year college graduate
- Some high school
High school graduate

Esthic or Racial Background

12. How much do you weigh?

Please turn page over and complete survey. Thank You
If you do not currently drink alcohoh, please go to questlon 16.

13. During the last 12 months, how ofien did you usually dink eny alcoholic bevemges, inchuding beer, light beer, wine, wine coolers, or liquor? (Check only one). Every day - Neasty every

Three or lour days a week One or two days a week Two or threc days a month

- Never.

14. When you drink aleohol bevemges, which one of the following beverages do you drink most ofien? - Beer Hard Liquor or mixed drinks - Wine

15. If you spend mo hours in a bar or restaurant, how many drinks do you feel you can consume before it would become 100 dangerous 10 drive?

16. Are you aware of a "ifde senvice" program in our commuinity?

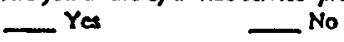

17. Which of the following programs have you heand about? - Tipsy Taxd

18. What do you know of this ride senvice program?

Have you at times thought yous were unable to ditve safely afer drinking? Yes No Which of the following have you ever done to avoid driving affer dinting? (Check all that apply.)
called a cab - called a cab

- designated a driver who would not drink - wailed until efroces of alcohol wore of - waiked to my destination - never done anything to avoid driving atter drinking - Other (specily):

21. Why did you decide nor so drive?

22 If you chose not to use a ride service program to get home, why not?

23. Have you ever received a cilotion or been arrested for a drinking diving offense? Yes No No If yes, when?

THLNK YOU VERY MUCII FOR YOUR TTME IN COMPLETING THIS SURVEYI 


\section{NEW YORK DRIVER INFORMATION SURVEY}

This questionnaire is part of a study to determine attitudes and behavlors from the driving public. This survey will provide us information related to an important public safety program. Your answers are completely confidentigl, so plense do not include your name. Plense note that your particlpation is completely voluntary, and you are in no way obligated to answer these questlons. We uppreclate your assistance in completing this survey and ask that you answer all questions as accurately as possible.

1. Age:

2. Ser: $M$

3. Marital Status: Married _ Single __ Divorced _ L Living with Partner

4. Number of Children:

5. Zip Code at Home Address:

6. Employed? Yes _ No

7. Occupation or Type of Work

8. Which of the following categories best describes your total household income before taxes in 1991? - Less than $\$ 5,000$ _ $\$ 30,000$ to $\$ 49,999$ _ $\$ 100,000$ or more — $\$ 5,000$ to $\$ 14,999$ - $\$ 50,000$ 10 $\$ 74,999$ - Not sure

Why did you come to the Motor Vehicle Deparment Office today? (Check all that apply.) To register vehicle for first time To take a drive lest

- To renew vehicle registration To obtain an identification card

- To transfer ownership of vehicle To get a copy of driving record

To obtain new driver's license To apply for license following suspension or revocation To renew driver's license Other (specify):

10. Educarion:

$\begin{array}{ll}\text { No formal schooling } & \text { Some college } \\ \text { First through 7th grade } & \text { Four year college graduate } \\ \text { - 8th grade } & \text { Some graduate school } \\ \text { Some high school } & \text { Completed graduate degree }\end{array}$

Completed graduate degree _ High school graduate

11. Elhnic or Racinl Background:

12. How much do you weight?
If you do not currently drink alcohol, plause go to question 16.

13. During the last 12 months, how ofien did you usually drink any alcoholic bevernges, including beer, light beer, wine, wine coolers, or liquor? (Check only one.)

Every day

Nearly every day

- Three or four days a week

One or two days a week

Other (specify)

Two or three days a month

- Oren (specin):

14. When you drink alcoholic bevernges, which one of the following beverages do you drink most ofien? - Beer Hard Liquor or mixed drinks _- Wine $\overline{\text { Other (specify): }}$ Wine coolers

5. If you spend mo hours in a bar or restaurnnt, how many drinks do you feel you can consume before it would become 100 dangerous to drive?

16. Are you aware of a "ride senvice" program in your community?

Yes

7. Which of the following programs in your community have you heard about?

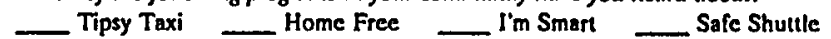

18. How did you hear of this ride service progrnm? (check all that apply.) TV Radio Newspaper _ Work Bar _ Friend/Family Other (please specily):

19. What do you know of this ride senvice progrom?

20. Have you at times thought you were unable to drive safely after drinking? - Yes No

21. Which of the following have you ever done to avoid driving after drinking? (Check all that apply.) — called a cab called a ride service program

- asked someone for a ride _osignated a driver who would not drink stayed overnight as a guest walked to my destination - waited until effects of alcohol wore off took public transil

22. Why did you decide not to drive?

23. If you chose not 10 use a ride service program 10 get home, why not?

24. Have you ever received a citation or been arrested for a drinking driving offense? Yes No If yes, when?

THANK YOU VERY MUCH FOR YOUR TIME IN COMPLETING; THIS SURVEY! 


\section{Appendix C \\ Discussion Topics with Alcohol-Serving Establishment Customers and SoberCab Users}

With the approval of owners of alcohol-serving establishments, and drivers for SoberCab, research staff members conducted informal discussions with customers. The topics the research staff tried to cover are listed below along with the locations and dates. The person in charge of field research is a cultural anthropologist, with an extensive background in bar research. Research staff took brief notes on small hand-held note pads when appropriate. Conversations with the customers were done on a strictly voluntary basis. Concluding the conversations the customers were given a BAC card as well as numbers for taxi cabs, or the local ride service program (if in operation at the time).

\section{Topics included in all discussions:}

How often do you typically drink?

How many drinks do you typically have?

When you drink, where do you typically drink (ie. home, bars, friends' homes)

How often do you drink in bars?

Do you typically drink when celebrating holidays?

Do you go to bars during holiday times?

Do you typically drink alone or with others?

About how intoxicated to you feel (customers given a five point scale: $1=$ "I feel perfectly sober"; $3=$ "I feel moderately intoxicated"; $5=$ "I feel drunk".

How long have you been drinking tonight, or what time did you start drinking today?

How many drinks have you had?

Do you feel you are safe to drive?

How did you get here (or get around) tonight?

How are you planning to get home?

Are you employed? Occupation?

Age?

Gender, ethnic group, approximate weight (observational)?

\section{Topics included in Syracuse 1992, Syracuse 1993 and Albany discussions:}

Do you live in this neighborhood?

How often do you come to this bar?

Do you come to this bar during holidays?

(For those who drove) Did you think about h ow you would get home safely? How?

Have you heard of I'm Smart?

Do you know of other alternative ways of getting home?

Syracuse Only:

How did you learn of I'm Smart?

(Pointing to I'm Smart sign, if visible) Do you know what that program/service is?

Do you know how to use I'm Smart?

Have you ever used I'm Smart? If so, how many times? What did you think?

\section{Albany Only:}

Have you ever driven after you thought you had too much to drink (or felt intoxicated)?

If you felt too intoxicated to drive home safely, would you: Take a free taxi ride home if available? Pay for

a cab ride home? How much? Pay for a cab ride home and back for your car? Pay someone to drive you and your car home? How much? Who should pay for this (you, bar, employer, government)? 
Topics included in Minneapolis 1992 (Experimental), Minneapolis 1993 (Control) and SoberCab RideAlongs:

What bars (or how many bars) have you been to today?

Do you have a home (favorite) bar?

Do you go to your home bar during holidays?

(If customer said they drank in a group) What type of group (eg. work, friends, family)?

What have you been drinking?

(For those who drove) How are you getting your car home?

Have you ever driven after you thought you had too much to drink (or felt intoxicated)?

How many times (in reference to question above)

How you used SoberCab before? How often? When?

How do you get home when SoberCab is not available?

Enough pocket money for a cab?

Number of moderate and severe signs of intoxication (observational).

Ride-Along Only:

$\mathrm{BAC}$ reading from portable passive breath analyzer.

In Bars Only:

Do you know about SoberCab? Do you know how to use SoberCab?

1993 Only:

If you felt too intoxicated to drive home safely, would you: Take a free taxi ride home if available? Pay for a cab ride home? How much? Pay for a cab ride home and back for your car? Pay someone to drive you and your car home? How much? Who should pay for this (you, bar, employer, government)? 


\section{REMOVE INTOXICATED DRIVERS - NEW YORK STATE APPRECIATFS YOUR THOUGITTEUL COMMENTS ABOUT TIE FOLLOWING ISSUES.}

\section{ON TRAFFIC SAFETY}

1. Are you aware of auy "safe ride" or "ride service" progran in your communlty to assist drivers who are unable to drive home safely? Yes _. No

2. If so, what do you know about this program?

3. Have you at times thought that you might be unable to drivo home safely?

Yes No

4. If yes, how did you get home? How many times In the last 12 mouths?

I drove anyway

Thad a friend or relative drive

I took a cab

I used public transportation

I used a "safe ride" service

I rode with a designated driver

I didn't go home

5. Drivers refusing a legitimate request for a breall-alcohol tost should lose their drivers llceuse for ut lcast 1 year, 6 montlss, not at all. other

6. People who continue to drtve after theli llecense has been revolced for alcohol-related offonses should have their vehicles confiscated. Yes No _. Not Sure

\section{ON JUSTICE FOR CRIME VICTIMS}

7.Should an intoxicated driver who causes a crash that bills or lifures others be charged with crininal manslaughter or assault? Yes No Not Sure

8. Do we need a constitutional anendinent to insure the rights of crime victims?

Yes No Not Sure

The following information will help us organke the data in meaningful ways.

NYS Resident _ Yes___No, If yes what is your county of residenoc.

Sex

Age

Do you currently drink alcohol? Yes No. If yes please check the statement that best describes your use of alcoholic dinks. 4-6 drinks per week on special occasions only; 1-4 drinks per montli; 1-3 drinks per week,

Have you ever been charged with an alcoliol-rclated traflio offonse? Yes No: Convicted? Yes No Have you or a family member been the viotim of a drinking driver? 


\section{Appendix E \\ University of Minnesota Survey questions on SoberCab}

Questions on SoberCab:

QG5. Are you aware of a holiday season safe-ride program called Sober Cab? (Yes, No, DK, RA)

QG5a. (IF YES) Have you ever used Sober Cab? (Yes, No, DK, RA, NA)

QG6. In the last 10 years, have you ever driven during the holiday season when you felt you've had too much to drink? (Yes, No, DK, RA) 


\section{Appendix F}

Formulas use to calculate B.A.C.

A modified Segal and Sisson (1985) formula was employed:

BAL in mg./100 ml. $=(80 \times g) /(f \times w)-(15 m g x t)$

Where BAL is the estimated blood alcohol level, 80 is the percent of alcohol absorbed in body tissue water, $\mathrm{g}$ is the number of grams of alcohol consumed calculated by multiplying the number of drinks (all assumed to have the same amount of alcohol) by 13.6 grams, $f$ is the individual's body water expressed as a decimal fraction of body weight and type and $\mathrm{w}$ is body weight in kilograms, $15 \mathrm{mg}$ represents the average reduction of $\mathrm{BAL}$ for each hour and $\mathrm{t}=$ time spent drinking in hours. $\mathrm{f}$ was given an average rating, .6 , for all individuals.

The other, simplified formula developed by the Project Director was:

$\mathrm{BAC}=.02(150 \mathrm{D} / \mathrm{W}-\mathrm{T})$

Where $\mathrm{D}=$ number of drinks, $\mathrm{W}=$ weight in pounds, $\mathrm{T}$ is the amount of time spent drinking in hours and .02 is the number of grams of alcohol in average size drink as well as the rate at which a 150 pound man metabolizes alcohol in a one hour period. 
Appendix G

I'm Smart Driver Observation Form

Date

Pickup time

1. Approximate age: $20-25 \_26-30$ $31-35$ $36-40$ 41-45 $46-50$ $51+$

2. Ethricity: Anglo Black Asian Hispanic Amer. Indian

3. Socioeconomic level of dropoff neighborhood: Poor

Blue collar Middle class Above avg. Affluent

4. Estimated degree of intoxication on a 5-point scale: where $1=$ no visible signs of intoxication

3 = moderate intoxication (e.g., silliness, reduced inhibition)

5 = severely intoxicated (e.g., slurred speech, unsteady gait) 


\section{Appendix $\mathrm{H}$}

SoberCab Driver Interview Form

(Drivers can gain this information through conversation)

1. How did you hear about Sober Cab?

Radio_ $\mathrm{TV}$ B_____ Friend

Bartender/Mgr Other

2. Have you used Sober Cab Before? Yes

No

How Often?

3. How do you get home after drinking when Sober Cab is not available?

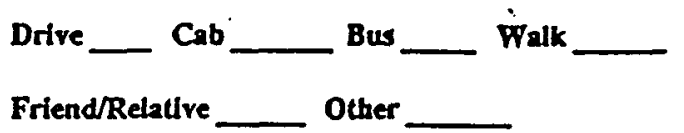

4. About how orten have you driven after having to much to drink to drive safely.

5. How long have you been driaking today?

About how many drinks hare you had?

About bow intoxicated do jou fed on a 5 point scale?

$$
1=\text { sober } \quad S=\text { drunk }
$$

6. Please estimate how intoxicated the patroa appears?

drunk somewhat intoxicated

not visibly Intoxicated

7. Age (ask or estimate)

Male

Female 
Appendix I

I'M SMART Corporate Member Questionnaire

\section{PLEASE RATE YOUR SATISFACTION WITH THE I'M SMART PROGRAM IN EACH ASPECT BELOW ON THE FOLLOWING SCALE:}

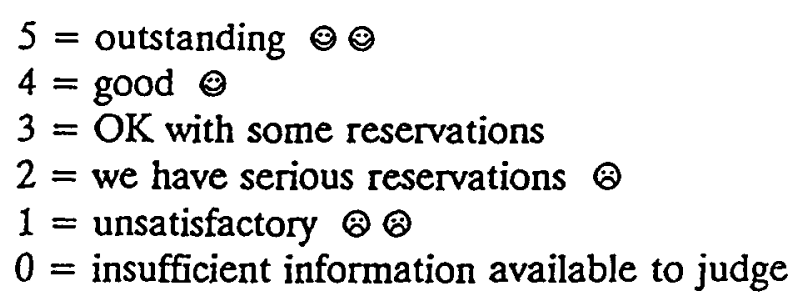

1. Program goals and strategies

2. Employee awareness sessions

3. Corporate host risk management planning 0

4. Stand-by service for company events

5. Efficiency of ride service for employees

6. Convenience of system to management

7. Confidentiality for ride service users

8. Trust and confidence of employees

9. Employee satisfaction with program

10. Cost vs. benefits (value for the money)

$\begin{array}{llllll}0 & 1 & 2 & 3 & 4 & 5 \\ 0 & 1 & 2 & 3 & 4 & 5 \\ 0 & 1 & 2 & 3 & 4 & 5 \\ 0 & 1 & 2 & 3 & 4 & 5 \\ 0 & 1 & 2 & 3 & 4 & 5 \\ 0 & 1 & 2 & 3 & 4 & 5 \\ 0 & 1 & 2 & 3 & 4 & 5 \\ 0 & 1 & 2 & 3 & 4 & 5 \\ 0 & 1 & 2 & 3 & 4 & 5 \\ 0 & 1 & 2 & 3 & 4 & 5\end{array}$

11. What percent of your employees do you believe have used the ride service? $\%$

12. Have you used I'M SMART for company events? no

13. How many employees does your company provide with I'M SMART services?

14. Additional comments:

15. Suggested improvements: 